\title{
A Taxonomic Study of the Genus Haemophilus, with the Proposal of a New Species
}

\author{
By M. KILIAN \\ Department of Microbiology, The Royal Dental College, \\ Vennelyst Boulevard, DK-8000 Aarhus C, Denmark
}

(Received 20 February 1975; revised 29 September 1975)

\begin{abstract}
S UM M A R Y
A collection of 426 Haemophilus strains isolated from people with infectious diseases and from the normal flora of mucous membranes in humans and various animal species was studied in an attempt to revise and improve the taxonomy of the genus Haemophilus. The examinations included the determination of a number of biochemical and physiological properties, of which several had not previously been applied to the taxonomy of haemophili. The resulting data revealed many hitherto unrecognized characters of taxonomic significance, and several of the species can now be more accurately defined. The classification presented is supported by the DNA base composition of a large number of representative strains. A diagnostic key to the different taxa is presented. Haemophilus influenzae and $H$. parainfluenzae have been subdivided into a number of biotypes. It is possible to demonstrate a relationship between the individual biotypes of $H$. influenzae and the origin of the strains assigned to them. The results indicate that $H$. aegyptius, $H$. parahaemolyticus and $H$. paraphrohaemolyticus do not merit specific status. Four unnamed taxa of $\mathrm{V}$-factor-dependent haemophili have been recognized. The name Haemophilus segnis is proposed for one of these taxa, which consists mainly of strains isolated from the human oral cavity. It is demonstrated that the name $H$. ducreyi has been used for different groups of bacteria, and that only one of these groups can legitimately be assigned to the genus Haemophilus. Haemolytic V-factor-dependent strains from swine, previously included in $H$. parahaemolyticus, are significantly different from strains of human origin and should be named $H$. pleuropneumoniae. None of the strains from swine and fowls were haemindependent. The relationships of these strains to the species $H$. suis and $H$. gallinarum, and to $H$. parasuis and $H$. paragallinarum are discussed. Haemophilus piscium is shown not to belong to the genus Haemophilus. The taxonomic position of $H$. aphrophilus is uncertain and its possible relationship to Actinobacillus actinomycetemcomitans requires further study. The positive correlation found between the ecology of the strains studied and their affiliation with the different taxa is discussed.
\end{abstract}

\section{INTRODUCTION}

The genus Haemophilus is based on the 'influenza bacillus' discovered and described by Pfeiffer in I892. In spite of the loss of interest in this group of bacteria immediately after I933, following the discovery of the influenza virus, interest has increased recently, and haemophili are now recognized as pathogens in their own right and implicated in a wide range of pathological conditions in man and various animal species.

The circumscription of the genus Haemophilus has been gradually but significantly contracted since the original proposals of the American Committee on Classification and Nomenclature (Winslow et al., 1920). At present there is general agreement that the genus 
should be restricted to Gram-negative rods or coccobacilli with a requirement for haemin or certain other porphyrins (X-factor) and/or NAD (V-factor) or other definable coenzymelike substances (Zinnemann, 1967). Parallel with the narrowing of the genus, however, the number of proposals for new species of Haemophilus has been increasing. Whereas the 7 th edition of Bergey's Manual of Determinative Bacteriology (1957) referred to 15 Haemophilus species, the number has been decreased by 4 in the recent 8 th edition (1974). Concomitantly, however, 5 of the older species are now designated species incertae sedis. Of the I 9 species referred to, 5 require both $\mathrm{X}$ - and $\mathrm{V}$-factors $(H$. influenzae, $H$. suis, $H$. haemolyticus, $H$. gallinarum, $H$. aegyptius), 6 require V-factor only $(H$. parainfluenzae, $H$. parasuis, $H$. parahaemolyticus, $H$. paraphrophilus, $H$. paragallinarum, $H$. paraphrohaemolyticus), 5 require X-factor only ( $H$. haemoglobinophilus, $H$. influenzaemurium, $H$. aphrophilus, $H$. ducreyi, $H$. ovis), 2 require factors as yet unidentified (H. putoriorum, $H$. citreus), and the last $(H$. piscium) requires diphosphothiamine or ATP but neither haemin nor NAD for growth. Little is known about several of these species and no representative strains are available for study.

In the intervening period between the last two editions of Bergey's Manual of Determinative Bacteriology, some additional species have been described. These include Hacmophilus pleuropneumoniae Shope 1964 , an organism which is the causative agent of a characteristic, frequently fatal, contagious pleuropneumonia in swine. Requiring V-factor only and being haemolytic, this organism is considered to be a synonym of Haemophilus parahaemolyticus Pittman I953 (Nicolet, I968; Zinnemann, I97I; Bergey's Manual of Determinative Bacteriology, 1974). An organism associated with encephalitis of cattle has been referred to as Haemophilus somnus (Brown, Dierks \& Dillman, 1970) as proposed by Bailie (1969) or Haemophilus somnifer (Miles, Anthony \& Dennis, 1972), but obviously does not meet the criteria for inclusion in the genus Haemophilus (Bailie, Coles \& Weide, 1973). Likewise, Haemophilus agni (Kennedy et al., I958), an organism implicated in septicaemia of lambs, is no longer considered to be a member of Haemophilus (Zinnemann, 1971). Although still under discussion (Criswell et al., 1971), Haemophilus vaginalis Gardner \& Dukes 1955 is now usually considered Gram-positive and consequently as belonging to some other genus (Zinnemann \& Turner, 1963; Reyn, Birch-Andersen \& Lapage, I966; Jones \& Weitzman, 197I ; Bergey's Manual of Determinative Bacteriology, 1974).

The study of biochemical reactions of haemophili has been retarded by the difficulty experienced in preparing media which allow copious growth. Few biochemical tests, generally applicable to other bacterial groups, have been used with success in studies of haemophili. The consequent paucity of comparable data, and reliance on single or few characters of uncertain taxonomic significance when establishing new species, has not only hampered the development of a satisfactory classification but has also rendered an exact identification of Haemophilus strains difficult.

Finally, inadequate recognition of the fact that haemophili are a constituent of the normal flora of the mucous membranes of the human throat (Dawson \& Zinnemann, I952; Kilian, Heine-Jensen \& Bülow, I972), oral cavity (Fleming \& Maclean, I930; Sims, 1970) and sometimes genital tract (Lapage, I96r ; Bergey's Manual of Determinative Bacteriology, 1974) has resulted in a lack of incentive for a closer study of virulence factors of pathogenic haemophili, and impeded the evaluation of the significance of results obtained in clinical bacteriological laboratories. The same problems also apply to the veterinary field.

I have attempted to revise and improve the taxonomy of the genus Haemophilus. A large collection of strains, heterogenous in origin and pathogenicity, has been studied using a number of methods not previously applied to this group of bacteria. The validity of the 
resulting classification has been supported by the determination of the DNA base composition of a large number of strains.

\section{Selection of bacterial strains}

\section{METHODS}

The general prerequisite for including a strain in the survey as a member of the genus Haemophilus has been a negative Gram reaction, a coccobacillus- or rod-shape, and a proven requirement for either or both of the two growth factors NAD (V-factor) and haemin (X-factor) or for precursors to these. The only exception to the latter has been strains resembling Haemophilus aphrophilus. Strains maintained in culture collections have been included as far as possible and, with named strains mentioned in the literature, have been included without restrictions. The strains were collected from many sources in an attempt to obtain as diverse a collection as possible. In addition to strains isolated from various infectious diseases, both human and veterinary, a large proportion were isolated from the normal flora of mucous membranes. These, as well as strains from conjunctivitis, were selected from a larger number of strains after a preliminary examination. The relative composition of the selected strain materials does not reflect the composition of the original materials, which are described in detail elsewhere (Kilian \& Schiøtt, 1975; Kilian et al., I976).

The collection includes 426 strains received and/or identified as Haemophilus; for comparison, I 2 strains of the species Actinobacillus actinomycetemcomitans, Eikenella corrodens and Pasteurella multocida were also studied. Apart from recent isolates from clinical bacteriological laboratories in Denmark, all strains were received as freeze-dried cultures. On receipt, the strains were checked for purity, and after the lowest possible number of subcultures, Levinthal broth cultures were frozen in sealed glass ampoules at $-70{ }^{\circ} \mathrm{C}$. An ampoule was opened whenever a new series of tests was performed.

A code number (HK) has been assigned to each strain of the collection. Table I lists the strains under the species to which they have been assigned as a result of this study. Table 2 summarizes the sites of origin of the strains.

\section{Culture methods}

Chocolate agar [10\%, v/v, heated, defibrinated horse blood in blood agar base (Difco)] was used for maintaining strains, for inoculum cultures for all test media and for growth of strains for DNA extraction. Levinthal's agar (Alexander, 1958) was used for the detection of capsule production. Unless otherwise stated, agar plates were incubated in anaerobic jars evacuated then filled with air plus 10\% carbon dioxide. Levinthal 'stock' (Turk \& May, 1967) was used whenever fluid cultures were needed, the basal broth being brainheart infusion (Difco). The medium will be referred to as Levinthal broth.

Stock cultures and inoculated test media were incubated at $37^{\circ} \mathrm{C}$, except for strains of H. piscium which were incubated at $22{ }^{\circ} \mathrm{C}$.

\section{Morphology and staining}

Colonial morphology was described from $48 \mathrm{~h}$ cultures on chocolate agar. A saline suspension of a colony was examined by phase-contrast microscopy for shape and motility, and a heat-fixed film was Gram-stained by Hucker's modification (Hucker \& Conn, I923). 
Table I. Strains studied, listed according to the classification resulting from this study

Study reference number
Isolated from

Haemophilus influenzae, biotype

HK2, 6, 20, 27, 41, Haemophilus sp. $43,61,66,76$

$\begin{array}{ll}\text { HKI 4I, I44 } & \text { Haemophilus sp. } \\ \text { HKI62 } & \text { H. influenzae } \\ \text { HKI63 } & \text { H. influenzae } \\ \text { HKI7I-179 } & \text { H. influenzae } \\ \text { HKI 80-I9I } & \text { H. influenzae }\end{array}$

$\begin{array}{ll}\text { HK192 } & \text { H. influenzae } \\ \text { HK193-205 } & \text { H. influenzae } \\ \text { HK213-216 } & \text { H. influenzae } \\ \text { HK217, 220 } & \text { H. influenzae } \\ \text { HK224, 226 } & \text { H. influenzae } \\ \text { HK234, 235, 236, } & \text { H. influenzae } \\ 243,246,247,254 & \\ \text { HK293 } & \text { Haemophilus sp. } \\ \text { HK297 } & \text { H. influenzae } \\ \text { HK390 } & \text { H. influenzae } \\ \text { HK391 } & \text { H. influenzae } \\ \text { HK392 } & \text { H. influenzae } \\ \text { HK393 } & \text { H. influenzae } \\ \text { HK395 } & \text { H. influenzae } \\ \text { HK403 } & \text { H. influenzae }\end{array}$

HKI , 4, 9, I I, I3, Haemophilus sp.

$21,24,25,28,30$,

$37,38,42,46,50$,

$54,58,62,63,68$

HKI 66, I 68

HK206, 208

HK210-2I 2

HK21 8, 219, 221,

222

HK225, 227, 23 I,

232

HK237, 242, 244,

245,248

HK263

HK $264,266,268$

HK27I

HK273

HK274, 275, 283, 285

HK287-290

Haemophilus sp.

HK298, 299

HK300, 30I, 302

$\mathrm{HK} 342$

HK389

Pharynx

Human saliva
Epiglottitis
Epiglottitis
Meningitis
Meningitis

Meningitis

Meningitis

Human blood

Sinusitis

Otitis media

Otitis media

Conjunctivitis

Pneumonia

Respiratory infection

Meningitis

Meningitis

Meningitis

Meningitis

Haemophilus influenzae, biotype II

Pharynx

Human saliva

Conjunctivitis

Meningitis

Meningitis

Sinusitis

Otitis media

Otitis media

Conjunctivitis

Conjunctivitis

Conjunctivitis

Conjunctivitis

Conjunctivitis

Conjunctivitis

Pneumonia

Chronic bronchitis

Haemophilus sp.

$H$. influenzae

H. influenzae
Source* and strain designation

Kilian et al. (1972)

Kilian \& Schiøtt (1975)

W. Frederiksen (I00672)

K. Zinnemann (Rustforth)

H. Lautrop (strains ABI 872 and $\mathrm{ABI} 876$ to $\mathrm{AB} 1883$, respectively)

Engbaek (1949) (strains 383, 392, $844,868,875$, I035, I 065, I 266a, $1379,4857,984$ and spiooo, respectively) $\dagger$

W. Frederiksen (351483)

P. Bülow

P. Bülow

P. Bülow

V. F. Thomsen $\uparrow$

P. Bülow

C. R. Dawson (539) (Tunisia)

P. Bülow

NCTC8465 (serotype a)

NCTC8466 (serotype a)

NCTC 7279 (serotype b)

NCTC 8467 (serotype b)

CIP5423 (Rb)

NCrC8473 (serotype f)

Kilian et al. (1972)

Kilian \& Schiøtt (1975)

N. Hegazy (Cairo) $!$

P. Bülow

Engbaek (1949) (strains 865, 870 and 876 , respectively) $\dagger$

P. Bülow

V. F. Thomsen $\dagger$

P. Bülow

C. H. Mordhorst (AB 1 785) †

C. H. Mordhorst

C. H. Mordhorst (AB1905) $\dagger$

P. Bülow

C. H. Mordhorst (strains AB I 862, ABI 870, ABI 857 and ABI 946 , respectively) $\dagger$

C. R. Dawson (strains 443, 518 , 873 and 839 respectively) (Tunisia)

P. Bülow

Engbaek (I949) (Ruggier)† 
Study reference number

HК 396

HK4O2

нк $7,56,57,70$, $7 \mathrm{I}, 72,73$

HK207

HK24I

HK265, 267, 269

HK27O

HK272

HK277-279, 284, 286

HK29I, 292, 294, 295

HK367

HK368

HK369

HK 387

HK 388

HK 1 7, 32, 44, 69

HK209

HK343

HK 394

HK 397

HK 398

HK399

HK40O

HK4OI

HK 223, 233

H. influenzae

HK238, 239, 240, H. influenzae

$249,250,25 \mathrm{I}$,

252,253

HK 39

HK280, 28 I

HK 5, I 2, 29, 33, $45,53,59,75$ HK 386

HK 365

HK 375

Received as

H. influenzae

$H$. influenzae

H. aegyptius

$H$. influenzae
Isolated from

Source* and strain designation

Haemophilus influenzae, biotype II (cont.)

$\begin{array}{lll}H . \text { influenzae } & \text { Sputum } & \text { NCTC8469 (serotype c) } \\ H . \text { influenzae } & \text { Pus, mastoid } & \text { NCTC7918 (serotype f) }\end{array}$

Haemophilus influenzae, biotype III

Haemophilus sp. Pharynx Kilian et al. (1972)

Haemophilus sp.

Haemophilus sp.

Haemophilus sp.

Meningitis

Otitis media

Conjunctivitis

Conjunctivitis

Conjunctivitis

Conjunctivitis

P. Bülow (non-capsulated)

P. Bülow

C. H. Mordhorst

C. H. Mordhorst (ABI 888) †

P. Bülow

C. H. Mordhorst (strains AB I 866, ABI 886, ABI 884, ABI9OI and AB I 890 , respectively) $\dagger$

Haemophilus sp.

Conjunctivitis

Conjunctiva

C. R. Dawson (strains 4I5, 864, 614 and 429 , respectively) $\dagger$ NCTC8502; suggested working type (Sneath \& Skerman, 1966) NCTC8134

NCTC8 I 35

Conjunctiva
Conjunctiva

NCTC4560; suggested working

-

Respiratory tract

type (Sneath \& Skerman, 1966)

NCTC 4842

Haemophilus influenzae, biotype IV

Haemophilus sp.

Pharynx
Meningitis
Meningitis
Throat -
-
-

Kilian et al. (1972)

Engbaek (1949) (204)†

Engbaek (1949) (Dingle) $\uparrow$

NCTC 8468 (serotype b)

NCTC 8470 (serotype d)

CIP5424 (Rd)

NCTC 10479 (serotype $e_{1} e_{2}$ )

NCTC8455 (serotype $e_{2}$ )

NCTC 8472 (serotype $\mathrm{e}_{1} \mathrm{e}_{2}$, and degraded $\mathrm{e}_{2}$ )

Haemophilus influenzae, biotype $\mathrm{V}$

Otitis media

V. F. Thomsen (ABI928 and ABI927, respectively) $\dagger$

Otitis media

Haemophilus influenzae, unclassified strains
Haemophilus sp.
Haemophilus sp.
Pharynx
Conjunctivitis

Kilian et al. (1972)

H. Lautrop (strains AB I 863 and AB I 865, respectively)

Haemophilus haemolyticus

$\begin{array}{lll}\text { Haemophilus sp. } & \text { Pharynx } & \text { Kilian et al. (1972) } \\ \text { H. haemolyticus } & \text { Sputum } & \text { NCTC 10659 }\end{array}$

Haemophilus haemoglobinophilus (canis)
H. canis
Prepuce, dog
Prepuce, dog

W. Frederiksen $(\mathrm{P} 30 \mathrm{I}) \leftarrow \mathrm{J} . \mathrm{E}$.
Smith $(404)$
NCTCI $659 ;$ cotype (Sneath \& Skerman, 1966) 
Study reference number

Received as

Isolated from

Source* and strain designation

Haemophilus haemoglobinophilus (canis) (cont.)

\begin{tabular}{|c|c|c|c|}
\hline HK376 & H. canis & - & NCTC 8540 \\
\hline HK377 & H. canis & Dog & NCTC106I9 \\
\hline HK 378 & H. canis & Prepuce, dog & $\begin{array}{l}\text { ATCCI } 9416 \text {; same as NCTCI } 659 \text {, } \\
\text { but see comment }\end{array}$ \\
\hline \multicolumn{4}{|c|}{ Unclassified strain } \\
\hline HK43I & Haemophilus sp. & Perianal abscess & NCTCI0555, Ryan (I968) \\
\hline \multicolumn{4}{|c|}{ Hatmophilus ducreyi } \\
\hline HK $344-350$ & H. ducreyi & Soft chancre & $\begin{array}{l}\text { Reymann (I95I) (strains II, IX, X } \\
\text { XI, I 29, I } 33 \text { and I } 34 \text { respec- } \\
\text { tively) } \ddagger\end{array}$ \\
\hline HK379 & H. ducreyi & - & $\mathrm{ClP} 542$ \\
\hline HK 380 & H. ducreyi & - & CIP A75 \\
\hline
\end{tabular}

Haemophilus parainfluenzae, biotype I

\begin{tabular}{|c|c|c|c|}
\hline НКı $8,47,79$ & Haemophilus sp. & Pharynx & Kilian et al. (1972) \\
\hline $\begin{array}{l}\text { Hк } 82,86,88,89, \\
90,91,92,93,94, \\
96,100,105,109, \\
110,111,115,116, \\
\text { I1 } 8,119,124,128, \\
130,132,133,134, \\
\text { I36, I39, I40, 145, } \\
\text { I46, I } 50,151,155, \\
156,158,160\end{array}$ & Haemophilus sp. & Human saliva & Kilian \& Schiøtt (1975) \\
\hline HK $256,257,259$ & Haemophilus sp. & Vagina & - \\
\hline HK282 & H. parainfluenzae & Conjunctivitis & H. Lautrop (Fsk 3567 ) \\
\hline HK409 & H. parainfluenzae & Septic finger & NCTC7857 \\
\hline HK4l 6 & H. paraphrophilus & Trachea & $\begin{array}{l}\text { NCTCI0558; cotype (strain } \\
\text { 'Haywood') }\end{array}$ \\
\hline
\end{tabular}

Haemophilus parainfluenzae, biotype II

\begin{tabular}{|c|c|c|c|}
\hline $\begin{array}{l}\mathrm{HK}_{3}, 10, \mathrm{I} 4, \mathrm{I} 6, \\
23,26,31,34,36, \\
40,49,55,60,64, \\
67,77,78\end{array}$ & Haemophilus sp. & Pharynx & Kilian et al. (1972) \\
\hline $\begin{array}{l}\text { HK } 8 \text { I, 95, 97, 98, } \\
99, \text { IOI, 102, I } 3 \text {, } \\
\text { I04, I07, I08, I I } 3 \text {, } \\
\text { II } 7, \text { I } 20, \text { I } 22, \text { I } 25, \\
\text { I } 38,142, \text { I } 52\end{array}$ & Haemophilus sp. & Human saliva & Kilian \& Schiøtt (I975) \\
\hline HK $255,260,262$ & Haemophilus sp. & Urethra & - \\
\hline HK33 I & H. parahaemolyticus & Pus, oral cavity & W. Sims (2I) \\
\hline HK 332 & H. parahaemolyticus & Jental plaque & W. Sims $(28)$ \\
\hline HK 335 & H. parahaemolyticus & Human saliva & $\begin{array}{l}\text { W. Sims (strains } 3 \mathrm{I} \text { and } 32 \text {, } \\
\text { respectively) }\end{array}$ \\
\hline HK339 & H. haemolyticus & - & J. Frazer $\leftarrow$ M. Pittman (734) \\
\hline HK4IO & H. parainfluenzae & Human saliva & NCTCI 0665 \\
\hline
\end{tabular}

Haemophilus parainfluenzae, biotype III

\begin{tabular}{|c|c|c|c|}
\hline нК $8,19,22,48$, & Haemophilus sp. & Phayrnx & Kilian et al. (1972) \\
\hline $\begin{array}{c}5 \mathrm{I}, 52,65,74 \\
\text { HKII } 2, \mathrm{I} 21, \mathrm{I} 26,\end{array}$ & Haemophilus sp. & Human saliva & Kilian \& Schiøtt (1975) \\
\hline $\begin{array}{c}137 \\
\text { HKI } 69\end{array}$ & Haemophilus sp. & Conjunctivitis & N. Hegazy (Cairo) \\
\hline HK258 & Haemophilus sp. & Vagina & - \\
\hline
\end{tabular}


Study reference number

Received as

Isolated from

Source* and strain designation

Haemophilus parainfluenzae, biotype III (cont.)

\begin{tabular}{|c|c|c|}
\hline HK 26I & Haemophilus sp. & Urethra \\
\hline HK 276 & H. parainfluenzae & Conjunctivitis \\
\hline $\begin{array}{l}\mathrm{HK}_{3} \mathrm{O}_{3}, 304,305, \\
3 \mathrm{I}_{2}\end{array}$ & Haemophilus sp. & Dental plaque \\
\hline HK330 & H. parahaemolyticus & Tooth abscess \\
\hline HK333 & H. parahaemolyticus & Pus, oral cavity \\
\hline HK334 & H. parahaemolyticus & Human saliva \\
\hline HK 338 & H. parahaemolyticus & Pus, oral cavity \\
\hline HK 385 & H. haemolyticus & Pulmonary infection \\
\hline HK4O4 & H. parahaemolyticus & Throat \\
\hline HK4I I & H. paraphrohaemolyticus & Sputum \\
\hline HK4I 2 & H. paraphrohaemolyticus & Sputum \\
\hline HK4 I 3 & H. paraphrohaemolyticus & Throat \\
\hline HK 444 & Haemophilus sp. & Rat, oral cavity \\
\hline
\end{tabular}

H. Lautrop (ABI 852)

Kilian \& Schiøtt (1975)

W. Sims ( I 7)

W. Sims (29)

W. Sims (strains 30 and 33 , respectively)

W. Sims (34)

NCTC8479; suggested working

type (Sneath \& Skerman, 1966)

NCTCIO794

NCrCI0670; holotype

NCTC1067I; paratype

NCTC10672; paratype

Haemophilus parainfluenzae, unclassified strains

$\begin{array}{llll}\text { HKI5 } & \text { Haemophilus sp. } & \text { Pharynx } & \text { Kilian et al. (1972) } \\ \text { HK80, I47 } & \text { Haemophilus sp. } & \text { Human saliva } & \text { Kilian \& Schiøtt (1975) } \\ \text { HK408 } & \text { H. parainfluenzae } & \text { Human tongue } & \text { NCTC4IOI }\end{array}$

Haemophilus paraphrophilus

HK83, 85, 143, I 59 Haemophilus sp. HK296 Haemophilus sp. Hк306, 318, 319, Haemophilus sp. $32 \mathrm{I}$

HK41 4

HK4I 5

H. paraphrophilus

H. paraphrophilus

HK308, 309, 310, Haemophilus sp. 3 II, 3 I 5

HK322

HK 323

HK 324

HK 325

HK326

HK 327

HK329

HK 37 I

HK 372-374
H. aphrophilus
H. aphrophilus
H. aphrophilus
H. aphrophilus
H. aphrophilus
H. aphrophilus
H. aphrophilus
H. aphrophilus
H. aphrophilus

Human saliva Chronic bronchitis Dental plaque

Parietal abscess Paronychia

Haemophilus aphrophilus

Dental plaque

Endocarditis

Gingiva

Abdominal wound

Joint infection

Sinusitis pus

Crural ulcer

Endocarditis

Endocarditis

Endocarditis

Haemophilus segnis, sp.nov.

Pharynx
Human saliva

Dental plaque

Haemophilus parasuis

Piglet, bronchopneumonia

$$
\begin{aligned}
& \text { H. parasuis } \\
& \text { H. parasuis } \\
& \text { H. suis }
\end{aligned}
$$

NCTC4IOI
Kilian \& Schiøtt (I975)

Kilian \& Schiøtt (1975)

NCTCI 0556; cotype

NCTCI0557; holotype

\section{Kilian \& Schiøtt (1975)}

W. Frederiksen (P404)

W. Frederiksen (P406)

W. Frederiksen (P527)

W. Frederiksen (P536)

W. Frederiksen (P537)

W. Frederiksen (334542)

Dorff \& Kilian, (1974)

NCTC 5886; holotype

NCTC5906, NCTC5907 and

NCTC5908, respectively)

Kilian et al. (1972)

Kilian \& Schiøtt (1975)

Kilian \& Schiøtt (I975)

H. U. Bertschinger $(538 / 70) \dagger$

CCM5749

CCM575I

CIP52203 
Study reference number

Received as

Isolated from

Haemophilus parasuis (cont.)

$\begin{array}{ll}\text { HK423 } & \text { H. suis } \\ \text { HK424 } & \text { H. suis } \\ \text { HK425-427 } & \text { H. suis }\end{array}$

Haemophilus pleuropneumoniae

HK35I-355, H. parahaemolyticus $\quad$ Pig, pleuropneumonia 357-36I

HK356

H. parahaemolyticus

Pig, pleuropneumonia

HK 363

HK405

HK406

HK407

HK364

HK 38 I

HK I 64, I 65, I 67, Haemophilus sp. 170

$\begin{array}{ll}\text { HK366 } & \text { Haemophilus sp. } \\ \text { HK445, 446, 447 } & \text { Haemophilus sp. }\end{array}$

HK 383

HK 384

HK428

HK429

HK4 I 9-42 I, 448-450

HK432

HK433

HK434

HK435

HK436

HK442, 443

Haemophilus sp.

$H$. parahaemolyticus

$H$. parahaemolyticus

$H$. parahaemolyticus

Haemophilus paragallinarum
H. paragallinarum

H. gallinarum
Pig, pneumonia

\section{-}

\section{Unnamed taxon $\mathbf{A}$}

Conjunctivitis

Unnamed taxon B

$$
\begin{aligned}
& \text { Rat, lung } \\
& \text { Rat, oral cavity }
\end{aligned}
$$

Unnamed taxon $C$

H. gallinarum

Cock

Cock

Haemophilus sp.

Pig, pneumonia

H. parainfluenzae var. suis

Pig, pneumonia

Haemophilus piscium

H. piscium

'Trout ulcer

Actinobacillus actinomycetemcomitans
A. actinomycetemcomitans

A. actinomycetemcomitans

A. actinomycetemcomitans

A. actinomycetemcomitans

$A$. actinomycetemcomitans

A. actinomycetemcomitans

CCM 5747

NCTC4557; cotype

NCTC6359, NCTC7440 and NCTC744I, respectively

R. Nielsen (strains 4969, 2282 , 2226, 5617, 5130, 2934, 2845, 4226,2374 and 97 I I, respectively); all serotype 2

R. Nielsen (Canada); serotype 'K 17 ' (Schiefer et al., 1974) H. U. Bertschinger $(543 / 70) \dagger$ CCM5869; serotype I CCM 5870; serotype 2 CCM5871; serotype 3

E. L. Biberstein (H37)

Fowl, respiratory tract $\mathrm{NCTC}_{3438}$

N. Hegazy (Cairo) $\dagger$

R. Nielsen

P. H. A. Sneath (J102), CAPM5OI $5 \$$

P. H. A. Sneath (JIO3), CAPM50668

P. H. A. Sneath (J104), CAPM5080

P. H. A. Sneath (J94), CAPM5III $\$$

P. H. A. Sneath (J95), CAPM5I I 38

ATCCI 0801 , ATCCI 4360, ATCCI 571 I, ATCCI436I, ATCCI 4362 and ATCC I 4363, respectively

W. Frederiksen (P2O2) (King I I 53)

W. Frederiksen (P228) (Holm 248/48-49)

W. Frederiksen (P230) (Holm 363/49-50)

W. Frederiksen (P506)

W. Frederiksen (200771) NCTC9709 and NCTC97IO, respectively 
Study reference number

HK 328

HK340, 34I

HK440

HK44I

HK437-439
Received as

H. aphrophilus

H. canis

Ei. corrodens

Bacteroides corrodens

Pasteurella multocida
Eikenella corrodens

Oral cavity

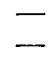

-
Source* and strain designation

J. Frazer (Turk)

W. Sims (strains 18 and 35

respectively)

J. Henrichsen (Eiken 310A)

NCTC 10596

W. Frederiksen (strains P437,

* Abbreviations: ATCC, American Type Culture Collection, Rockville, Maryland, U.S.A.; CAPM, Collection of Animal Pathogenic Microorganisms, Brno-Medlánky, Czechoslovakia; CCM, Czechoslovak Collection of Microorganisms, Brno; cIP, Collection de l'Institut Pasteur, Paris, France; NCTC, National Collection of Type Cultures, Colindale, London; E. L. Biberstein, School of Veterinary Medicine, University of California, Davis, California, U.S.A.; P. Bülow, Department of Medical Bacteriology, Statens Seruminstitut, Aarhus Kommunehospital, Aarhus, Denmark; C. R. Dawson, Francis I. Proctor Foundation for Research in Ophthalmology, University of California, San Francisco, U.S.A.; J. Frazer, Department of Microbiology, School of Medicine, Leeds; W. Frederiksen, Department of Medical Bacteriology, Statens Seruminstitut, Aalborg Amstssygehus, Aalborg, Denmark; H. Lautrop, Department of Diagnostic Bacteriology, Statens Seruminstitut, Copenhagen, Denmark; C. H. Mordhorst, Ornithosis Department, Statens Seruminstitut, Copenhagen; R. Nielsen, Statens Veterinaere Serumlaboratorium, Copenhagen; W. Sims, Royal Dental Hospital, London; P. H. A. Sneath, M.R.C. Microbial Systematics Unit, Leicester; K. Zinnemann, Department of Microbiology, School of Medicine, Leeds.

+ Strains received from $\mathbf{H}$. Lautrop.

+ Strains isolated and partly described by Reymann (1951). Ampoules of the strains, freeze-dried in 19461949, were received from the Serum and Vaccine Department, Statens Seruminstitut, Copenhagen. See Results.

$\S$ Strains described by Sneath \& Johnson (1973).

Table 2. Sites from which the 426 Haemophilus strains studied originated

Origins

No. of strains

Strains from humans:

Respiratory tract $\quad 83$

Oral cavity $\quad 105$

Meningitis $\quad 47$

Blood cultures and/or epiglottitis 6

Otitis media $\quad 29$

Respiratory infections 2 I

Conjunctivitis $\quad 43$

Endocarditis $\quad 6$

Chancroid 9

Vaginal and urethral cultures $\quad 8$

Various other infections or origin unknown $\quad 22$

Strains from animals:

Swine

Fowls

Fish

Various other animals

Capsule production and serotyping of capsulated strains

Strains producing iridescent colonies on Levinthal's agar after $18 \mathrm{~h}$ incubation were typed by slide agglutination and the capsule swelling technique using antisera a to $\mathrm{fHyland}$ Laboratories, Los Angeles, U.S.A.). 


\section{Biochemical and physiological tests}

Growth factor requirements. The requirement for V-factor was tested by observing the satellitism phenomenon on $10 \%(\mathrm{v} / \mathrm{v})$ citrate-stabilized calf blood agar streaked with a strain of Staphylococcus aureus. As a confirmatory test for selected strains, V-factor discs (Oxoid) were used on brain-heart agar (Difco) or calf blood agar. The ability to carry out the biosynthesis of porphyrins from $\delta$-aminolaevulinic acid (ALA) was determined by the Porphyrin test (Kilian, 1974). Porphyrin was demonstrated by observation of fluorescence under Wood's light.

Requirement for increased $\mathrm{CO}_{2}$ tension in the incubation atmosphere was determined by comparing growth on a lightly inoculated duplicate set of chocolate agar plates incubated in air and in an anaerobic jar containing air plus $10 \% \mathrm{CO}_{2}$.

Haemolysis of horse blood around single colonies was examined after growth for 24 to $48 \mathrm{~h}$ on $5 \%(\mathrm{v} / \mathrm{v})$ defibrinated horse blood in blood agar base (Difco). A streak of $S$. aureus served as supply of $\mathrm{V}$-factor.

Haemagglutination test. The method was essentially that used by Davis, Pittman \& Griffitts (1950). Equal quantities $(0.4 \mathrm{ml})$ of a $5 \%(\mathrm{v} / \mathrm{v})$ suspension of red blood cells of group $\mathrm{O}$ in saline $(0.85 \%, \mathrm{v} / \mathrm{v}, \mathrm{NaCl})$ and a 24 to $48 \mathrm{~h}$ Levinthal broth culture were mixed in a Perspex agglutination tray. The results were read from the pattern of the sedimented cells on the bottom of the depressions after incubation at room temperature for $2 \mathrm{~h}$.

Reduction of nitrate and nitrite was tested as described by Cowan \& Steel (1965) after 5 days growth in Levinthal broth with 0.1 and $0.0 \mathrm{I} \% \mathrm{KNO}_{3}$, respectively. A Durham tube was inserted to detect gas production.

Indole production was demonstrated in a 24 to $48 \mathrm{~h}$ Levinthal broth culture and by the NCTC method (Clarke \& Cowan, 1952) using Kovács's reagent.

Catalase activity. A few colonies were removed from a chocolate agar culture with a coverslip and placed in a drop of $3 \%(\mathrm{v} / \mathrm{v}) \mathrm{H}_{2} \mathrm{O}_{2}$ on a glass slide. Effervescence was noted.

Oxidase activity was tested by Kovács"s method (1956).

Production of acid from carbohydrates was determined in phenol red broth base (Difco). The respective carbohydrates were added to the autoclaved and cooled medium as sterile 25 to $50 \%(\mathrm{w} / \mathrm{v})$ solutions to give a final concentration of $\mathrm{r} \%(\mathrm{w} / \mathrm{v})$. Haemin $(\mathrm{BDH})$ dissolved in triethanolamine (Kodak) and NAD grade III (Sigma) were added in filter-sterilized solutions to a final concentration of $10 \mu \mathrm{g} / \mathrm{ml}$. The broth $(\mathrm{pH} 7 \cdot 6)$ was dispensed in $7 \mathrm{ml}$ volumes in tubes, and a Durham tube was inserted in the glucose broth for the detection of gas. The tubes were inoculated with a loopful of bacteria and incubated for 5 days. The final $\mathrm{pH}$ was measured on a $\mathrm{pH}$-meter (Radiometer, Copenhagen, Denmark). The following carbohydrates were used: $\mathrm{D}(+)$-glucose, sucrose, 2-deoxy-D-ribose, $\mathrm{D}(+)$-xylose, lactose, and $D(-)$-mannitol throughout the study, and fructose, $D(+)$-galactose, raffinose, inulin, dulcitol, $\mathrm{D}(-)$-sorbitol, $\mathrm{D}(-)$-arabinose and cellobiose with some of the strains. An inoculated control of basal medium without carbohydrate was included for each strain to detect any change in $\mathrm{pH}$ of non-glycolytic origin.

Hydrogen sulphide production was determined by placing a lead acetate strip (Merck) in the lid of an inoculated chocolate agar plate and reading after 2 days incubation. Distinct blackening of the paper was recorded as a positive result. In addition, a ferrous chloride medium was used. This contained $18.5 \mathrm{~g}$ brain-heart infusion (Difco), $6.0 \mathrm{~g}$ Noble agar (Difco), and $440 \mathrm{ml}$ distilled water. After autoclaving and cooling to $50{ }^{\circ} \mathrm{C}, 2.5 \mathrm{ml}$ of a $10 \%$ (w/v) filter-sterilized aqueous solution of $\mathrm{FeCl}_{2}$ was added. Haemin and NAD dissolved in $60 \mathrm{ml}$ water were added to give a final concentration of $10 \mu \mathrm{g}$ each $/ \mathrm{ml}$. The medium was 
distributed in narrow tubes, inoculated with a platinum needle and read after incubation for 5 days.

DNAase activity was determined on the following agar medium: brain-heart infusion, I $8.5 \mathrm{~g}$; Noble agar, 6.0 g; calf thymus DNA (Sigma), $2 \mathrm{~g}$; distilled water, $440 \mathrm{ml}$. After autoclaving and cooling to $50^{\circ} \mathrm{C}$, haemin and NAD were added as described above. Inoculated plates were incubated for 2 days, flooded with $\mathrm{I} \mathrm{M}-\mathrm{HCl}$ and examined for clear zones. A strain of $S$. aureus acted as a positive control.

Esterase activity was determined with indoxyl acetate (Koch-Light) discs placed on top of the growth on a chocolate agar plate as described by Kersters \& De Ley (1971). A blue colour developing within $10 \mathrm{~min}$ was recorded as positive.

Micromethods. Determinations of the enzymes or enzyme systems were performed by suspending a loopful of bacteria from a 24 to 48 h chocolate agar culture in $0.5 \mathrm{ml}$ (unless otherwise stated) of the respective enzyme substrates. The results were recorded after incubation for 4 and $48 \mathrm{~h}$. Urease was tested as described by Lautrop ( 1960). Decarboxylation of ornithine and lysine and dihydrolation of arginine were determined in the media (I $\mathrm{ml}$ ) of Møller ( 1955). Alkaline phosphatase was determined as described by Kersters \& De Ley (197l). Phenylalanine deaminase activity was determined in a modified Bergquist \& Seracy (1963) medium. The enzyme substrate was I $\mathrm{ml}$ of a $0.5 \%(\mathrm{w} / \mathrm{v})$ aqueous solution of L-phenylalanine (Calbiochem). Aqueous ferric chloride solution $(8 \%, \mathrm{w} / \mathrm{v})$ was used as the test reagent. The glycosidases, $\beta$-galactosidase, $\alpha$-glucosidase, $\beta$-glucosidase, $\beta$-glucuronidase, $\beta$-xylosidase and $\alpha$-fucosidase were determined in $0 . \mathrm{I} \%(\mathrm{w} / \mathrm{v})$ solutions of the following chromogenic nitrophenyl glycosides: 2-nitrophenyl- $\beta$-D-galactopyranoside (Koch-Light), 4-nitrophenyl- $\alpha$-D-glucopyranoside (Merck), 4-nitrophenyl- $\beta$-D-glucopyranoside (Merck), 4-nitrophenyl- $\beta$-D-glucopyranosiduronic acid (Merck), 2-nitrophenyl- $\beta$-D-xylopyranoside (Koch-Light), and 4-nitrophenyl- $\alpha$-L-fucopyranoside (Koch-Light) (Kilian \& Bülow, 1976).

\section{Gas chromatography}

The gas evolved during growth in glucose medium was analysed as follows: $500 \mathrm{ml}$ of the glucose fermentation medium contained in an initially gas-free Erlenmeyer flask with arrangements for pressure adjustment, were inoculated and incubated for $48 \mathrm{~h}$. The $\mathrm{pH}$ was then lowered to below $\mathrm{I}$ by addition of conc. $\mathrm{HCl}$ to drive off $\mathrm{CO}_{2}$ dissolved in the medium. After $24 \mathrm{~h}, 300 \mu \mathrm{l}$ of the gas were collected and injected into a gas chromatograph equipped with a Gow-Mac thermal conductivity cell (w2 $\times$ filaments). The two columns were packed with Porapak Q (80 to Ioo mesh) and molecular sieves $(0.5 \mathrm{~nm}, 50$ to 80 mesh), respectively. The carrier gas was helium, $50 \mathrm{ml} / \mathrm{min}$. The determinations were carried out at $25^{\circ} \mathrm{C}$.

\section{DNA extraction and purification}

All strains were harvested from 24 to $48 \mathrm{~h}$ chocolate agar cultures and rechecked for identity. The bacteria were washed in cold saline-EDTA (O. I 5 M-NaCl-O.I M-EDTA, pH 8), resuspended in saline-EDTA and lysed with sodium lauryl sulphate according to Marmur (I96I). The DNA was extracted and purified by Stenderup \& Bak's (I968) modification of Marmur's (I96I) method. The final precipitate of pure DNA was dissolved in standard saline citrate (SSC; 0. I $5 \mathrm{M}-\mathrm{NaCl}-0.015 \mathrm{M}$-trisodium citrate, $\mathrm{pH} 7.0$ ) and stored at $4{ }^{\circ} \mathrm{C}$ over a few drops of chloroform. 


\section{Determination of DNA base composition by thermal denaturation}

The measurements were carried out on one of two different systems. One was that described by Stenderup \& Bak (I968), except for the introduction of an electronically-heated cuvette holder and a Unicam SP 876 temperature controller in the arrangement. The temperature was increased by $0.25^{\circ} \mathrm{C} / \mathrm{min}$, and the recorded temperature values were used without corrections. The alternative arrangement consisted of a Gilford spectrophotometer 2400 equipped with a thermosensor model $24 \mathrm{I} 7$. The cuvettes were heated $0.5{ }^{\circ} \mathrm{C} / \mathrm{min}$ by a Hetotherm gradient unit type PG which circulated ethylene glycol through the cuvette holder. The values for mean denaturation temperature $\left(T_{m}\right)$ obtained from this apparatus were corrected by reference to a DNA preparation measured simultaneously. Three to four measurements were carried out on each DNA sample.

\section{RESULTS}

\section{General survey of the taxonomic results}

The 426 Haemophilus strains were assigned to species according to the results of the examination (Table 3). The results for each taxon are described in detail below. In nearly all cases it was possible to equate the preliminary taxa with existing named species, although type strains are available for only a few of these. However, several of the species pose different problems, mainly of nomenclature, and these are discussed below.

The two species $H$. influenzae and $H$. parainfluenzae have been subdivided into a number of biotypes. According to the results, H. aegyptius, H. parahaemolyticus and $H$. paraphrohaemolyticus do not merit specific status, and strains received with these labels have been included in $H$. influenzae or $H$. parainfluenzae. In Table $3, H$. aphrophilus is placed after $H$. paraphrophilus. The similarity between the two species is significant, and they will be described together, although it is questionable whether $H$. aphrophilus belongs to the genus Haemophilus. Haemophilus ducreyi presents special problems. The nine strains assigned to this species divide naturally into two groups consisting of seven and two strains respectively. Only the latter two can legitimately be assigned to the genus Haemophilus, but as it is impossible to decide which of these groups are identical to Ducrey's bacillus ( 1889 ), all nine strains will be described under the heading $H$. ducreyi.

It has been possible to recognize four taxa among the strains not assignable to any of the previously described species. One of these, consisting of 17 strains mainly isolated from the human oral cavity, merits specific status and the name Haemophilus segnis is proposed. The three other taxa, also NAD-dependent and haemin-independent strains, are temporarily designated taxa A, B and $\mathrm{C}$, respectively, because of the small number of strains available. The species $H$. piscium has been rejected from the genus Haemophilus for various reasons, but the strains will be described according to the label under which they were received.

Table 4 lists the phenotypic characters which are most useful for distinguishing the named species of Haemophilus. The characters included in the Table are those that seem to be constant and most reproducible in tests.

\section{Observations on some of the methods and characters}

Satellite phenomenon. Satellitism, which was used for the demonstration of V-factor requirement, could not always be demonstrated convincingly on horse blood agar, but calf blood agar nearly always gave satisfactory and clear-cut results. In case of doubt, a V-factor 
Table 3. Specific assignment of 426 Haemophilus strains

\begin{tabular}{lclr}
\multicolumn{1}{c}{ Species } & No. of strains & \multicolumn{1}{c}{ Species } & No. of strains \\
H. influenzae & & H. paraphrophilus & II \\
Biotype I & $7 \mathrm{I}$ & H. aphrophilus (species incertae sedis) & I6 \\
Biotype II & 64 & H. segnis sp.nov. & I7 \\
Biotype III & 28 & H. parasuis & 9 \\
Biotype IV & I2 & H. pleuropneumoniae & I5 \\
Biotype V & IO & H.paragallinarum & 2 \\
Unclassified strains & 3 & Unnamed NAD-dependent taxa: & 4 \\
H. haemolyticus & 9 & Taxon A & 4 \\
H. haemoglobinophilus & 5 & Taxon B & 5 \\
Unclassified strain & I & Taxon C & 6 \\
H. ducreyi & 2 & Strains rejected from Haemophilus: & 7 \\
H.parainfluenzae & & H.piscium & 7 \\
Biotype I & 45 & H.ducreyi? & \\
Biotype II & 45 & &
\end{tabular}

requirement of haemin-independent strains could be verified on brain-heart agar supplied with a NAD-containing disc. Some strains received as $H$. ducreyi, but not assignable to the genus Haemophilus, showed a slight satellite growth around staphylococcal colonies on horse blood agar, but the same growth-enhancing effect could not be obtained around a NAD-containing disc.

Haemolysis. Several of the strains, primarily isolated as haemolytic, lost the property after one or more subcultures, with consequent problems in the classification of some of the NAD-dependent strains of human origin. The instability of haemolysis was also noted with strains assigned to the species $H$. pleuropneumoniae, but the species was fairly well defined by many other phenotypic traits.

Requirement for carbon dioxide. Nearly all strains assigned to the species $H$. paraphrophilus, $H$. aphrophilus, and the NAD-dependent taxon $\mathrm{C}_{\text {. grew better in air supplemented }}$ with $10 \% \mathrm{CO}_{2}$. $\mathrm{A} \mathrm{CO}_{2}$ stimulation was also noted with a few strains assigned to other groups, but such strains did not differ otherwise from the remaining strains of the taxonomic groups to which they were assigned. Haemophilus paraphrohaemolyticus has therefore not been listed as a separate species.

Fermentation reactions and production of gas. A pilot study revealed that only a limited number of carbohydrates were of value for differentiating between species. However, glucose, sucrose, lactose, mannitol, xylose and deoxyribose were used throughout the study and proved useful. With a few exceptions, acid was produced in sufficient amounts to give a clear-cut change of indicator within I to 2 days' incubation. The $\mathrm{pH}$ normally decreased from 7.6 to between 5.0 and $6 \cdot 3$. The decrease of $\mathrm{pH}$ of non-glycolytic origin, as measured in the inoculated control tube, never exceeded $0.4 \mathrm{pH}$ units. There was no rise in $\mathrm{pH}$ in the sugar-free medium with any of the strains after incubation for 5 days, but tubes occasionally showed an alkaline reaction after about 10 days.

Gas was evolved after I to 3 days in glucose broth by strains of the species $H$. haemolyticus, $H$. parainfluenzae, $H$. paraphrophilus, $H$. aphrophilus and Actinobacillus actinomycetemcomitans. The amount of gas produced was never very great (5 to $20 \%$ of the total volume of the Durham tube) but was more pronounced with the last three species. Chromatographic studies of gas produced by representative aerogenic strains revealed that the constituents were hydrogen and carbon dioxide. Evolution of gas of the same composition was also seen in $0.01 \%$ nitrate broth with most strains of the species mentioned, whereas only strains of 


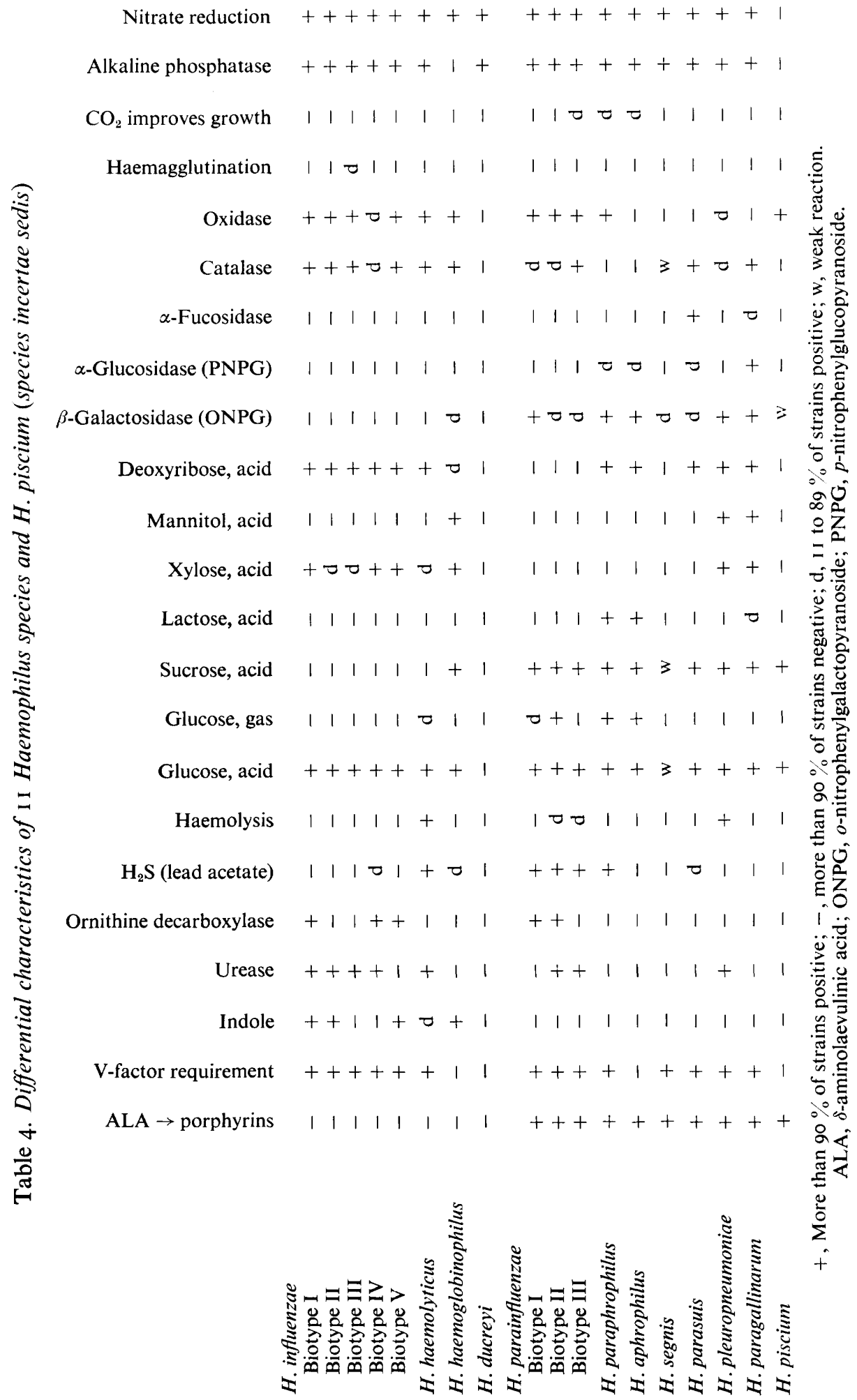


$H$. aphrophilus and $H$. paraphrophilus produced gas in $0.1 \%$ nitrate broth. Nitrogen was not detected in any of the gas samples examined.

Reduction of nitrate and nitrite. All strains assigned to Haemophilus, except one unnamed strain, reduced nitrate. No significant differences were found between the levels to which nitrate was reduced by strains of the different taxa. Although most strains of the purely NAD-dependent species, in contrast to strains of $H$. influenzae and $H$. haemolyticus, were capable of reducing all nitrate beyond nitrite in $0.1 \%$ nitrate broth, these two species were also capable of reducing beyond nitrite provided the amount of nitrate in the medium was reduced to $0.01 \%$.

Oxidase and catalase activity. All strains of $H$. influenzae were oxidase positive, although in some strains the reaction was delayed ( $5 \mathrm{~s}$ ). Most other species gave equivocal results, and only strains of $H$. aphrophilus and $H$. ducreyi were invariably devoid of oxidase activity. All strains were oxidase negative when picked from Levinthal's agar. Similarly, with few exceptions, strains of $H$. influenzae, $H$. haemolyticus, biotype III of $H$. parainfluenzae, $H$. parasuis and $H$. paragallinarum were strong catalase producers. Strains of the species $H$. paraphrophilus, $H$. aphrophilus and $H$. ducreyi were catalase negative, whereas the remaining species gave equivocal results.

Hydrogen sulphide production. Hydrogen sulphide was never detected in the ferrous chloride medium, whereas lead acetate paper divided the strains into those causing no change and those giving a distinct blackening within 2 days.

DNAase activity. DNAase activity was not observed.

Esterase activity. In the esterase test, results ranged from a strong blue colour developed within I min to complete absence of a reaction. Esterase activity was encountered in some haemolytic strains assigned to $H$. parainfluenzae, and some strains of the species $H$. paraphrophilus, $H$. aphrophilus, H. pleuropneumoniae, $H$. parasuis and $H$. paragallinarum. Because of poor reproducibility, the character has not been included in the Tables.

Micromethods. The micromethods used for the detection of porphyrin synthesis, production of indole, urease, amino acid decarboxylases, glycosidases and alkaline phosphatase proved satisfactory for the examination of nearly all strains. Only some $H$. parasuis strains growing with diminutive colonies on chocolate agar presented difficulties in obtaining sufficiently large inocula. The same problem also applied to strains of Eikenella corrodens producing colonies adhering to the agar plate. With such strains, satisfactory tests could be performed with bacteria harvested from a broth culture by centrifugation.

The media used for determination of decarboxylases were originally devised for growth (Møller, 1955) but, although not meeting the growth requirements of haemophili, the results obtained with a heavy suspension of bacteria were identical to those obtained with the same media supplemented with NAD and haemin. Arginine dihydrolase was demonstrated only in occasional strains.

All Haemophilus strains, except for strains of $H$. haemoglobinophilus and a strain of $H$. parainfluenzae isolated from a rat, produced alkaline phosphatase.

The micromethods used normally gave strong and clear-cut results within $4 \mathrm{~h}$ incubation.

DNA base composition. Seventy-nine strains were analysed for the guanine + cytosine (GC) content of their DNA (Table 5). Escherichia coli $\mathrm{B}$ was included for reference purposes. There was good agreement between results obtained with the two systems used to determine $T_{m}$, with results varying by only $\pm 0.2{ }^{\circ} \mathrm{C}$ from the mean. Table 5 gives the mean values for each species and the calculated standard deviations, excluding unclassified strains. Figure I summarizes graphically the mean GC content of the DNA of Haemophilus species and the biotypes of species. The range of values obtained for strains assigned to the genus 
Table 5. GC content of DNA of species of Haemophilus and related genera

\begin{tabular}{|c|c|c|c|c|}
\hline \multirow[b]{2}{*}{ Species } & \multirow[b]{2}{*}{ Biotype } & \multirow{2}{*}{$\begin{array}{l}\text { No. of } \\
\text { strains } \\
\text { tested* }\end{array}$} & \multicolumn{2}{|c|}{ Mean GC $(\mathrm{mol} \%$, \pm S.D. $)$} \\
\hline & & & Biotype & Species \\
\hline H. influenzae & $\begin{array}{l}\text { I } \\
\text { II } \\
\text { III } \\
\text { IV } \\
\text { V } \\
\text { Unc. }\end{array}$ & $\begin{array}{l}4 \\
4 \\
5 \\
4 \\
2 \\
\text { I }\end{array}$ & $\left.\begin{array}{l}38 \cdot 5 \pm 0 \cdot 12 \\
39 \cdot 1 \pm 0 \cdot 31 \\
38 \cdot 6 \pm 0 \cdot 28 \\
38 \cdot 9 \pm 0 \cdot 48 \\
38 \cdot 3 \pm 0 \cdot 71 \\
38 \cdot 3\end{array}\right\}$ & $38 \cdot 7 \pm 0 \cdot 44$ \\
\hline H. haemolyticus & - & 3 & - & $38 \cdot 5 \pm 0 \cdot 0$ \\
\hline H. haemoglobinophilus & $\overline{\text { Lnc. }}$ & $\begin{array}{l}3 \\
\text { I }\end{array}$ & $37^{6} 6^{-}$ & $38 \cdot 1 \pm 0.96$ \\
\hline$H:$ ducreyi & - & 2 & - & $37 \cdot 8 \pm 0 \cdot 14$ \\
\hline H. parainfluenzae & $\begin{array}{l}\text { I } \\
\text { II } \\
\text { III } \\
\text { Unc. }\end{array}$ & $\begin{array}{l}5 \\
7 \\
8 \\
\text { I }\end{array}$ & $\left.\begin{array}{l}39 \cdot 7 \pm 0 \cdot 22 \\
40 \cdot 2 \pm 0 \cdot 35 \\
40 \cdot 6 \pm 0 \cdot 49 \\
43 \cdot 7\end{array}\right\}$ & $40.2 \pm 0.5 I$ \\
\hline H. aphrophilus & - & 5 & - & $42 \cdot 0 \pm 0.58$ \\
\hline H. paraphrophilus & - & 5 & - & $41 \cdot 9 \pm 0 \cdot 69$ \\
\hline H. segnis & - & 4 & - & $43.5 \pm 0.54$ \\
\hline H. parasuis & -- & $\mathbf{I}$ & - & $41 \cdot 5$ \\
\hline H. pleuropneumoniae & - & 3 & - & $42 \cdot 0 \pm 0 \cdot 35$ \\
\hline H. paragallinarum & 一 & I & - & $42 \cdot 2$ \\
\hline Taxon A & - & I & - & $39 \cdot 3$ \\
\hline Taxon C & - & 2 & - & $42 \cdot 0 \pm 0 \cdot 0$ \\
\hline H. piscium & - & 2 & - & $55 \cdot 1 \pm 0 \cdot 0$ \\
\hline A. actinomycetemcomitans & - & I & - & $42 \cdot 7$ \\
\hline Ei. corrodens & - & I & - & $55 \cdot 9$ \\
\hline E. coli в & - & $\mathbf{I}$ & - & $5 r \cdot 7$ \\
\hline
\end{tabular}

Haemophilus was about 37 to $44 \mathrm{~mol} \%$. All haemin-requiring species had a GC content of DNA below $39.4 \mathrm{~mol} \%$, whereas all haemin-independent species had a GC content above this value. The difference between the two main groups is significant at the $0.1 \%$ level (Table 6). Strains assigned to $H$. segnis had the highest GC value.

The calculated significant differences of mean GC contents (sum of squares simultaneous test, SS-STP; Sokal \& Rohlf, 1969) are provided in Table 6.

\section{Characteristics of the individual taxa}

The taxa to be described must be considered preliminary at this stage because type strains are available only for a few of the Haemophilus species. The names used are those used in the revised classification resulting from this study. Although this means that the main results of the study are anticipated it makes the presentation easier to follow. Most of the taxonomic deliberations and decisions are presented under Discussion.

\section{Haemophilus influenzae}

One hundred and eighty-eight strains isolated from humans were assigned to $H$. influenzae (Table I). 

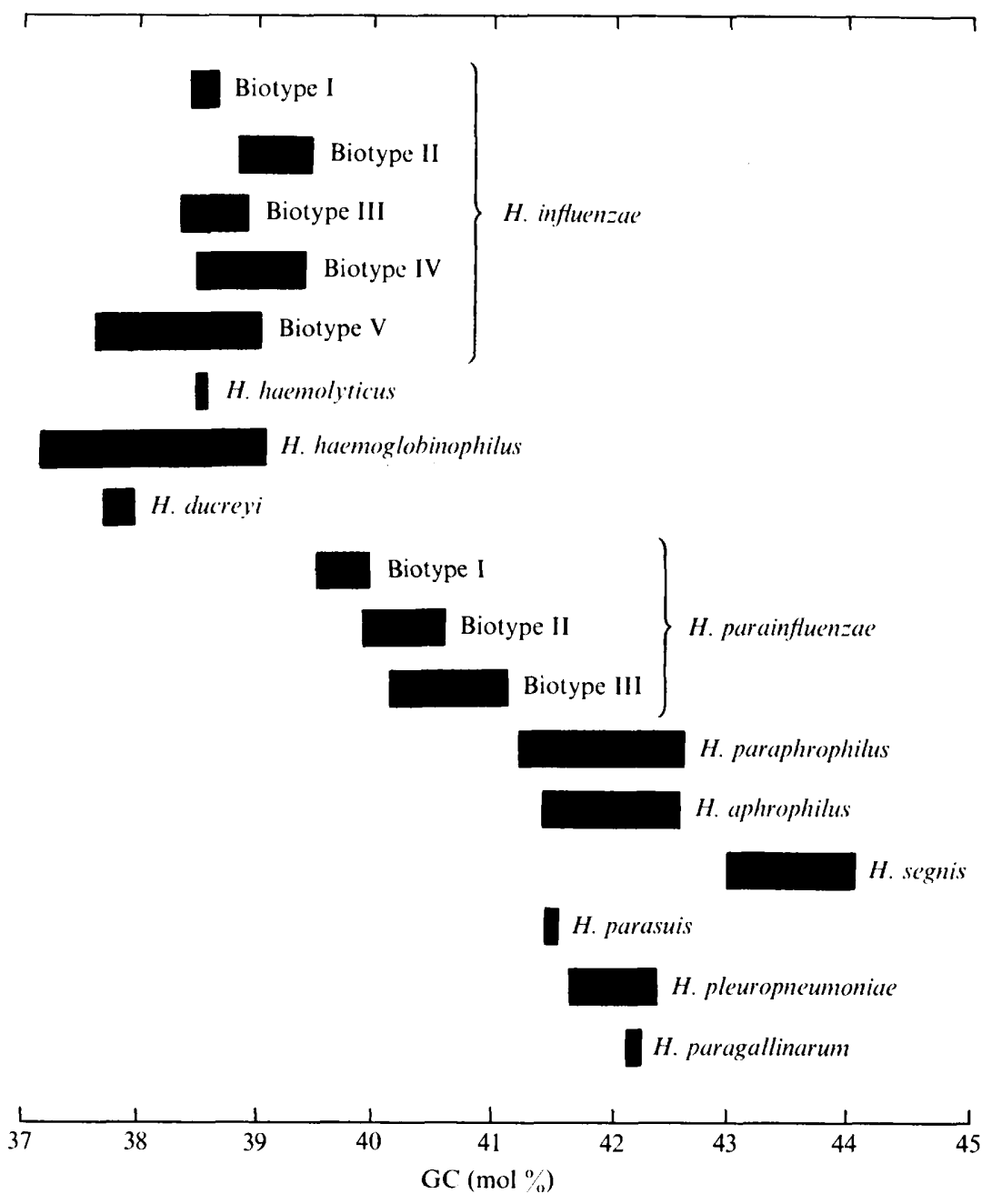

Fig. I. The GC contents of the DNAs of I I Haemophilus species. Values plotted are the means \pm I S.D.

Characteristics of $H$. influenzae. The strains assigned to $H$. influenzae included all nonhaemolytic strains that were V-factor-dependent and devoid of the enzymic capacities to convert $\delta$-aminolaevulinic acid to porphyrins. A number of almost constant properties further characterized the strains of the species. They were small, non-motile, slightly pleomorphic rods or coccobacilli with only occasional filamentous forms. Colonies on chocolate agar were smooth, low, convex, greyish, translucent and attained a diameter of 0.5 to $\mathrm{I} \cdot \mathrm{O} \mathrm{mm}$. Capsulated strains usually produced larger and more mucoid colonies ( $\mathrm{I}$ to $3 \mathrm{~mm}$ ) and showed a greater tendency to coalesce with no visible line of division than colonies of non-capsulated strains. Carbohydrates were fermented to a final $\mathrm{pH}$ of $5 \cdot 3$ to $5 \cdot 9$. All strains fermented glucose and deoxyribose with the production of acid but no gas. Most strains fermented xylose but none fermented sucrose, lactose or mannitol. With a few exceptions they were catalase and oxidase positive, possessed alkaline phosphatase and were $\mathrm{H}_{2} \mathrm{~S}$ and esterase negative. All strains were devoid of $\alpha$-glucosidase, $\beta$-glucosidase, $\beta$-galactosidase, 
Table 6. Significant differences of mean GC contents of DNAs of Haemophilus species

H. influenzae
H. haemolyticus
H. haemoglobinophilus
H. ducreyi
H. parainfluenzae
H. paraphrophilus
H. aphrophilus
H. segnis
H. parasuis
H. pleuropneumoniae
H. paragallinarum

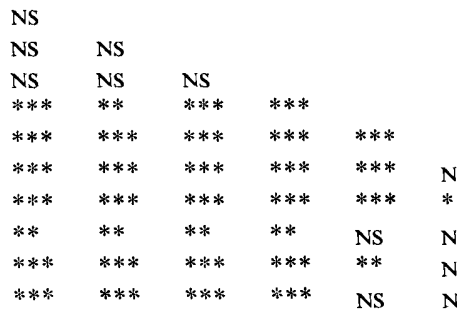 NS NS NS NS NS NS NS NS NS NS *, $P<0.05 ;{ }^{* *}, P<0.01$; ***, $P<0.001$; NS, not significant.

$\beta$-xylosidase, $\beta$-glucuronidase (except for HK224, 235, 387 and 388 ) and $\alpha$-fucosidase, and none of the strains required $\mathrm{CO}_{2}$ for good growth. The $\mathrm{GC}$ content of their DNA (mean value for the 19 strains HK6, 30, 32, 76, 223, 238, 279, 28I, 367, 369, 387, 388, 389, 390, 393, $396,397,400$ and $40 \mathrm{I}$ ) was $38 \cdot 7 \pm 0.44 \mathrm{~mol} \%$ (Table 5).

Sixty-eight $(36 \%)$ of the strains were capsulated. All but two could be assigned to one of Pittman's serotypes a to f. The proportion of capsulated strains and the distribution of six serotypes are summarized in Table 8 .

Subdivision of $H$. influenzae. All except three of the strains included in the species $H$. influenzae could be subdivided into five biotypes (I to V). Strains received as $H$. aegyptius were assigned to biotype III. The differential characteristics of the biotypes are summarized in Table 7, and the relationship between the biotypes and the sites from which they were isolated is shown in Table $\mathrm{I} 8$, below.

Biotype I. Seventy-one strains belonged to this biotype (Table I). With a few exceptions the strains were isolated from acute infections only. Growth of the strains gave a pungent smell of indole. All strains were indole, urease, and ornithine decarboxylase positive. Seventythree per cent of the strains were capsulated, and serotype b was predominant (Table 8). The phenotypic characters of the strains are given in Table 7. Two strains (HK I4I, HK293) did not grow in the fermentation media.

Biotype II. Sixty-four strains were included in this biotype (Table I). The lack of ornithine decarboxylase was the most prominent phenotypic character distinguishing biotype II from biotype I. The strains were isolated from various infections as well as from the flora of normal throats. Growth on agar media produced the same characteristic smell of indole as for strains of biotype I. Thirteen per cent of the strains were capsulated, but one of them was not typable with Pittman type antisera a to $\mathrm{f}$ (Table 8). The phenotypic characters of the strains are given in Table 7 .

Biotype III. The 28 strains of biotype III (Table I) were, with a few exceptions, isolated from cases of conjunctivitis and from normal throats. Some of the strains produced long 


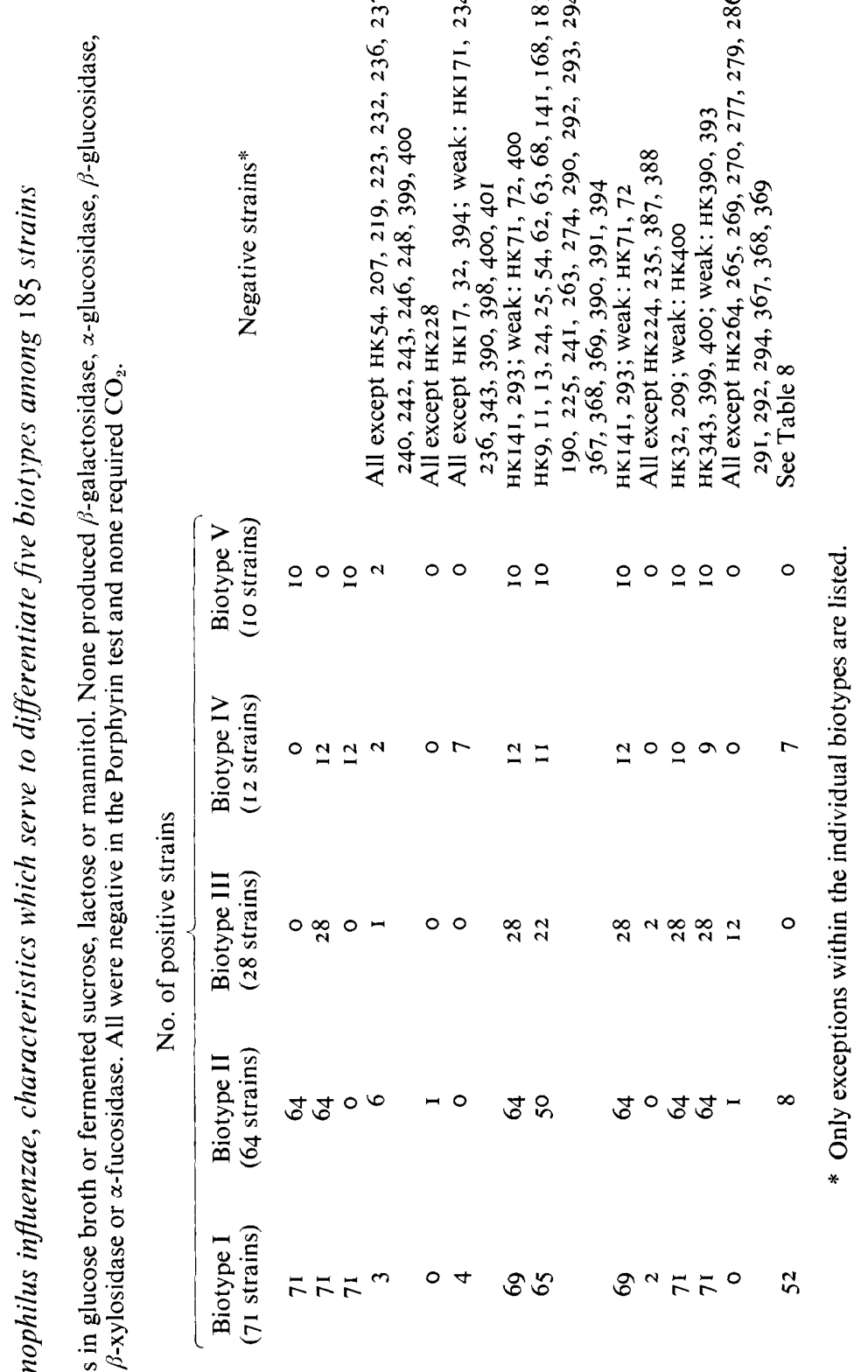

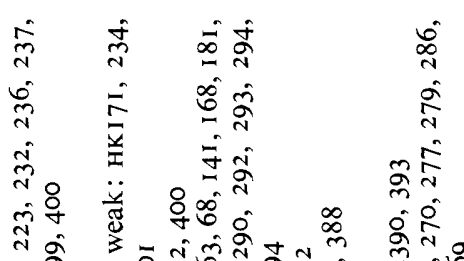

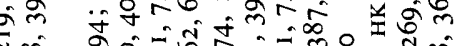

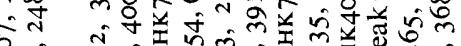

पे mo

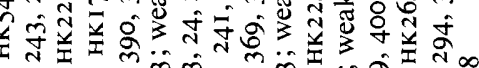

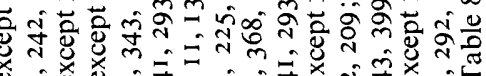

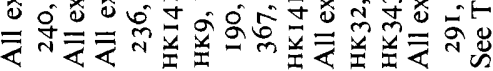

हू
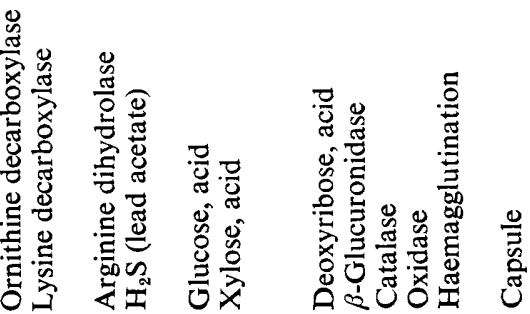
Table 8. Proportion of $188 \mathrm{H}$. influenzae strains which formed capsules

\begin{tabular}{|c|c|c|c|c|}
\hline & $\begin{array}{l}\text { Total no. } \\
\text { of strains }\end{array}$ & $\begin{array}{l}\text { No. of } \\
\text { capsulated } \\
\text { strains }\end{array}$ & $\begin{array}{l}\text { Serotype, and } \\
\text { no. of capsulated } \\
\text { strains }\end{array}$ & $\begin{array}{l}\text { Reference nos. of } \\
\text { capsulated strains }\end{array}$ \\
\hline Biotype I & $7 \mathrm{I}$ & $52(73 \%)$ & $\begin{array}{l}\text { a: } 3 \\
\text { b: } 45\end{array}$ & $\begin{array}{l}\text { HKI } 190,390,39 \text { I } \\
\text { HK27,76, I 62, I63, I71, 173-189, 19I, } \\
\text { I93-205, 21 } 3-216,254,293,297, \\
392,393 \\
\text { HKI } 72,192,247,403\end{array}$ \\
\hline Biotype II & 64 & $8(12 \%)$ & $\begin{array}{l}\text { b: } 4 \\
\text { c: } 2 \\
\text { f: I } \\
\text { NT: I }\end{array}$ & $\begin{array}{l}\text { HK 206, 2IO, } 2 \text { II }, 2 \text { I } 2 \\
\text { HK342, } 396 \\
\text { HK402 } \\
\text { HKI } 68\end{array}$ \\
\hline Biotype III & 28 & 0 & - & - \\
\hline Biotype IV & 12 & $7(58 \%)$ & $\begin{array}{l}\text { b: } 2 \\
\text { d: } 2 \\
\text { e: } 3\end{array}$ & $\begin{array}{l}\text { HK 209, } 394 \\
\text { HK343, } 397 \\
\text { HK } 399,400,401\end{array}$ \\
\hline Biotype V & 10 & 0 & - & - \\
\hline Unclassified & 3 & I $(33 \%)$ & NT & HK 280 \\
\hline
\end{tabular}

slender rods in addition to the normal microscopic picture of $H$. influenzae, but the relative number of these rods varied considerably from strain to strain. This property was most pronounced in HK367 and HK368. Two strains (HK7I and HK72) showed a markedly pleomorphic microscopic picture, with long irregular filaments. Colonies formed by strains of biotype III were generally smaller than those of the other biotypes of $H$. influenzae, and the odour emitted by them was sweet. None of the strains were capsulated. Forty-four per cent of the strains agglutinated red blood cells, but three had lost the property when retested. Only strains isolated from conjunctivitis were haemagglutinating. The phenotypic characters of the strains are shown in Table 7.

Biotype IV. Twelve strains were included in biotype IV (Table I), which was the least satisfactory biotype of $H$. influenzae. Several of the common characters of the species were variable within biotype IV. Six of the 12 strains were received from culture collections as representatives of serotypes $\mathrm{d}$ and e of $\boldsymbol{H}$. influenzae (HK398 is a converted rough strain of type d) (Table 8 ). The odour emitted by strains of this biotype was sweet. The phenotypic characters of the strains are given in Table 7.

Biotype V. All ten strains of this biotype (Table I) were isolated from ear infections, and the group was homogeneous. None of the strains was capsulated. Their characteristics are shown in Table 7 .

Unclassified strains. The three remaining strains (Table I), that could not be accommodated in any of the five biotypes, were very similar and might represent a sixth biotype. The strains were ornithine decarboxylase, catalase and oxidase positive, but indole, urease, lysine decarboxylase and arginine dihydrolase negative. They fermented glucose and xylose, and two of them (HK39 and HK28I) fermented deoxyribose. None of the strains fermented sucrose, lactose or mannitol. One of the strains (HK280) was capsulated, but did not belong to the serotypes a to $\mathrm{f}$. The DNA base composition as determined for one of the strains (HK28I) was not significantly different from that of other strains of $H$. influenzae (Table 5). 
Table 9. Characteristics of 9 strains of $H$. haemolyticus

All strains were negative in ornithine and lysine decarboxylases, arginine dihydrolase and glycosidases, and in the Porphyrin test.

Indole

Urease

$\mathrm{H}_{2} \mathrm{~S}$ (lead acetate)

Haemolysis

Glucose, acid

Glucose, gas

Sucrose, acid

Lactose, acid

Xylose, acid

Deoxyribose, acid

Mannitol, acid

Catalase

Oxidase

$\mathrm{CO}_{2}$ improves growth

Haemagglutination

$\begin{array}{cc}\begin{array}{c}\text { No. of positive } \\ \text { strains }\end{array} & \text { Negative strains } \\ 8 & \text { HK386 } \\ 9 & - \\ 9 & - \\ 9 & \text { See text } \\ 9 & - \\ 8 & \text { HK29 } \\ 0 & - \\ 0 & - \\ 5 & \text { HK33, 53,75, 386 } \\ 9 & - \\ 0 & - \\ 9 & - \\ 9 & - \\ \text { O } & \text { All except HK45 } \\ \text { I } & \end{array}$

\section{Haemophilus haemolyticus}

Nine strains were included in this species (Table $\mathrm{I}$ ). These were all haemolytic strains that required $\mathrm{V}$-factor and were unable to synthesize porphyrins from $\delta$-aminolaevulinic acid. Apart from the haemolytic ability, these strains differed from strains of $H$. influenzae in producing gas from glucose broth and being $\mathrm{H}_{2} \mathrm{~S}$ positive. The other features of the group were very similar to those described for $H$. influenzae. They were small, regular, non-motile and non-capsulated coccobacilli or short rods with occasional filamentous forms. Colonies on chocolate agar were smooth, convex, greyish, translucent, and reached a diameter of 0.5 to $\mathrm{I} \cdot 5 \mathrm{~mm}$. Growth was not enhanced by excess of $\mathrm{CO}_{2}$ in the incubation atmosphere. The indole-producing strains emitted a pungent smell. On primary isolation all strains were haemolytic, but one strain (HKI2) lost the property after several transfers. Carbohydrates were fermented to a final $\mathrm{pH}$ of 5.3 to 5.7 . The GC content of their DNA (mean value for the three strains HK53, HK75 and HK386) was $38.5 \mathrm{~mol} \%$ (Table 5). The characteristics of the strains are summarized in Table 9.

\section{Haemophilus haemoglobinophilus (canis)}

Five strains isolated from dogs were assigned to this species (Table I). In addition, an unclassified strain isolated from a human perianal abscess (Ryan, I968) is also described here.

Characteristics of $H$. haemoglobinophilus. The strains included in H. haemoglobinophilus were fairly well distinguished from all other Haemophilus species by the requirement for haemin only, the production of indole and the fermentative pattern. They were also differentiated from all other haemophili studied by the failure to produce alkaline phosphatase. The following properties further characterized the strains of this species. They were small, slightly pleomorphic, non-motile and non-capsulated rods. Colonies on chocolate agar were smooth, convex and translucent with a small granular area on top, and reached a diameter of $\mathrm{I}$ to $2 \mathrm{~mm}$. They grew well and without haemolysis on blood agar and showed no satellite growth around a streak of staphylococcus. Excess of $\mathrm{CO}_{2}$ in the incubation atmosphere did not improve growth. The GC content of their DNA (mean value for the three strains $\mathrm{HK}_{3} 65$, 
Table 10. Biochemical and physiological characteristics of H. haemoglobinophilus and an unnamed strain

All strains were non-haemolytic and negative in the Porphyrin test, and in urease, ornithine and lysine decarboxylases, and arginine dihydrolase.

\begin{tabular}{|c|c|c|c|}
\hline & $\overbrace{\begin{array}{c}H . \text { haemo- } \\
\text { globinophilus } \\
\text { (5 strains) }\end{array}}^{\text {No. of } \mathrm{p}}$ & $\begin{array}{c}\text { NCTCIO555/ } \\
\text { HK43 I }\end{array}$ & Negative strains \\
\hline Indole & 4 & o & HK378 (see comment) \\
\hline $\mathrm{H}_{2} \mathrm{~S}$ (lead acetate) & 3 & 0 & HK 375,378 (reactions weak) \\
\hline Glucose, acid & 5 & $\mathbf{I}$ & - \\
\hline Glucose, gas & 0 & o & 一 \\
\hline Sucrose, acid & 5 & I & - \\
\hline Lactose, acid & 0 & I & - \\
\hline Xylose, acid & 5 & $\mathbf{I}$ & - \\
\hline Deoxyribose, acid & 4 & I & HK 376 \\
\hline Mannitol, acid & 5 & o & - \\
\hline$\beta$-Galactosidase & 2 & I & HK365, 375,378 \\
\hline$\alpha$-Glucosidase & 0 & $\mathbf{I}$ & - \\
\hline$\beta$-Glucosidase & 0 & $\mathbf{I}$ & 一 \\
\hline$\beta$-Glucuronidase & 0 & 0 & - \\
\hline$\beta$-Xylosidase & 0 & I & - \\
\hline$\alpha$-Fucosidase & 0 & 0 & - \\
\hline Catalase & 5 & 0 & - \\
\hline Oxidase & 5 & 0 & 一 \\
\hline $\mathrm{CO}_{2}$ improves growth & 0 & 0 & 一 \\
\hline Nitrate reduction & 5 & 0 & - \\
\hline Alkaline phosphatase & 0 & $\mathbf{I}$ & - \\
\hline
\end{tabular}

HK376 and HK378) was $38 \cdot \mathrm{I} \pm 0.96 \mathrm{~mol} \%$ (Table 5). The phenotypic characters are listed in Table ro.

Unnamed strain. Strain HK43I has been considered as a variety of $H$. influenzaemurium (Ryan, I968), but in the absence of identical or similar strains it is conveniently described under H. haemoglobinophilus because it resembles this species in several ways, especially in the requirement for haemin only. It was a non-capsulated coccobacillus with occasional filamentous forms. Colonies on chocolate agar were smooth, convex, greyish, translucent and reached a diameter of about $\mathrm{I} \mathrm{mm}$. Colonies on blood agar were smaller and there was no satellite effect of a staphylococcus on the plate. It was non-haemolytic and excess of $\mathrm{CO}_{2}$ in the incubation atmosphere did not affect growth. The GC content of its DNA was $37.6 \mathrm{~mol} \%$ (Table 5). The characteristics of the strain are listed in Table 10.

\section{Haemophilus ducreyi}

Nine strains designated $H$. ducreyi were included in this study (Table I). Although only two of the strains can legitimately be assigned to the genus Haemophilus, they are all described here for the reasons discussed below.

Characteristics of the strains. Common to all nine strains was a very poor growth on all media. One of the strains (HK350) was distinctly Gram-positive and reduced nitrate, and since none of these characters agree with the description of Reymann (1949 $b$ ), the authenticity of the strain is dubious and it will not be dealt with further. The remaining eight strains fell within two distinct groups, made up of the Reymann strains and the CIP strains respectively. The two groups will therefore be described separately. 
Table 1 I. Characteristics of two groups of strains designated H. ducreyi

All strains were non-haemolytic, and indole, urease, ornithine and lysine decarboxylases, arginine dihydrolase, catalase and oxidase negative. None produced glycosidases.

\begin{tabular}{lccc} 
& \multicolumn{2}{c}{ No. of positive strains } & \\
Perphyrin test & $\begin{array}{c}\text { CIP strains } \\
\text { (2 strains) }\end{array}$ & $\begin{array}{c}\text { Negative } \\
\text { strains }\end{array}$ \\
$\mathrm{H}_{2}$ S (lead acetate) & 6 & 0 & - \\
Glucose, acid & 0 & 0 & - \\
Glucose, gas & $5^{*}$ & 0 & HK349 \\
Sucrose, acid & 0 & 0 & - \\
Lactose, acid & $4^{*}$ & 0 & HK348, 349 \\
Deoxyribose, acid & 0 & 0 & - \\
Xylose, acid & 0 & 0 & - \\
CO improves growth & 0 & 0 & - \\
Nitrate reduction & 0 & 0 & - \\
Alkaline phosphatase & 0 & 2 & -
\end{tabular}

* Positive after incubation for 6 to 8 days.

Reymann's strains. All six strains (HK344 to HK349) were non-motile coccobacilli or short slender rods. They were predominantly Gram-negative but interspersed with varying numbers of cells that resisted total decolorization with ethanol. A closer examination by electron microscopy showed that the fine structure of the cell wall of these strains was typical of a Gram-positive bacterium (Kilian \& Theilade, 1975). Colonies on chocolate agar were smooth, convex, greyish and translucent and reached a diameter of about $0.5 \mathrm{~mm}$. Only very sparse growth was obtained on horse blood agar. There was slight satellite growth around a staphylococcus streak but not around a V-factor disc. The final $\mathrm{pH}$ in fermentation media after 6 to 8 days was $4 \cdot 5$ to $4 \cdot 9$. All attempts to extract DNA from the strains were unsuccessful. The characteristics of the strains are listed in Table I I.

CIP strains. These two strains (HK379 and HK380) were non-motile, irregular, slender rods often arranged in long chains. They were distinctly Gram-negative as shown by staining and by electron microscopic examination of the cell wall (Kilian \& Theilade, 1975). Colonies on chocolate agar after $72 \mathrm{~h}$ incubation were predominantly small (about $0.5 \mathrm{~mm}$ ), flat, smooth, greyish and translucent but with a few interspersed larger colonies ( .5 to $2.0 \mathrm{~mm}$ ) with an otherwise identical appearance. Growth on horse blood was sparse and no haemolysis was seen. There was no satellitism around a staphylococcus streak on blood agar, and $\mathrm{CO}_{2}$ had no effect on the growth. The GC content of their DNA (mean value for the two strains) was $37 \cdot 8 \pm 0 \cdot 14 \mathrm{~mol} \%$ (Table 5 ).

\section{Haemophilus parainfluenzae}

The 125 strains assigned to this species (Table 1) were mainly isolated from the oral cavities and throats of healthy persons.

Characteristics of $H$. parainfluenzae. The taxonomically important characters distinguishing $H$. parainfluenzae from $H$. influenzae were the enzymic capacities to carry out porphyrin synthesis, the ability to ferment sucrose and the inability to ferment deoxyribose and xylose. Among other phenotypic characters, fermentation reactions distinguished $H$. parainfluenzae from other haemin-independent Haemophilus species. The following properties characterized the species. They were small, non-motile, pleomorphic rods, normally with long filamentous forms. When grown on chocolate agar they emitted a sweet smell. Colonial 

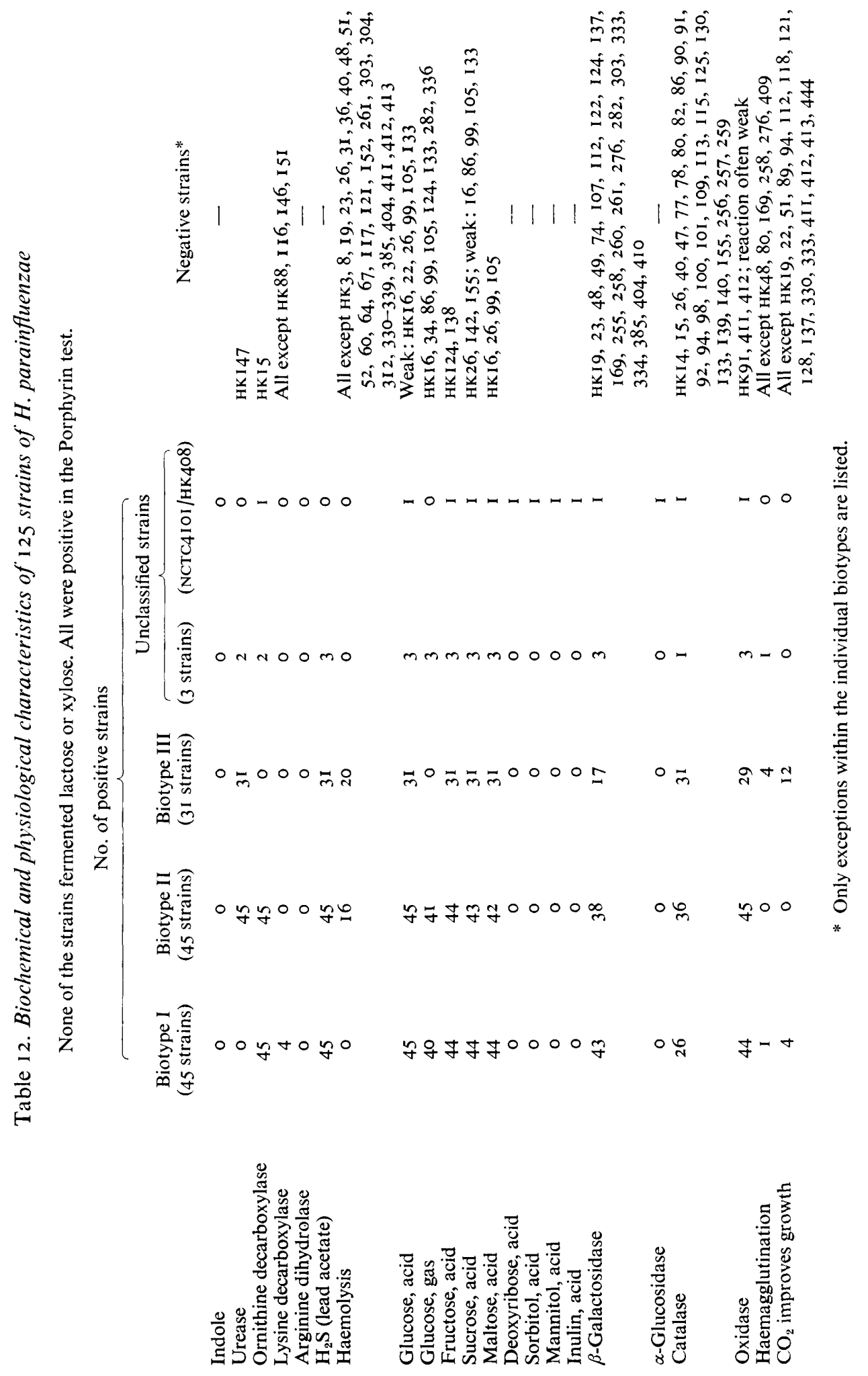
Table 13. Characteristics of traditional species $H$. parahaemolyticus, $H$. paraphrohaemolyticus and two biotypes of $H$. parainfluenzae

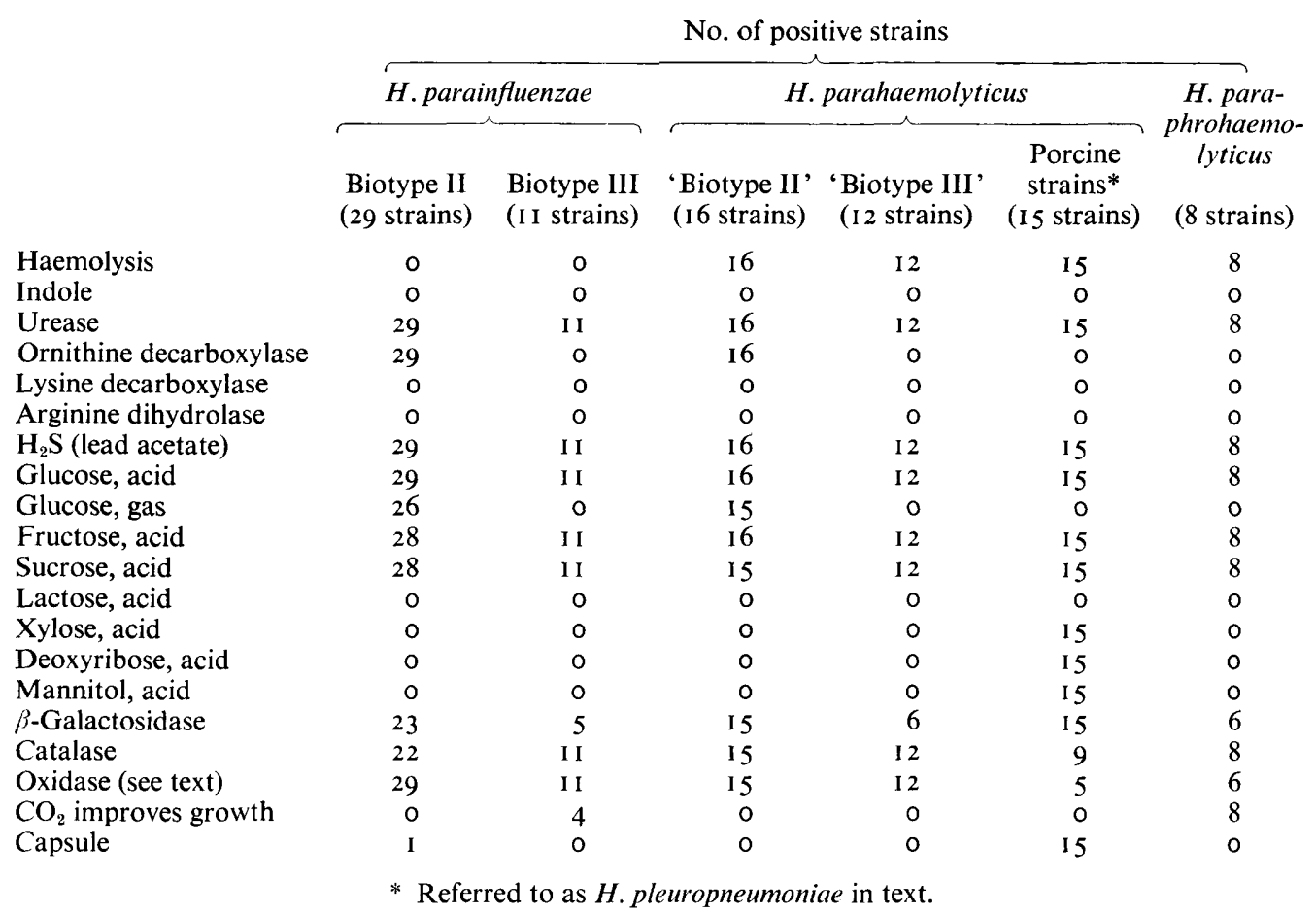

morphology was variable and is discussed for each biotype. The strains were V-factordependent, indole negative, $\mathrm{H}_{2} \mathrm{~S}$ and alkaline phosphatase positive (except HK444), and fermented glucose, sucrose, maltose, galactose, and fructose but never lactose, deoxyribose, xylose, mannitol, dulcitol, sorbitol or inulin. Most strains produced $\beta$-galactosidase but none produced $\alpha$-glucosidase, $\beta$-glucosidase, $\beta$-xylosidase or $\alpha$-fucosidase (except HK4I3). Some of the strains were $\beta$-haemolytic and some required $\mathrm{CO}_{2}$ for good growth. All were oxidase positive, although the reaction was weak in some, but the catalase reaction was variable. Only occasional strains were capsulated or haemagglutinating. The GC content of their DNA (mean value for the 20 strains HK3, 22, 23, 5I, 65, 8I, 90, 102, I24, I69, 282, $33 \mathrm{I}, 335,385,404,409,4 \mathrm{IO}, 4 \mathrm{II}, 4 \mathrm{I} 2$ and $4 \mathrm{I} 6$ ) was $40 \cdot 2 \pm 0 \cdot 5 \mathrm{I} \mathrm{mol} \%$ (Table 5).

Subdivision of $H$. parainfluenzae. Except for four, the 125 strains which were assigned to H. parainfluenzae could be subdivided into three biotypes (I, II and III). The differential characteristics of the three biotypes are given in Table I2. Biotypes II and III, characterized by urease production, include haemolytic $(H$. parahaemolyticus) as well as non-haemolytic strains. Some of the haemolytic strains of biotype III showed improved growth when incubated with extra $\mathrm{CO}_{2}(H$. paraphrohaemolyticus $)$. The characteristics of the haemolytic and non-haemolytic strains of biotypes II and III are listed separately in Table I3. Also included in the Table are the characteristics of haemolytic strains of porcine origin.

Biotype I. This biotype, which included 45 strains (Table I), was the most homogeneous of the three biotypes of $H$. parainfluenzae. It comprised, with few exceptions, strains isolated from human saliva only. Colonies on chocolate agar were greyish-white or yellowish opaque and reached a diameter of $\mathrm{I}$ to $2 \mathrm{~mm}$. On primary isolation, $50 \%$ of the strains formed 
smooth, convex colonies with an entire edge, $30 \%$ very rough wrinkled colonies and $20 \%$ formed flat smooth colonies with a serrated edge. Colonies of the two latter types were dry and coherent in texture and could often be slid intact across the surface of the agar plate. However, the colonial morphology was not a consistent property, as most of the strains of the rough type converted to the smooth type after some transfers. None of the strains was capsulated. The biochemical and physiological characteristics of the strains are listed in Table I2. With a few exceptions, the carbohydrates attacked were fermented to a final $\mathrm{pH}$ of $5 \cdot 3$ to $5 \cdot 7$.

Biotype II. The 45 strains of biotype II (Table I) differed from those of biotype I in being urease positive. Sixteen strains $(36 \%)$ were $\beta$-haemolytic at primary testing but two of the strains (HK64 and HK336) had lost the property when retested. Two strains (HKI2O and HK I22) produced greening of horse blood agar. On chocolate agar the colonial morphology was of the same types as biotype I. The detailed phenotypic traits are listed in Table I2. With a few exceptions, carbohydrates were fermented to a final $\mathrm{pH}$ of $5 \cdot 3$ to $5 \cdot 7$.

Biotype III. The 3 I strains of biotype III (Table I) differed from the two previous biotypes, being ornithine decarboxylase negative, not producing gas from glucose, and giving a weaker acid production in carbohydrate media (final $\mathrm{pH} 5.6$ to $7^{\circ} 0$ ). Twenty of the strains $(65 \%)$ were haemolytic at primary isolation or on receipt. When retested, three strains (HK I I, HK26I and HK338) had lost the property. Colonies on chocolate agar were butyrous, flat, greyish, smooth, translucent and reached a diameter of 0.5 to $\mathrm{I} .5 \mathrm{~mm}$. The growth of twelve strains $(39 \%)$ was enhanced by $10 \% \mathrm{CO}_{2}$ added to the incubation atmosphere. The phenotypic characters of the strains are listed in Table 12.

Unclassified strains. The four remaining strains tentatively assigned to $H$. parainfluenzae shared most of the characters of this species. However, three of the strains (HK I5, HK80 and HK I47) differed by being indole positive. The other characters of the three strains are listed in Table I2. The fourth strain (HK408) occupied a unique position among all the strains of the collection. On superficial examination the strain was very similar to the strains of $H$. parainfluenzae biotype I. It had, however, a number of distinctive characters (Table I2), including a wider spectrum of carbohydrates attacked. Colonies on chocolate agar were smooth, convex, butyrous, reddish-translucent, and reached a diameter of $\mathrm{I} \cdot 5$ to $2 \cdot 0 \mathrm{~mm}$. The GC content of its DNA $(43.7 \mathrm{~mol} \%)$ was significantly different $(P<0.00 \mathrm{I})$ from the value obtained for other strains of $H$. parainfluenzae (Table 5).

\section{The aphrophilus group}

The two species $H$. paraphrophilus and $H$. aphrophilus were included in this group, to which 27 strains were assigned (Table 1 ).

Characteristics of the aphrophilus group. The group consisted of haemophili which almost all required $\mathrm{CO}_{2}$ and which had nearly uniform characteristics and differed from all other haemophili in several phenotypic features. The specific characters of the group were the ability to ferment lactose, the fermentation of carbohydrates to a final $\mathrm{pH}$ of 4.9 to 5.4 and with production of relatively large amounts of gas from glucose, the $\alpha$-glucosidase activity, and the requirement for $\mathrm{CO}_{2}$ by most strains. The strains were non-motile, short regular rods with only occasional filamentous forms. Colonies on chocolate agar were highly convex, granular, yellowish, opaque and reached a diameter of 1.0 to $1.5 \mathrm{~mm}$. When incubated without $\mathrm{CO}_{2}$ the growth was characteristically stunted, with very small'colonies interspersed with a few larger colonies. The odour of the growth was sweetish. Haemolysis was not seen on horse blood agar. Growth in broth was granular, with a heavy sediment on the bottom of the tube and adhering colonies on the walls. It was difficult to remove this 
Table I4. Biochemical and physiological characteristics of H.paraphrophilus, H. aphrophilus and Actinobacillus actinomycetemcomitans

All strains were negative in indole, urease, ornithine and lysine decarboxylases, arginine dihydrolase, haemolysis, haemagglutination, $\beta$-glucuronidase, $\beta$-xylosidase and $\alpha$-fucosidase. All strains were positive in alkaline phosphatase and the Porphyrin test.

No. of positive strains

$\begin{array}{lcc}\begin{array}{l}\text { H.paraphrophilus } \\ \text { (I } 1 \text { strains) }\end{array} & \begin{array}{c}\text { H. aphrophilus } \\ \text { (16 strains) }\end{array} & \begin{array}{c}\text { actinomycetem- } \\ \text { comitans }\end{array} \\ \text { (7 strains) }\end{array}$

$V$-factor requirement

$\mathrm{H}_{2} \mathrm{~S}$ (lead acetate)

Glucose, acid

Glucose, gas

Fructose, acid

Sucrose, acid

Lactose, acid

Maltose, acid

Xylose, acid

Deoxyribose, acid

Mannitol, acid

$\beta$-Galactosidase

$\alpha$-Glucosidase

$\beta$-Glucosidase

Catalase

Oxidase

$\mathrm{CO}_{2}$ improves growth

\section{I}

I I

I I

IO

I I

II

I I

II

I

II

II

9

I

I I
8 (16 strains)

(7 strains)

Negative strains*

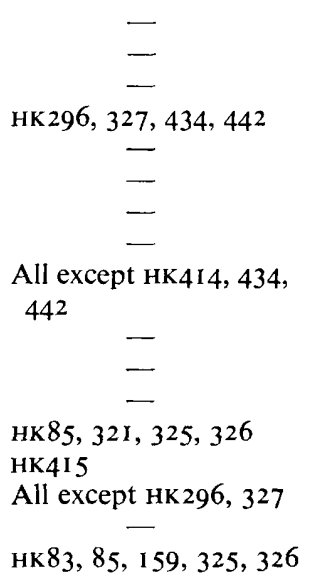

* Only exceptions within the individual species are listed.

adherent growth from the tube. It resembled the growth of Streptococcus mutans and $S$. sanguis, but in contrast to these bacteria the characteristic adherent growth was independent of the presence of sucrose in the medium. The GC content of their DNA (mean value for the ten strains $\mathrm{HK} 83,85, \mathrm{I} 59,308,325,37 \mathrm{I}, 372,373,4 \mathrm{I} 4$ and $4 \mathrm{I} 5$ ) was $4 \mathrm{I} \cdot 9 \pm 0.60 \mathrm{~mol} \%$ (Table 5). The biochemical and physiological characters of $H$. paraphrophilus and $H$. aphrophilus are listed in Table I4.

Two strains (HK296 and HK327) were only tentatively assigned to the group, because they differed from all other strains in important ways: they were catalase positive, were anaerogenic in glucose broth, and failed to grow on chocolate agar with bacitracin $(300 \mu \mathrm{g} / \mathrm{ml})$. Furthermore, НК296 produced very small colonies, even when incubated in air plus $10 \% \mathrm{CO}_{2}$.

The characters distinguishing these two species from $H$. haemoglobinophilus and from Actinobacillus actinomycetemcomitans, Eikenella corrodens and Pasteurella multocida, are summarized in Table 17.

\section{Haemophilus segnis sp.nov.}

The name Haemophilus segnis (from the Latin adjective segnis, sluggish) is proposed for a distinctive and not previously described group of V-factor-dependent and haemin-independent haemophili. The differentiation of the species from other haemophili is unfortunately based mainly on negative characters. The high GC content of the DNA, however, separates the strains from other species. Seventeen strains were assigned to the species (Table I).

Characteristics of $H$. segnis. All strains were non-motile and non-capsulated, and were 
Table 15. Biochemical and physiological characteristics of H. segnis sp.nov., $H$. parasuis and $H$. paragallinarum

All strains were negative in indole, urease, ornithine and lysine decarboxylases, arginine dihydrolase, $\beta$-glucuronidase and $\beta$-xylosidase. All were positive in the Porphyrin test.

No. of positive strains

\begin{tabular}{|c|c|c|}
\hline $\begin{array}{l}\text { H. segnis } \\
\text { (I } 7 \text { strains) }\end{array}$ & $\begin{array}{l}\text { H. parasuis } \\
\text { (9 strains) }\end{array}$ & $\begin{array}{l}\text { H. paragallinarum } \\
\text { (2 strains) }\end{array}$ \\
\hline
\end{tabular}

$\mathrm{H}_{2} \mathrm{~S}$ (lead acetate)

0

Haemolysis

Glucose, acid

Glucose, gas

Maltose, acid

Sucrose, acid

Lactose, acid

Cellobiose, acid

Xylose, acid

Deoxyribose, acid

Inulin, acid

Mannitol, acid

$\beta$-Galactosidase

$\alpha$-Glucosidase

$\beta$-Glucosidase

$\alpha$-Fucosidase

Catalase

Oxidase

$\mathrm{CO}_{2}$ improves growth

o

o

w

w

o

0

0

0

0

I 2

\section{5}

w†

$\mathrm{o}$
$\mathrm{O}$
$\mathrm{O}$
$\mathrm{W}$
$\mathrm{O}$
$\mathrm{O}$

* Only exceptions within individual species are listed.

$\uparrow$ Weak to negative reactions (see text).
All except HK417, 424, 425, 426 427 (weak reactions)

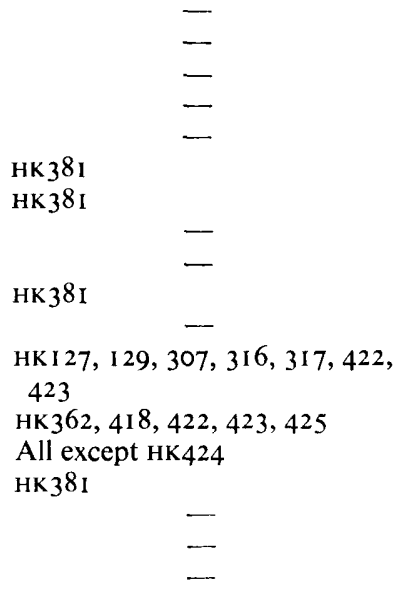

predominantly irregular filaments interspersed with a few bacillary forms. On chocolate agar the colonies were smooth or granular, highly convex, greyish-white, opaque and reached a diameter of about $0.5 \mathrm{~mm}$. No odour was emitted from the growth. Satellite growth was obtained on both horse and calf blood agar around staphylococcal colonies or a NAD-containing disc. They were not haemolytic, and excess $\mathrm{CO}_{2}$ was not required for good growth. The growth in carbohydrate media was sparse, and acid was not produced or produced in very small amounts (final pH 6.5 to $7 \cdot 0$; control tube without sugar: $7 \cdot 2$ ). Catalase and oxidase reactions were negative to weakly positive. The GC content of the DNA was the highest value obtained for any species of Haemophilus: $43.5 \pm 0.54 \mathrm{~mol} \%$ (Table 5; mean value for the four strains HK35, HK84, HK3O7 and HK3I6). The phenotypic characters are listed in Table $\mathbf{5}$.

Proposed type strain. Strain HK3I 6 is proposed as type strain for Haemophilus segnis and has been deposited in the National Collection of Type Cultures as NCTCI0977.

\section{Haemophilus parasuis}

Nine strains of porcine origin (Table I) were tentatively labelled $H$. parasuis according to the proposal of Biberstein \& White (1969). The problems of nomenclature for the group are discussed below.

Characteristics of $H$. parasuis. The properties differentiating $H$. parasuis from other $\mathrm{V}$-factor-dependent species were its marked, but partly unknown, nutritional requirements, 
the $\alpha$-fucosidase activity, a positive catalase reaction, and a weak fermentation of carbohydrates (final $\mathrm{pH} 6.4$ to 6.8 ) without production of gas from glucose. The following properties further characterized the strains assigned to this species: they were non-motile, predominantly thin, pleomorphic rods of varying length. Growth on chocolate agar was very feeble after 48 to $72 \mathrm{~h}$ incubation. The colonies were smooth, greyish, translucent and reached a diameter of about $0.5 \mathrm{~mm}$. A marked enhancement of growth, with colonies attaining a diameter of $\mathrm{I}$ to $2 \mathrm{~mm}$, was seen around contaminating organisms or a streak of a staphylococcus on the chocolate agar. The same growth stimulation on chocolate agar was not obtained around a NAD-containing disc. No haemolysis was seen on horse blood agar. Growth was not enhanced by excess $\mathrm{CO}_{2}$ in the incubation atmosphere. The GC content of DNA of HK424 was $41.5 \mathrm{~mol} \%$. The phenotypic characters of the strains are listed in Table 15 .

\section{Haemophilus pleuropneumoniae}

Fifteen strains of porcine origin were assigned to this species (Table I). The serotypes of the strains quoted in Table I are as stated by the donor.

Characteristics of $H$. pleuropneumoniae. The strains assigned to $H$. pleuropneumoniae were $\mathrm{V}$-factor-dependent and possessed the ability to synthesize porphyrins from $\delta$-aminolaevulinic acid. The group was very homogeneous and corresponds to the organism designated $H$. pleuropneumoniae by Shope (1964) and $H$. parahaemolyticus by Nicolet (1968). The problems of nomenclature for the group are discussed below.

The production of urease and fermentation of mannitol, xylose and deoxyribose differentiated this species from other V-factor-dependent haemophili of porcine and human origin. The following properties characterized the group. All strains were non-motile coccobacilli or rather large rods, with only occasional filamentous forms. Two types of colonies, both opaque and reaching a diameter of $\mathrm{I} \cdot 0$ to $1.5 \mathrm{~mm}$, were produced on chocolate agar. On primary isolation a rounded, hard, 'waxy' colony type predominated, which adhered to the platinum loop, but after several transfers on chocolate agar a flatter, soft, glistening colony was mainly found. All strains were capsulated and produced iridescent colonies on Levinthal's agar. None of the strains required $\mathrm{CO}_{2}$ for good growth. They were all $\beta$-haemolytic on primary isolation, but five strains (HK355, 356, 358, 359 and 360) had lost the property on receipt. Carbohydrates were fermented to a final $\mathrm{pH}$ of 5.3 to $6 \cdot 0$. The GC content of their DNA (mean value for the three strains HK353, HK356 and HK 358 ) was $42 \cdot 0 \pm 0.35 \mathrm{~mol} \%$ (Table 5). The phenotypic characteristics of the strains are listed in Table 13 (under 'Haemophilus parahaemolyticus: Porcine strains').

Strain HK 36 I has been deposited in the National Collection of Type Cultures as NCTC 0976.

\section{Haemophilus paragallinarum}

Haemophilus paragallinarum was represented by only two strains (Table 1), and they were only tentatively assigned to this species which was originally proposed by Biberstein \& White (1969). The nomenclatural problems of the species are discussed below.

Characteristics of the strains. The two strains were in many ways similar to $H$. parasuis. The most useful features differentiating the two species were the stronger fermentative ability of $H$. paragallinarum (final $\mathrm{pH} 5.0$ to 5.3 ) and the fermentation of several carbohydrates not metabolized by $H$. parasuis (Table I 5). The two strains were short, non-motile rods with occasional filaments. Colonies on chocolate agar were smooth, greyish and translucent, and reached a diameter of 0.5 to $\mathrm{I} \cdot 0 \mathrm{~mm}$. The strains were not haemolytic and 
Table I6. Biochemical and physiological characteristics of three unnamed $N A D$-dependent taxa, $A, B$ and $C$

None of the strains produced $\beta$-glucosidase, $\beta$-glucuronidase, $\beta$-xylosidase or $\alpha$-fucosidase. All strains were positive in the Porphyrin test.

\begin{tabular}{|c|c|c|c|c|c|}
\hline & \multicolumn{3}{|c|}{ No. of positive strains } & \multirow{2}{*}{\multicolumn{2}{|c|}{ Negative strains* }} \\
\hline & $\begin{array}{c}\text { Taxon A } \\
\text { (4 strains) }\end{array}$ & $\begin{array}{c}\text { Taxon B } \\
\text { (4 strains) }\end{array}$ & $\begin{array}{c}\text { Taxon C } \\
\text { (5 strains) }\end{array}$ & & \\
\hline Indole & 4 & 4 & 0 & & - \\
\hline Urease & 0 & 4 & 0 & & - \\
\hline Ornithine decarboxylase & 4 & 4 & 0 & & - \\
\hline Lysine decarboxylase & 4 & o & 0 & & - \\
\hline Arginine dihydrolase & 0 & 0 & 0 & & 一 \\
\hline $\mathrm{H}_{2} \mathrm{~S}$ (lead acetate) & 4 & 4 & 5 & $\begin{array}{r}\text { Weak: HK I } 6 \\
384,428,42\end{array}$ & $\begin{array}{l}64,167,382,383 \\
29\end{array}$ \\
\hline Haemolysis & 0 & 0 & 0 & & $\cdots$ \\
\hline Glucose, acid & 4 & 4 & 5 & & - \\
\hline Glucose, gas & 2 & 0 & 0 & HKI 64,170 & \\
\hline Galactose, acid & NT & NT & 5 & & 一 \\
\hline Sucrose, acid & 4 & 4 & 5 & & - \\
\hline Lactose, acid & 0 & 0 & 0 & & $\ldots$ \\
\hline Xylose, acid & 3 & 3 & 0 & HK I 7O, 447 & \\
\hline Deoxyribose, acid & 4 & 4 & 3 & $\mathrm{HK} 428,429$ & \\
\hline Inulin, acid & NT & NT & 3 & $\mathrm{HK}_{3} 83,428$ & \\
\hline Mannitol, acid & 0 & 0 & 0 & & - \\
\hline Arabinose, acid & NT & NT & 4 & $\mathrm{HK}_{3} 83$ & \\
\hline$\beta$-Galactosidase & 0 & 4 & 0 & & 一 \\
\hline$\alpha$-Glucosidase & 0 & 0 & 5 & & - \\
\hline Catalase & 4 & 4 & 5 & & - \\
\hline Oxidase & o & 4 & 0 & & - \\
\hline $\mathrm{CO}_{2}$ improves growth & 0 & 0 & 4 & HK382 & \\
\hline Capsule & 3 & 0 & 0 & HKI 70 & \\
\hline Haemagglutination & 3 & 0 & 0 & HKI 67 & \\
\hline
\end{tabular}

did not require $\mathrm{CO}_{2}$ for good growth. The GC content of DNA extracted from HK38I was $42 \cdot 2 \mathrm{~mol} \%$. The biochemical and physiological features of the strains are summarized in Table I5.

\section{Unnamed $V$-factor-dependent taxa}

Among $13 \mathrm{~V}$-factor-dependent strains not assigned to any of the taxa described above, three distinct groups were recognized. It is possible that these groups merit specific rank, but at present they will only be labelled taxon A, taxon B, and taxon C. Taxa A and B seem to be in an intermediate position between $H$. influenzae and $H$. parainfluenzae, possessing several characters of each of the two species.

Description of the individual taxa. Taxon A. The four strains in this taxon (Table I) were short, non-motile rods with occasional filamentous forms. Colonies on chocolate agar were smooth, convex, greyish and translucent, and reached a diameter of $\mathrm{I}$ to $2 \mathrm{~mm}$. The GC content of DNA from HKI 64 was $39 \cdot 3 \mathrm{~mol} \%$. The characteristics of the strains are listed in Table 16.

Taxon B. These four strains (Table I) were non-capsulated and non-motile coccobacilli and short rods, with occasional filamentous forms. Colonies on chocolate agar were smooth, 
convex, white and opaque, and reached a diameter of 1.5 to $2.0 \mathrm{~mm}$. The characters of the strains are summarized in Table 16.

Taxon $\mathrm{C}$. The five strains in this taxon (Table 1 ) resembled $H$. paraphrophilus in many ways, for example in the requirement for $\mathrm{CO}_{2}$, but differed by failing to ferment lactose and to produce gas from glucose broth. Some of the strains have been designated by others as $H$. suis, $H$. parasuis and $H$. paragallinarum, but they differed from other strains of these species by the ability to grow abundantly on chocolate agar, the appearance of the colonies, a distinct improvement of growth by $\mathrm{CO}_{2}$, the failure to produce $\alpha$-fucosidase and by the ability to ferment arabinose (Table 16). They were non-capsulated and non-motile, and were regular rods or occasionally filaments. Colonies on chocolate agar were granular, highly convex, yellowish and opaque, and reached a diameter of 1.0 to $1.5 \mathrm{~mm}$. The GC content of their DNA (mean value for the two strains $\mathrm{HK}_{3} 83$ and $\mathrm{HK} 428$ ) was $42.0 \mathrm{~mol} \%$ (Table 5).

\section{Species rejected from Haemophilus: H. piscium}

This species was represented by six strains (Table $\mathrm{I}$ ) originally isolated from trout ulcers and described by Snieszko, Griffin \& Friddle (1950). The taxonomic position of the species is discussed below.

Characteristics of $H$. piscium. The six strains had identical characteristics but differed from all other strains of the collection in several ways. They were non-motile, small rods of varying length, with occasional filamentous forms. All strains were predominantly Gramnegative when stained, but with a few cells that resisted decolorization. This variation was especially marked in HK42O. An examination of the fine structure of the cell walls of the strains revealed, however, that they were typical for a Gram-negative organism (Kilian \& Theilade, 1975). The strains grew equally well on fish extract agar (Snieszko et al., 1950) and on chocolate agar at $22{ }^{\circ} \mathrm{C}$. No growth was obtained at $37{ }^{\circ} \mathrm{C}$. On chocolate agar after 4 days incubation colonies were smooth, convex, whitish and translucent, and reached a diameter of I to $2 \mathrm{~mm}$. They did not emit the characteristic sweetish smell of most haemophili. The main characters of the strains are summarized in Table 4. Characters not included in the Table are: arginine dihydrolase negative, negative in glycosidases except for a weak positive reaction of $\beta$-galactosidase after $24 \mathrm{~h}$, carbohydrates fermented to a final $\mathrm{pH}$ of $5 \cdot 2$. Nitrate was not reduced, contrary to the information given in Bergey's Manual of Determinative Bacteriology (1957) but in agreement with the findings of Snieszko et al. (1950). The GC content of their DNA (mean value calculated for the two strains HK42O and HK421) was $55 \cdot \mathrm{I} \mathrm{mol} \%$ (Table 5 ).

\section{Strains of related genera}

A list of strains of the species $A$. actinomycetemcomitans, Ei. corrodens and P. multocida included in the study for comparative purposes is given in Table I. These three species all consist of non-motile, Gram-negative pleomorphic rods which resemble especially $H$. aphrophilus and $H$. haemoglobinophilus, and therefore problems in differential diagnosis may arise. The most useful differentiating features between these species are summarized in Table 17. All the strains of Ei. corrodens were shown to be identical with regard to the properties tested as were the strains of $P$. multocida. These results are shown in Table 17 . The strains of $A$. actinomycetemcomitans are described in detail in the following paragraph, with special reference to the relationship to $H$. aphrophilus.

Actinobacillus actinomycetemcomitans. All strains examined were small coccobacilli with only occasional filamentous forms. Colonies on chocolate agar were usually smaller and 
Table I7. Characters of diagnostic value for the differentiation of $H$. paraphrophilus, $H$. aphrophilus, $H$. haemoglobinophilus, and selected species of related genera

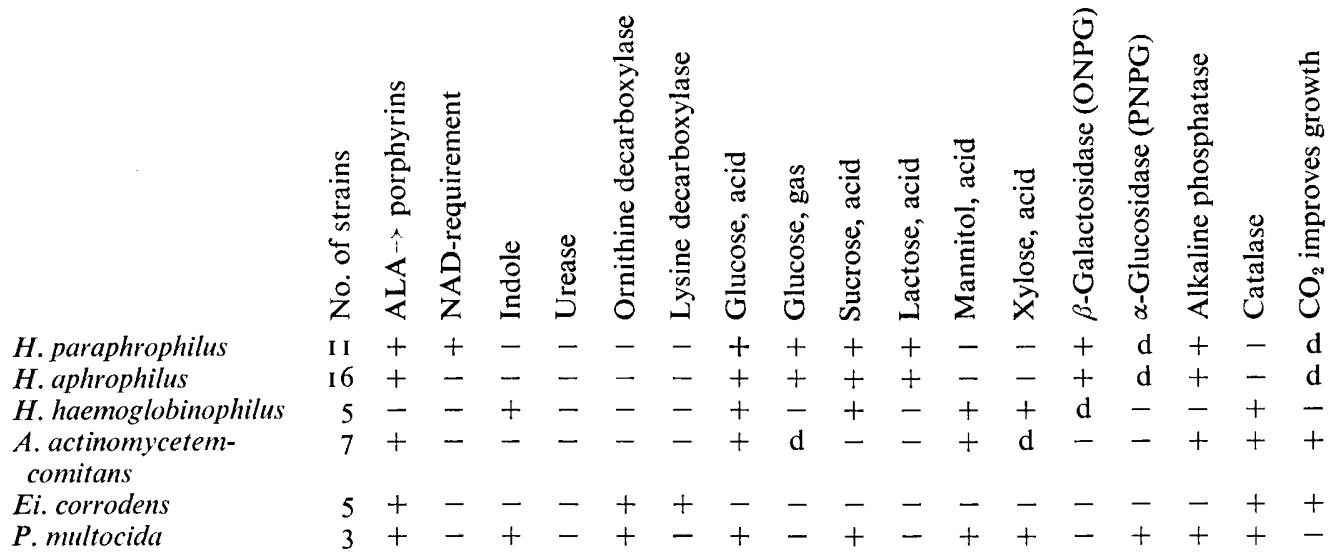

For symbols, see Table 4 .

Table I8. Correlation between origin and species assignment of 367 Haemophilus strains isolated from humans

The figures in parentheses indicate the number of strains possessing a capsule.

\begin{tabular}{|c|c|c|c|c|c|c|c|c|c|c|c|c|}
\hline & 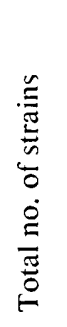 & 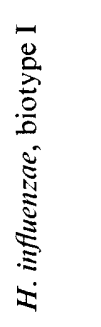 & 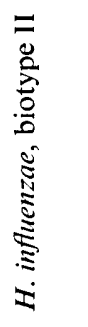 & 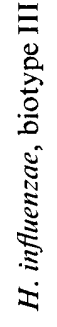 & 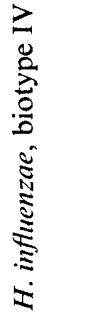 & 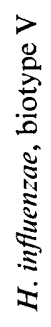 & 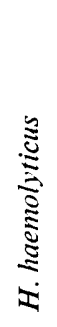 & 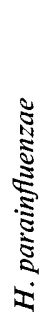 & 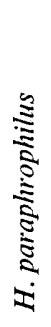 & 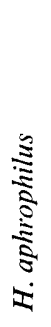 & 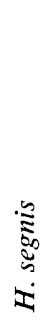 & 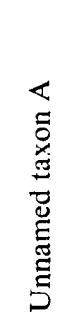 \\
\hline Upper respiratory tract & $8 \mathrm{I}$ & $9(2)$ & 20 & 8 & $5(\mathrm{I})$ & - & 8 & 30 & - & - & I & - \\
\hline Oral cavity & 105 & 2 & $\mathbf{I}$ & - & - & - & - & 72 & 8 & 6 & 16 & - \\
\hline Meningitis & 47 & $39(39)$ & $5(4)$ & I & $2(2)$ & - & - & - & - & - & - & - \\
\hline $\begin{array}{l}\text { Blood cultures and } \\
\text { epiglottitis }\end{array}$ & 6 & $6(6)$ & - & - & - & - & - & - & $\cdots$ & - & - & - \\
\hline Otitis media & 29 & $9(2)$ & 9 & 1 & 一 & 10 & - & - & - & - & - & - \\
\hline Conjunctivitis & 43 & I (I) & $16(1)$ & 17 & - & 一 & - & 5 & - & - & - & 4 \\
\hline Respiratory infections & $2 \mathrm{I}$ & $4(2)$ & $10(\mathrm{I})$ & - & - & - & I & 4 & I & I & 一 & - \\
\hline Endocarditis & 6 & - & - & - & 一 & - & - & - & - & 6 & - & - \\
\hline $\begin{array}{l}\text { Pus from abscesses and } \\
\text { wound infections }\end{array}$ & 10 & - & - & - & - & 一 & - & 5 & 2 & 3 & - & - \\
\hline $\begin{array}{l}\text { Other infections, or } \\
\text { origin unknown }\end{array}$ & II & I & $3(2)$ & I & $5(4)$ & - & - & I & - & - & - & - \\
\hline $\begin{array}{l}\text { Vaginal and urethral } \\
\text { cultures }\end{array}$ & 8 & - & - & 一 & - & - & - & 8 & - & - & - & - \\
\hline
\end{tabular}

more adherent, but otherwise resembled those of $H$. aphrophilus. Excess $\mathrm{CO}_{2}$ in the incubation atmosphere was essential for growth on chocolate agar; H. aphrophilus was less demanding in this respect. None of the strains was haemolytic. Growth in broth was granular and adhered to the tube as described for $H$. aphrophilus. The GC content of DNA extracted from HK435 was $42 \cdot 7 \mathrm{~mol} \%$. The phenotypic characters of the strains are listed in Table I 4. 


\section{Observations on the correlation between source and species}

For the 367 isolates of human origin, Table 18 shows the correlation between the origin and the specific groups to which the Haemophilus strains were assigned. The clinical diagnoses summarized in this Table are mainly those provided by the donor of each strain. Verification through the original case sheets of the patients has not been attempted, since for most this would be impossible. The strains from oral cavities and conjunctivae were selected from a larger number of strains, so that the collection included in this"study would be of a suitable composition; therefore, the relative composition of these parts of the collection does not reflect the composition of the original materials. A proportion of the strains from conjunctivae were not epidemiologically independent and some of the strains may have originated from a single strain. With these reservations in mind, Table 18 demonstrates that all strains isolated from meningitis, blood cultures, epiglottitis and otitis media belonged to $H$. influenzae, whereas almost all strains isolated from oral cavities and from vaginal and urethral cultures belonged to the haemin-independent species. This latter group of species also encompassed most strains cultured from pus from abscesses and wound infections. Many of these infections were directly or indirectly related to the oral cavity (Table I).

\section{DISCUSSION}

Early studies on the haemophilic bacteria revealed a number of important characteristics which they had in common, as well as characteristics which differentiated between them, such as differences in serology, haemolytic ability and various biochemical properties (Jordan, 1919; Pritchett \& Stillman, 1919; Yabe, 1921; Kristensen, 1922). After recognition of the two distinct growth factors, generally known as X and V (Davis, I9I7; Fildes, I92I ; Thjøtta \& Avery, I92I), and the differences in the requirement for them (Rivers, 1922 $a, b$; Valentine \& Rivers, 1927), one of the common features of all attempts to classify the Haemophilus group has been the overriding weight placed on these requirements. Only a few other properties, e.g. the haemolytic ability, have been accepted as useful in the subdivision of the genus.

\section{Growth factor requirements}

The V-factor is closely concerned in oxidation-reduction processes of the growing cell (Pittman, 1935) and is one of the two co-dehydrogenases, NAD or NADP (Lwoff \& Lwoff, $1936 a, b, 1937 a, b)$ or certain undefined precursors to these (Gingrich \& Schlenk, 1944; Shifrine \& Biberstein, 1960). The value of differentiating haemophili on the basis of this requirement is generally accepted and its determination does not usually give rise to problems. The satellite phenomenon originally described by Grassberger (1897) provides a simple way of determining the V-factor requirement, but the method should not be used uncritically since other factors produced by the feeder organism can be responsible for a satellite phenomenon (Ryan, 1968) as confirmed here. This problem could probably be avoided by the application of NAD-containing discs in place of a staphylococcus, although the possibility exists that occasional strains are unable to take up the NAD molecule. The V-factor excreted by feeder bacteria, where it has been examined, has turned out to be some precursor to NAD (Shifrine \& Biberstein, I960). To obtain a valid result, a basal medium free of available $\mathrm{V}$-factor must be used. Blood agar contains variable amounts of $\mathrm{V}$-factor, depending on the freshness of the medium and on uncontrollable, individual factors related to the medium. The unsatisfactory satellite phenomenon often seen in this study, especially on horse blood 
agar, confirms this. Thus it is possible that the use of blood-containing media for the primary screening of strains may result in an erroneous rejection of some strains as being independent of V-factor.

The haemin requirement of some Haemophilus strains has been the subject of extensive studies which have contributed to the general understanding of the respiratory systems in micro-organisms. Lwoff \& Lwoff (I937c) showed that haemin is used by $H$. influenzae in the biosynthesis of the iron-containing respiratory enzymes, cytochrome, cytochrome oxidase, catalase and peroxidase. Haemin is apparently required for growth under any conditions, but much less is required under anaerobic incubation (Gilder \& Granick, 1947). Various precursors in the haemin biosynthetic pathway such as protoporphyrin IX or other iron-free porphyrins can normally be substituted for haemin, provided they contain vinyl side-chains (Gilder \& Granick, I947; Brumfitt, 1959). It is evident, however, that some of the iron-free precursors of haemin are utilized with relative difficulty and reduce some of the functional activities of the bacterial cells which involve haem enzymes such as catalase and nitrate reductase (Smith, Hale \& O'Callaghan, 1953). Some strains of Haemophilus do not have the enzymic capacity to incorporate iron in the protoporphyrin molecule and thus have a requirement for haemin as such (White \& Granick, I963; Kilian et al., 1976). However, like most other micro-organisms, strains of the species $H$. parainfluenzae, $H$. aphrophilus, $H$. piscium and $H$. suis can form the cytochrome system without a supply of haemin (White \& Granick, 1963).

Although generally accepted, the taxonomic significance of haemin requirement has never clearly been established, mainly because of the paucity of other independent characteristics by means of which a correlation can be demonstrated. The value of differentiating haemophili on the basis of differences in this requirement has in fact been questioned by some. Smith et al. (I953) considered a sharp division of haemophili into haemin requiring and non-haemin requiring ones an oversimplification, and suggested that $H$. parainfluenzae may merely represent one end of a wide series of $H$. influenzae strains which range from those completely incapable of haemin synthesis to those which can synthesize sufficient haemin for all their requirements, even under aerobic growth. Their theory was based on the findings that strains of $H$. influenzae require different amounts of X-factor when grown anaerobically in infusion broth, and that some strains contain traces of the haem enzymes nitrate reductase and catalase even when grown in the absence of X-factor under these conditions. The ability of some strains to grow in a broth medium without haemin, however, suggests the presence of minute amounts of X-factor in the basal medium used by Smith et al. (1953) or transferred with the initial inoculum into the medium. Therefore the traces of the haem enzymes found do not necessarily indicate that bacteria are able to synthesize haemin. Studies on catalase activity of Haemophilus strains, however, led Biberstein \& Gills (I96I) to adopt the theory of Smith et al. (1953). Catalase production is a variable property in haemophili, as the present study has confirmed, and it is in varying degrees dependent on the presence of haemin, even in haemin-independent haemophili. Furthermore, it is highly dependent on the growth phase and growth condition of the bacteria (White \& Smith, I962; White, 1962). Biberstein \& Spencer (1962) suggested a rather subordinate role for catalase in the terminal oxidative processes of Haemophilus strains. The activity of catalase, although a haem enzyme, is therefore a poor marker for the haemin requirement of haemophili. Reports on haemin-independent mutants of haemophili usually considered to be haemin-dependent (Butler, 1962; Boyce, Frazer \& Zinnemann, I968) have questioned its differential value. Comparative studies of the formation of porphyrins and of the regulation of the electrontransport systems seem, however, to indicate basic differences between haemin-dependent 
and -independent haemophili (White \& Granick, I963; Biberstein, Mini \& Gills, I963; White, 1962, 1963). The difference between $H$. influenzae and $H$. parainfluenzae has been stressed by recent genetic studies of strains of the two species. Beattie \& Setlow (1970) found a low ratio of hetero- to homospecific transformation frequency in the two species, and Boling ( 1972 ) only found a $44 \%$ homology between DNAs from a strain of $H$. influenzae and $H$. parainfluenzae as revealed from DNA-DNA hybridization experiments. The quantitative differences in the haemin requirement experienced by many might be explained by the findings by Gilder \& Granick (1947). Small inocula of $H$. parainfluenzae often do not grow in culture media unless supplied with haemin, whereas large inocula grow readily in media devoid of added haemin. This is probably due to a constant inactivation of haemin by traces of peroxides produced in the culture medium during growth. The ability of haeminindependent haemophili to grow in media devoid of haemin is therefore not only dependent on the rate at which the bacteria synthesize haemin but also on the rate of its inactivation.

The heavy weighting normally placed on haemin requirement as a tool in the identification and classification of haemophili is in contrast to the difficulties experienced in an exact determination of the property (Gilder \& Granick, 1947; Kilian et al., 1972). This has been the main problem in Haemophilus taxonomy and undoubtedly accounts for much of the equivocal information on the biology of the species. Instead of the usual determination of haemin requirement by growth experiments, the present study has tested the ability of all strains to synthesize porphyrins from $\delta$-aminolaevulinic acid (Biberstein et al., 1963; Kilian, 1974). A primary subdivision of strains on the basis of this character showed a perfect correlation with DNA base composition, fermentation reactions and several other independent biochemical properties. This fact, together with the reliability of the porphyrin test, makes this property the most suitable character in the primary subdivision of the genus Haemophilus.

\section{Requirement for carbon dioxide}

The $\mathrm{CO}_{2}$ requirement has been used as one of the primary characters in establishing the species $H$. aphrophilus (Khairat, 1940), H. paraphrophilus (Zinnemann et al., 1968), and $H$. paraphrohaemolyticus (Zinnemann et al., I97I). In this study, a raised $\mathrm{CO}_{2}$ tension in the incubation atmosphere was obtained in an anaerobic jar. It should be stressed that this method does not exclude possible growth stimulation due solely to the increased humidity obtained in a jar. Nearly all strains assigned to $H$. aphrophilus and $H$. paraphrophilus, in addition to strains of taxon $\mathrm{C}$, grew better in air supplemented with $10 \% \mathrm{CO}_{2}$. The same improvement of growth was also noted with a few strains assigned to other groups, but such strains were otherwise similar to the other strains of the taxonomic groups to which they were assigned. Haemophilus paraphrohaemolyticus has thus not been listed as a separate species. The study indicates that a $\mathrm{CO}_{2}$ requirement is a valuable criterion for the identification of some species of Haemophilus, when allied to other characters.

\section{Haemolysis}

This property has been used as a primary character for the recognition of the species $H$. haemolyticus and $H$. parahaemolyticus (Pittman, 1953). Several of the strains included in this study, haemolytic on primary isolation, lost the property after one or more subcultures, with consequent problems in the classification of some of the NAD-dependent strains. Whereas haemolytic strains requiring both haemin and NAD differed in several ways from strains of $H$. influenzae (Table 4), NAD-dependent haemolytic strains of human origin which had lost their haemolytic ability were indistinguishable from the corresponding 
non-haemolytic strains (Table I3). The instability of haemolysis was also noted with strains assigned to the species $H$. pleuropneumoniae, but this species was fairly well defined by many other phenotypic characters (Table 13 ). These findings suggest that haemolysis is an unsatisfactory criterion for establishing a species. Consequently, the property was not used for the primary subdivision of NAD-dependent strains of human origin, and strains showing haemolysis were included in biotypes II or III of $H$. parainfluenzae established on other characters (Table I2).

\section{Fermentation of carbohydrates}

The value of fermentation reactions in the differentiation of Haemophilus species revealed by the present study was surprising as it conflicts with generally held opinion. Most species were relatively strong acid producers. Clear-cut and reproducible results were obtained with the commercial fermentation medium used. Kristensen (1922), McGaughey (1932) and Tunevall (I95I) have noted the ability of haemophili to produce acid in media devoid of sugar. Although confirmed by the present study, the increase in acidity of non-glycolytic origin never reached quantities sufficient to disturb the readings. However, fermentation experiments with haemophili, at least to some degree, seem to be dependent on the medium used. This is evident from a comparison of some of the results obtained here with those of Johnson (1972), for strains common to the two studies.

The production of gas in glucose media by strains of some species is also important. Except for some conflicting reports on $H$. aphrophilus (King \& Tatum, 1962; Boyce et al., I968; Sutter \& Finegold, I970), most authors describe haemophili as fermenting carbohydrates with the production of acid but no gas. The results of the present study are, however, a confirmation of the early and obviously overlooked findings of Stillman \& Bourn (1920). Although they were ignorant of the differences in growth requirements, their classification, based on gas production and fermentation of sucrose along with indole production and haemolysis, is in many ways similar to the one obtained in the present study. Most strains of $H$. haemolyticus, $H$. parainfluenzae, $H$. paraphrophilus and $H$.aphrophilus produced relatively small but definite amounts of a mixture of hydrogen and carbon dioxide from glucose, indicative of a mixed acid fermentation. The fact that the remaining species were anaerogenic indicates differences in the pathways of carbohydrate metabolism within the genus Haemophilus. The lack of gas production by strains of biotype III of $H$. parainfluenzae, $H$. segnis and $H$. parasuis were, however, associated with a less pronounced production of acid. Hydrogenlyase is induced only at a pH of 6 or less (Blackwood, Neish \& Ledingham, 1956), and the findings for these taxa therefore do not exclude a potential hydrogenlyase activity. Consequently, the taxonomic significance of the latter findings cannot be fully evaluated until further knowledge of the carbohydrate metabolism of these and other Haemophilus species is obtained.

The gas produced by most aerogenic strains in nitrate broth also consisted of hydrogen and carbon dioxide, and should not be taken to indicate a denitrification activity. The significantly reduced amounts evolved at higher nitrate concentrations can be explained by the inhibitory effect of nitrate on the hydrogenlyase activity (Billen, I95I ; Pinsky \& Stokes, 1952).

\section{Taxonomy and nomenclature}

General comments. Ideally, the taxonomy of a bacterial group is based on an unbiased analysis of a large set of properties of many strains of different origin. None of these ideal requirements has been totally met in the present study. As regards strains of human origin, 
the collection studied was probably sufficiently large and as representative as desirable. Unfortunately this is not true for the strains isolated from animals: haemophili can be isolated from many animal species not considered in this study.

The fairly large number of biochemical tests used in the study, of which several have not previously been applied to haemophili, revealed a number of hitherto unrecognized characters of taxonomic significance and have increased the information on the general properties of the genus. Considering the heterogeneity of the strain material, the number of properties determined was close to the minimum necessary for the recognition of so many different species, but even the use of this limited set of easily performed tests established a clear-cut distinction between most of the individual species (Table 4). Several of these can now be more accurately defined, but further characterization of some of the species is still desirable, particularly for the possible subdivisions or biotypes of $H$. influenzae and $H$. parainfluenzae.

The recent numerical taxonomic study by Sneath \& Johnson (1973) included the determination of a large number of characters. Although the usefulness of some of these characters may be debatable, the main limitation to their study was the small number of strains included, particularly because it can now be seen that several of the Haemophilus species are more heterogeneous than hitherto recognized. The results obtained in the present study would make it possible to select a relatively small but representative collection of strains for more extensive studies.

Although type strains are available for only a few of the Haemophilus species and often the description of the species has been inadequate, it has usually been possible to equate the preliminary groups with previously described named species. However, some of them pose problems that will now be discussed separately for the individual species.

Haemophilus influenzae. A type or neotype strain of the type species $H$. influenzae (Lehmann \& Neumann, 1896) Winslow et al., I917 has unfortunately never been designated. Sneath \& Johnson (1973) state that the organism given the name is well known, and that numerous strains could be accepted for that purpose. The results obtained for $H$. influenzae, however, demonstrate the heterogeneity of this species, which has been repeatedly suggested by strain-specific differences in pathogenicity (Rosher, 1931), various biochemical properties such as indole formation (Jordan, I919; Rhein, I919; Rivers, 1920; Yabe, I92 I), fermentation of carbohydrates (Stillman \& Bourn, 1920; Smith, 193I; Bergey's Manual of Determinative Bacteriology, 1957), urease and lysine decarboxylase activity (Huet, 1959) and antigenic constitution (Pittman, 1931 ; Wilson \& Miles, 1964; Turk \& May, 1967). Rivers \& Kohn (192I) and Kristensen (I922) noted that indole production is more often encountered in meningeal than in respiratory strains of $H$. influenzae, and Rosher (193I) showed that the property is correlated to some extent with pathogenicity under experimental conditions. Together with a few other biochemical properties, indole production was used here in the differentiation of $188 \mathrm{H}$. influenzae strains into five biotypes (Table 4). The value of distinguishing between these biotypes is indicated by the positive correlation with the sources of the strains. Eighty-five per cent of the strains isolated from meningitis and blood cultures, including cases of epiglottitis, could be assigned to biotype I, whereas all except one of the strains from conjunctivitis were assigned to biotypes II and III, which also contained most of the respiratory strains (Table I8). The distinguishing characters of the five biotypes are few, and a more extensive phenotypic characterization is desirable.

One of the important characters of haemophili causing meningitis and other acute infections is the production of a capsule. Capsule formation can be reintroduced in converted rough $H$. influenzae strains by transformation (Alexander \& Leidy, 1950, 1951 $a, b$ ). Only a few respiratory strains of $H$. influenzae can, however, be transformed in this way (Tunevall, 
1952) in spite of the fact that such strains are often transformable to streptomycin resistance. It is possible that these findings are reflexions of the heterogeneity of $H$. influenzae, which might explain the different incidence of capsulation found in the five biotypes (Table 8). Studies of frequency of transformation of genetic determinants of capsule production and antibiotic resistance between the biotypes may throw some light on this problem and provide more information on the relationship between the biotypes.

Some of the strains assigned to biotypes II and III of $H$. influenzae were isolated from eye swabs from Tunisian, Egyptian and Danish patients with conjunctivitis. As pointed out by Huet (1956), it has been the custom to label all haemophili recovered from eyes as KochWeeks bacilli or $H$. aegyptius, though plain $H$. influenzae strains can be isolated from eye infections as well (Pittman \& Davis, 1950; Rogers, Zinnemann \& Forster, 1960). The problems of distinguishing the Koch-Weeks bacillus from $H$. influenzae have been discussed in earlier papers (Pittman \& Davis, 1950; Ingham \& Turk, I969). Pittman and co-workers apparently had clarified the problems when reporting on a number of differences in serology, in biochemical reactions, in growth characteristics, and in the ability to agglutinate red blood cells. They showed that $H$. aegyptius is serologically more homogeneous than noncapsulated $H$. influenzae, that it never forms indole or ferments xylose (properties which may also be encountered in strains of $H$. influenzae) and that it is haemagglutinating (Pittman \& Davis, 1950; Davis et al., 1950). It has been stated that the cellular morphology alone is sufficient for differentiation; however, Pittman \& Davis (1950) found overlapping in size, although on the whole $H$. aegyptius tended to form more slender rods.

The validity of haemagglutination as a distinguishing character has been questioned by Ivler, Preston \& Portnoy (1963) on the grounds that even $H$. influenzae can cause haemagglutination if the procedure is suitably modified. The present study shows that haemagglutination is a character almost exclusively encountered in conjunctivitis strains. Yet it is also seen in occasional strains of $H$. parainfluenzae (Sims, 1970) and apparently in $H$. suis (Bakos, 1955), although the latter finding was not confirmed with our procedure. The haemagglutinating ability in conjunctivitis strains was, however, not restricted to non-xylose fermenting strains, and the delineation between $H$. aegyptius and $H$. influenzae is thus further blurred. The close relationship between these two organisms is also indicated by transformation experiments (Leidy, Hahn \& Alexander, 1959; Leidy, Jaffee \& Alexander, 1965).

Specific recognition of Koch-Weeks bacillus is therefore probably not justified. Strains received as $H$. aegyptius and other strains resembling them were included in biotype III of $H$. influenzae, together with the suggested working type of $H$. influenzae (Sneath \& Skerman, 1966). In agreement with these findings Bergey's Manual of Determinative Bacteriology (1974) lists $H$. aegyptius under species incertae sedis.

The so-called 'atypical $H$. influenzae' (Smith, I93I; Wilson \& Miles, 1964), showing predominantly bacillary or filamentous morphology and fermenting sucrose, probably represents erroneously classified strains belonging to the $H$. parainfluenzae group. Bergey's Manual of Determinative Bacteriology (1974) lists sucrose fermentation as one of the characteristics of $H$. influenzae, but the present study has shown that, with the exception of $H$. haemoglobinophilus, sucrose fermentation is an exclusive character of haemin-independent species.

Haemophilus haemolyticus. The species $H$. haemolyticus (Bergey et al., I923) was based on the beta-haemolytic 'Bacillus $X$ ' of Pritchett \& Stillman (I9I9). The growth requirements of the organism were not determined by these authors, but an interpretation of the biochemical reactions of 29 strains studied by Stillman \& Bourn (I920) indicates that the name was used for both haemin-dependent and haemin-independent haemolytic strains. More 
recently Pittman (1953) proposed that the name should be used for haemin- and NADdependent strains only.

The present study has shown that, in contrast to the haemin-independent haemolytic haemophili of human origin, $H$. haemolyticus forms a valid species well separated from other specific groups.

Strain HK 385 was suggested as the working type for the species by Sneath \& Skerman (1966), but has recently been found to be independent of haemin (Biberstein \& Zinnemann, I97I; Kilian, 1974). In another culture (ATCCIO0I4) of the same strain, White \& Granick (1963) found all the enzymic activities characteristic of the haemin-independent species but were unable to grow the strain on a simplified medium free of haemin. This finding probably explains why Sneath \& Johnson (1973) describe the strain as haemin-requiring, and it exemplifies the disadvantages of determining this requirement by growth experiments. In Sneath \& Johnson's (1973) study the strain fell within the same cluster as $H$. influenzae but joined the cluster at a rather low level. However, the strain has the typical fermentation reactions of the $H$. parainfluenzae group, and the relatively high GC content of its DNA confirms the affiliation to that group. Here the strain was assigned to biotype III of H. parainfluenzae.

Haemophilus haemoglobinophilus (canis). This species is fairly well circumscribed by several independent phenotypic traits. It is also readily separated from $H$. influenzae, although Sneath \& Johnson's (1973) study revealed a high degree of similarity between the two species.

The organism was originally isolated by Friedberger (1903) from dogs suffering from a suppurative inflammation of the prepuce, but it is usually regarded as a harmless parasite of the preputial sac because it can also be isolated from normal dogs (Kristensen, I922; Rivers, $1922 b$ ). Until recently it has been isolated only from dogs, but Frazer \& Rogers ( 1972 ) isolated a strain from otitis media in an agammaglobulinaemic child with no known contact with dogs.

Friedberger (1903) proposed the name $B$. haemoglobinophilus canis for the organism but it is frequently referred to as $H$. canis as proposed by Rivers (1922b). However, Index Bergeyana (1966) lists the correct name as Haemophilus haemoglobinophilus (Lehmann \& Neumann, 1907) Murray, 1939, H. canis being a later synonym.

One of the strains included in this study (NCTCI659 = ATCCI94I6) has been stated to be a cotype of the species (Sneath \& Skerman, 1966). Whereas the NCTC culture was typical of the species, the ATCC culture differed in one important way, namely in being consistently indole negative. It was identical to NCTCI659 in all other ways, and is likely to be a mutant of the original strain of Kristensen ( 1922 ).

Haemophilus ducreyi. Many reports on this organism have stressed the difficulties experienced in growing it. It is therefore not surprising that the information on its other properties is sparse and contradictory, and that it has been customary to rely on cultural and microscopic characteristics when identifying strains isolated from chancroid. About the action of $H$. ducreyi on carbohydrates there are conflicting reports. Whereas Reymann (1949b) and Ajello et al. (1956) did not find any fermentative ability, Hababou-Sala (1925) observed fermentation of glucose, sucrose and maltose, and de Assis (1926) noted fermentation of glucose. Haemophilus ducreyi is generally considered to be haemophilic, but the experimental results are equivocal and there are still doubts about the growth requirements of the organism. Several authors have reported that a thermostable serum factor and a thermolabile factor bound to erythrocytes is needed, whereas neither haemin nor yeast extract (NAD) have any effect on growth (Sanderson, I940; Beeson, 1946; Reymann, 195 I Ajello 
et al., 1956). In contrast, Lwoff \& Pirosky (1937) showed that the addition of haemin to a proteose peptone medium secured growth of their strains and they concluded that $H$.ducreyi resembles $H$. haemoglobinophilus in requiring haemin. Even the available information on the Gram-reaction is ambiguous. Nicolau \& Banciu (1926) reported that after a number of subcultures their strains became Gram-positive although they were markedly Gramnegative on primary isolation. de Assis ( 1926) found that the Gram-reaction was dependent on the method used for fixing of the preparation before the staining procedure and Reymann (195I) found all his newly isolated strains consistently Gram-negative. This obvious discrepancy seemed to be clarified when Deacon et al. (1954) reported on a Gram-positive and non-pathogenic phase of the Ducrey bacillus, but disappointingly they later realized that they had been working with strains of Corynebacterium acnes (Deacon et al., 1956). All these different findings reflect the uncertainty about the true nature of $H$. ducreyi. It is likely that the name has been used for several different bacteria. The present study partly confirms this assumption. None of the Reymann (1947, I $949 a, b$, I950, 195 I) strains studied here can be assigned to the genus Haemophilus as they have been shown to be Gram-positive (Kilian \& Theilade, 1975). However, the two strains from the Collection de l'Institut Pasteur conform to the present definition of the genus Haemophilus, and the DNA base composition of these strains falls within the limits accepted for Haemophilus strains. The taxonomic position of these strains within the genus Haemophilus is therefore fully justified. However, it is an open question which of these two groups is the Ducrey bacillus and the causative agent of chancroid. Only the CIP strains showed the characteristic streptobacillary morphology usually ascribed to $H$. ducreyi (Unna, I 892) but Reymann (I95I) was able to produce typical chancroids by inoculation of some of his strains in two volunteers. If the specific name $H$. ducreyi (Neveu-Lemaire, I92 I) Bergey et al., 1923 is to be conserved, it would be logical to use it for the Gram-negative haemin-dependent organism.

Haemophilus parainfluenzae. The specific name Haemophilus parainfluenzae was proposed by Rivers (1922a) for 'influenza-like bacilli which need only the heat-labile accessory food factor as present in unautoclaved yeast extract'. Fleming \& Maclean (1930) and Sims (I 970) isolated $H$. parainfluenzae from the oral cavities of all subjects studied, but except for a few well-documented cases of endocarditis caused by $H$. parainfluenzae (Miles \& Gray, 1938), this organism has remained of little clinical significance. Turk \& May (1967) believed that 'in general there is little point in attempting to distinguish between non-capsulated strains of the two species ( $H$. influenzae and $H$. parainfluenzae), especially as haemophili totally independent of X-factor are undoubtedly rare and are, so far as we know, no different from $H$. influenzae in their clinical significance'.

This study has shown that $H$. parainfluenzae is a valid species well differentiated from $H$. influenzae by several phenotypic characters. Furthermore, the results indicate that the pathogenicity and habitat of the organism is significantly different from that of $H$. influenzae.

As Sims (1970) suggested, $H$. parainfluenzae is a heterogenous group. Here the species was tentatively subdivided into three biotypes differentiated by a few biochemical features. The inclusion of biotype III in $H$. parainfluenzae is still under consideration. It differs from the other two biotypes in its failure to produce gas in glucose broth, and by a less pronounced acid production from the carbohydrates attacked. If future studies show that this is indicative of significant differences in the pathway of carbohydrate metabolism, biotype III would probably merit specific rank.

Valentine \& Rivers (1927), in an attempt to classify the haemophilic bacteria, proposed that all haemophili that require both $\mathrm{X}$ and $\mathrm{V}$ be classified as $B$. influenzae ( $H$. influenzae), whether haemolytic or non-haemolytic, and that those that require $\mathrm{V}$ factor only be classified 
as $B$. parainfluenzae ( $H$. parainfluenzae), whether haemolytic or non-haemolytic. This recommendation was adopted by Miles \& Gray (1938) and Wilson \& Miles (I964), and partially by Sims (1970). However, Pittman (1953) stated that apart from the growth requirements, 'there is no evidence to indicate that haemolytic bacteria should be classified as a variety of the non-haemolytic bacteria', and she accordingly proposed to separate the haemolytic haemin-independent strains from $H$. parainfluenzae and thus to subdivide haemolytic haemophili into $H$. haemolyticus and $H$. parahaemolyticus.

The present study shows that, whereas the species $H$. haemolyticus is fairly distinct from $H$. influenzae, the specific assignment of haemolytic NAD-dependent haemophili of human origin is highly questionable. The only distinguishing character of such strains, their haemolytic ability, seems to be unstable. The proposal of Valentine \& Rivers (1927) concerning the NAD-dependent haemophili has therefore been adopted, and haemolytic strains of this kind have been included in biotypes II and III of $H$. parainfluenzae.

Thirty-nine per cent of the strains assigned to biotype III required $\mathrm{CO}_{2}$ for good growth. The strains included those of Zinnemann et al. (1971) who designated one of them as the holotype of $\mathrm{H}$. paraphrohaemolyticus. The growth-stimulating effect of $\mathrm{CO}_{2}$, however, was not restricted to haemolytic strains. Therefore in my opinion $H$. paraphrohaemolyticus as described at present is not a valid species, but when more information on the carbohydrate metabolism of haemophili is obtained it is possible that biotype III as a whole will merit specific status.

One of the strains (HK4I6) assigned to biotype I was received as a cotype of $H$. paraphrophilus. This strain shared all the characteristics of biotype I of $H$. parainfluenzae and had none of the distinguishing characteristics of $H$. paraphrophilus. Furthermore, the GC content of the DNA of the strain was significantly lower than that of $H$. paraphrophilus. Another culture of the same strain had identical characteristics and it should consequently be rejected as a strain of $H$. paraphrophilus.

One of the strains assigned to biotype Il of $H$. parainfluenzae deserves special attention. The ICNB Subcommittee on the Taxonomy of Haemophilus regarded Pittman's strain 734 (HK339) as a neotype strain of $\mathrm{H}$. haemolyticus (Zinnemann, 197I), in place of the suggested working type strain NCTC8479 (HK385) (Sneath \& Skerman, 1966) which was rejected when it was realized that it is haemin-independent (see under $H$. parainfluenzae biotype III). In fact, another strain was subsequently placed in the National Collection of Type Cultures (NCTC10659) by Zinnemann as a true $H$. haemolyticus because, on detailed investigation, Pittman's strain 734 was found not to be X-dependent but only V-dependent (K. Zinnemann, personal communication). This is confirmed by the present study.

Haemophilus aphrophilus and $H$. paraphrophilus. The two $\mathrm{CO}_{2}$-requiring species $H$. aphrophilus and $H$. paraphrophilus are similar in nearly all respects, but whereas $H$. paraphrophilus meets the criteria for the inclusion in the genus Haemophilus as defined by the Subcommittee on the Taxonomy of Haemophilus (Zinnemann, 1967), H. aphrophilus does not meet these criteria as it is capable of synthesizing both NAD and haemin. Khairat (1940) reported dependence on haemin for growth on primary isolation, but with a gradual reduction of the stringency of the requirement with prolonged subculture. Several authors have obtained similar results, and all agree that there is a fairly high rate of mutation to haeminindependence, although there are strain variations (Toshach \& Bain, 1958; Boyce et al., 1968; Sneath \& Johnson, 1973). King \& Tatum (1962) found that the haemin requirement 'is certainly not an outstanding characteristic of this organism', and Sutter \& Finegold (1970) reported that their isolates of the species were independent of haemin. This view is supported by the results of White \& Granick (1963), who showed that one of Khairat's 
(I940) strains had all the enzymes of the haemin biosynthetic pathway characteristic for haemin-independent species. All strains of $H$. aphrophilus included in the present study also possessed the enzymic capacity to convert $\delta$-aminolaevulinic acid to porphyrins. Nearly all these strains were stock strains, but because of the many enzymic steps involved in this biosynthetic pathway, it is highly unlikely that the porphyrins, which can be detected after incubation, can be explained as having been synthesized by mutants. The reason for an apparent need for haemin-containing media at primary isolation remains to be elucidated.

The taxonomic position of $A$. actinomycetemcomitans is uncertain. The species does not fit the criteria for the genus Actinobacillus in Bergey's Manual of Determinative Bacteriology (1974), and is referred to as a species incertae sedis. It shares many of the characters of the aphrophilus group (Table 14), and seems to be more closely related to $H$. aphrophilus than to A. lignieresii, the type species of the genus Actinobacillus (King \& Tatum, 1962). Considering this fact, and the similarity between $H$. aphrophilus and $H$. paraphrophilus (a "true Haemophilus'), it is possible that all three species should be in the genus Haemophilus, although this would require a change in the definition of the genus. Sneath \& Johnson (1973) showed that various strains of Actinobacillus were more closely related to Pasteurella strains than to strains of Haemophilus, but their study unfortunately did not include strains of A. actinomycetemcomitans. At present, therefore, it is not possible to draw any definite conclusions as to the systematic position, and studies of nucleic acid homology are probably required to solve the question.

The three species usually require the addition of $\mathrm{CO}_{2}$ to the environment for growth, though the requirement is not invariable as in other $\mathrm{CO}_{2}$-requiring bacteria, for example Brucella abortus (Bouvier, I960). Thus stock strains of $H$. aphrophilus frequently become adapted to growth in the absence of $\mathrm{CO}_{2}$ (Khairat, 1940) and some of the strains assigned to the species $H$. aphrophilus and $H$. paraphrophilus in this study did not show the requirement. Accordingly, the property should not be used as a primary diagnostic character in the identification of strains of these species.

Haemophilus segnis sp.nov. The relatively high $\% \mathrm{GC} \mathrm{(43.5)}$ is one of the main characteristics of the NAD-dependent strains for which the name $H$. segnis is proposed. Several other characters, mainly of a negative nature, distinguish this species from other NADdependent and haemin-independent species (Tables 4 and I5). Haemophilus segnis in many ways resembles $H$. parasuis (Table ${ }_{5} 5$ ). The main features distinguishing the two species are the significant difference in the GC content of their DNA, the failure of $H$. segnis to produce $\alpha$-fucosidase, and its negligible fermentative activity. Current studies have shown that $H$. segnis is frequently isolated from dental plaques, and the normal habitat of the organism is probably the human oral cavity (Kilian \& Schiøtt, I975).

Haemophilus parasuis. Haemophili isolated from swine pose several problems of taxonomy and nomenclature. Haemophilus influenzae suis Lewis and Shope, I93 I, is the name originally proposed for an organism isolated from American swine influenza and probably identical to the Bacterium influenzae suis described by Köbe (1933). Haemophilus influenzae suis was described as dependent on both X-and V-factors. It has been stressed that it closely resembles $H$. influenzae and, apart from a more feeble growth, is indistinguishable from indole-negative strains of the latter species (Lewis \& Shope, I931; Zinnemann, I960). The organism is now usually referred to as $H$. suis in the literature, and because trinomial names are invalid the Subcommittee on the Taxonomy of Haemophilus has indicated that it prefers this epithet to the one originally proposed (Zinnemann, I97I). In Bergey's Manual of Determinative Bacteriology (1974) it is listed as Haemophilus suis Hauduroy, Ehringer, Urbain, Guillot and Magrou, 1937. 
The pathogenicity of $H$. suis has been discussed in a number of recent reports, and it seems clear that it is the causative agent of porcine polyserositis, polyarthritis and meningitis (Glässer's disease), bronchitis, rhinitis and nephritis (Hjärre \& Wramby, 1943; Bakos, Nilsson \& Thal, 1952; Braend \& Flatla, 1954a), whereas its aetiological role in swine influenza is variable and only secondary (Hjärre, Dinter \& Bakos, 1952). Although most authors state that the implicated organisms are identical to $H$. suis, it has unfortunately been the habit not to determine the exact growth requirements. However, during the past decade it has become clear that the overwhelming majority of strains named $H$. suis are haemin-independent, but otherwise agreeing in the characters described by Lewis \& Shope (1931) (Leidy, Hahn \& Alexander, 1956; Biberstein et al., 1963; Kilian, 1974). This finding stimulated Biberstein \& White (1969) to propose the establishment of a new species $H$. parasuis with otherwise identical properties. Considering the marked difficulties associated with an exact determination of the haemin requirement and the complex nature of the growth requirements of $H$. suis (Shope, I964), it is likely that the strains described by Lewis \& Shope (193I) in fact were haemin-independent. This assumption is justified by the fact that two of the H. suis strains included in the present study (HK424 and HK425) originated from Shope himself, and that these two strains, like all other strains of porcine origin, possessed the ability to carry out porphyrin synthesis. This is also in agreement with the findings of Matthews \& Pattison (I961). None of the strains of $H$. suis studied by them, including three strains received from Shope and four strains from Bakos, was haemindependent. Although it is thus highly likely that $H$. suis is the correct name for these haeminindependent strains, the name $H$. parasuis Biberstein \& White, 1969 has been tentatively adopted here because the prefix of the epithet of that name is in agreement with the usual convention in naming Haemophilus species.

Two other strains included in the study were isolated from pneumonia in pigs and labelled $H$. parasuis on receipt. They grew better on all agar plate media than the strains assigned to H. parasuis, provided they were incubated with additional $\mathrm{CO}_{2}$. Bakos et al. (I952) and Braend \& Flatla (1954b) noted differences in the growth intensities of strains isolated from swine, which had no correlation with other properties. However, the two strains were also separated from the strains assigned to $H$. parasuis by several biochemical features. This is in agreement with the rather low similarity found by Sneath \& Johnson (I973) between these strains and strains of $H$. parasuis. It is possible that the two strains represent a separate species, together with the three very similar strains isolated from fowls. All five strains have received the tentative label 'Haemophilus, taxon C'.

Haemophilus pleuropneumoniae. The specific name Haemophilus pleuropneumoniae was proposed by Shope (1964) for a NAD-dependent organism causing extensive lobar pneumonia with accompanying fibrinous pleuritis in swine. The disease is highly contagious under experimental conditions and the fatality rate approaches $50 \%$. This marked virulence of $H$. pleuropneumoniae as a respiratory pathogen contrasts with the relatively mild pathogenicity of H. suis (Shope, 1964; Little \& Harding, 1971). The organism is closely related to $H$. parasuis, as indicated by interspecific transformation experiments (White et al., 1964), and it is probably identical to the causal agent of a septicaemic disease of swine briefly described by Biberstein \& Cameron ( $196 \mathrm{I}$ ) and identified as $H$. parahaemolyticus by Olander (1963). Nicolet (1968) demonstrated many similarities between $H$. pleuropneumoniae and $H$. parahaemolyticus and proposed the use of the latter name which has priority. This proposal has recently been adopted by the Subcommittee (Zinnemann, I97I) and in Bergey's Manual of Determinative Bacteriology (1974). However, there are many reasons for retaining a separate species for the virulent organism isolated from swine. It can be distinguished from 
$\beta$-haemolytic NAD-dependent haemophili of human origin by several phenotypic differences (Table 13). The GC content of its DNA is significantly higher than that of human isolates $(P<0.0 \mathrm{I})$, and the two species possess a marked difference in their pathogenicity for swine. Four of the $\beta$-haemolytic human strains assigned to biotypes II and III of $H$. parainfluenzae were administered intranasally in large doses to piglets without causing any signs of disease, in contrast to the striking pathogenicity of strains of $H$. pleuropneumoniae even when inoculated in small numbers (Dr R. Nielsen, personal communication). Finally, haemolysis is not a distinctive taxonomic character within the genus Haemophilus. Shope (1964) in his description of $H$. pleuropneumoniae did not mention any haemolysis on blood agar plates and Nicolet (1970) noted a variable haemolytic activity. It is thus possible, as judged from the descriptions, that the causal agents of reported cases of porcine pneumonia and meningitis identified as $H$. parainfluenzae have been non-haemolytic strains of $H$. pleuropneumoniae (Matthews \& Pattison, I96I ; Radostits, Ruhnke \& Losos, 1963). Although it is evident that $H$. pleuropneumoniae causes other infections in addition to pleuropneumonia, this is not a valid reason for changing the name. The correct name for the organism should therefore be $H$. pleuropneumoniae Shope, 1964 .

The taxonomic and nomenclatural problems of porcine haemophili are far from resolved. As indicated by the present study, it is possible to recognize at least one haemolytic and two non-haemolytic NAD-dependent and haemin-independent taxa, and to this may probably be added a NAD- and haemin-dependent taxon (Biberstein et al., I963). Haemophili constitute a part of the normal respiratory flora of most swine (Radtke, 1938; Harris, Ross \& Switzer, 1969; Woods et al., 1972), and an extensive study of pathogenic strains as well as strains from normal respiratory flora is much needed to clarify the taxonomic situation.

Haemophilus paragallinarum. Haemophili isolated from fowls pose problems similar to those described for porcine haemophili.

Information on the growth requirements of the fowl-coryza bacillus $H$. gallinarum Delaplane, Erwin \& Stuart, 1934 is conflicting. Most of the early descriptions of the organism state that it is haemophilic (de Blieck, I932; Schalm \& Beach, 1934; Eliot \& Lewis, I934; Delaplane et al., 1934), but McGaughey (1932) was unable to show any dependence on the $\mathrm{X}$-factor in his strains. A distinct need for haemin has only been convincingly demonstrated by Schalm \& Beach (1936) and Delaplane, Erwin \& Stuart (1938) who also showed an obligate requirement for $\mathrm{NaCl}$. Several reports have been concerned with avian haemophili, but in none of these studies were haemin-dependent strains found (Page, 1962; Roberts, Hanson \& Timms, 1964; Hinz, 1973). However, it is evident from these studies that several types of haemophili can be isolated from fowls, as already suggested by McGaughey (1932) and Nelson (1933). Biberstein \& White (1969) proposed the name $H$. paragallinarum for haemin-independent haemophili with characters otherwise identical to $H$. gallinarum.

Only five strains isolated from fowls were included in the present study. All the strains required NAD only, but it was possible to recognize two groups among them. Two of the three strains, described together with the previously mentioned unnamed NAD-dependent strains from swine, were dependent on $\mathrm{CO}_{2}$. This is in agreement with the character described for H. gallinarum (Schalm \& Beach, 1934; Eliot \& Lewis, 1934; Gregory, 1944). The abundant growth of these strains, the yellow pigmentation and the fermentation reactions are, however, more reminiscent of the non-pathogenic H-strains of McGaughey (I932) or the group II strains of Hinz (1973) and the taxonomic position of these strains cannot be established at present.

The two remaining strains were independent of $\mathrm{CO}_{2}$ but grew with rather small colonies reminiscent of $H$. gallinarum. Page (I962), Roberts et al. (1964) and Hinz (1973) state that 
the pathogenic $H$. gallinarum is characterized by a negative catalase reaction. Both of the strains here were catalase positive. As both strains were NAD-dependent only and one of the strains is an authentic strain of $H$. paragallinarum Biberstein \& White (I969), they have both been assigned to this species. As with haemophili from swine, more extensive studies are needed to clarify the situation.

Haemophilus piscium. This species is usually considered the only Haemophilus species with no requirement for haemin or NAD, but with a need for diphosphothiamine or adenosine triphosphate (Griffin, I95I, 1952). The present study shows that the species differs from the type species $H$. influenzae by several other significant properties. The failure of $H$. piscium to reduce nitrate, to produce alkaline phosphatase and to grow at $37{ }^{\circ} \mathrm{C}$, together with the high GC content of its DNA, indicate that there is little justification for its retention as a species of Haemophilus. The appropriate taxonomic position of the organism cannot be established at present. It shares many of the characters of Francisella tularensis, among them the requirement for ATP (Tamura \& Fleming, 1949), but the DNA base composition of this species is very different from that of $H$. piscium.

\section{Ecology and pathogenicity}

Haemophili are parasites of the mucous membranes of man, and appear as a constituent of the normal microbial flora of the upper respiratory tract and, to a lesser extent, the mucous membranes of the genital organs. The same seems to be true for swine and fowls and probably also for a large variety of other animal species such as cats (Rivers \& BayneJones, I923), rats (Wolff, 1903; Harr, Tinsley \& Weswig, I 969), mice (Kairies \& Schwartzer, 1936), deer (Diernhofer, 1949), sheep (Mitchell, 1925), dogs, guinea-pigs (Kristensen, 1922), ferrets (Kairies, I935) and monkeys (Kilian, unpublished results). Detailed information on the occurrence in many of these animal species is not available, however, and many of the haemophili isolated from these animals are not well known or described.

The human upper respiratory tract provides at least two different ecosystems as regards haemophili. The pharynx gives shelter to both haemin-dependent and -independent species (Kilian et al., 1972), whereas haemin-independent species are almost the only species which can be isolated from the oral cavity (Sims, 1970; Kilian \& Schiøtt, 1975). These species include $H$. parainfluenzae, $H$. paraphrophilus and $H$. segnis, of which the latter is present mainly in dental plaques (Kilian \& Schiøtt, 1975). Haemophilus aphrophilus also occurs in dental plaques, although it is not invariably found, or at least not in detectable numbers (Kraut et al., 1972).

Haemophilus influenzae is by far the most important of the Haemophilus species in human pathology and its pathogenic potentialities for humans are probably closely related to the presence of a capsule. Strains cultivated from patients with meningitis, epiglottitis or bacteraemia can usually be differentiated from non-pathogenic strains by their capsule production. Non-capsulated strains, on the other hand, can often be isolated from chronic infections, but it is seldom possible to assign a primary pathogenic role to such strains.

The recognition of at least five biotypes within $H$. influenzae, and the correlation demonstrated between these biotypes and the sources of the strains assigned to them (Table 18), may indicate that strains producing pyogenic infections are more specific than hitherto assumed. However, the aetiological significance of a number of the strains in the present study, especially those isolated from chronic infections including infections of the respiratory tract, cannot be proved.

Biotype I of $H$. influenzae, which encompassed nearly all strains from meningitis, epiglottitis and blood cultures, included only a few of the strains from other sources. Nine of 
the 83 Haemophilus strains which originated from healthy upper respiratory tracts belong to this biotype. Two of these strains were capsulated strains of serotype $b$ and were probably potential pathogens. Eight strains isolated from meningitis were assigned to other biotypes than type I. Two of these strains, however, were atypical, being non-capsulated, and all but one of the remaining strains were old stock strains. As the differentiation of the five biotypes rests on very few characters, it is possible that these stock strains represent mutants of biotype I. Further characterization of the biotypes is needed to answer this question.

Otitis media is often present in $H$. influenzae meningitis as in $50(39 \%)$ of the 128 cases of $H$. influenzae serotype b meningitis reviewed by Koch \& Carson (1955). None of the 29 strains from otitis media included in the present study were associated with meningitis. Most of these strains belonged to different biotypes from most of the meningitis strains, and only two of the strains were capsulated. The predominance of non-capsulated strains in otitis media not associated with meningitis agrees with the observations of Harding et al. (1973) and Schneerson \& Robbins (1973).

Most strains isolated from conjunctivitis belonged to biotypes II and III of $H$. influenzae, but several other taxa were represented. It is possible that some of the strains, as for example the strains of $H$. parainfluenzae, had been part of a transient contamination of the conjunctivae with no aetiological significance.

A proportion of the strains from conjunctivitis possessed haemagglutinating ability. This property was almost exclusive to strains isolated from the eye, but was not restricted to strains dependent on both NAD and haemin. Pedersen, Frøholm \& Bøvre (1972) showed a connexion between fimbriation of Moraxella bovis and its ability to colonize the bovine conjunctivae and to produce keratoconjunctivitis. A positive correlation between haemagglutination and virulence has been demonstrated in Bordetella pertussis (Keogh \& North, 1948) and between haemagglutination and fimbriation in Enterobacteriae (Duguid et al., 1955), Vibrio sp. (Tweedy \& Park, 1968) and Bacteroides melaninogenicus (Okuda \& Takazoe, 1974). The true nature of haemaglutinin in Haemophilus strains is unknown, but it might be related to fimbriation and/or to the ability to colonize the conjunctivae.

The pathogenic potential of the species $H$. parainfluenzae, $H$. paraphrophilus and $H$. aphrophilus seems to be low as they only produce infections under special circumstances. The oral cavity is often a likely source of the aetiological organisms in such infections, which include endocarditis, dental abscesses, jaw infections and infections following human bites or finger sucking (Miles \& Gray, 1938; Zinnemann et al., 1968; Sims, 1970; Sutter \& Finegold, 1970). In most other infections where these species have been reported as causal agents, it is usually impossible to prove an aetiological connexion. Reports on $H$. parainfluenzae as a frequent cause of meningitis, without any attempt to determine the properties of the strains involved except for an inadequate determination of growth requirements (Hable, Logan \& Washington, I971), should be regarded with suspicion.

\section{The taxonomic situation of the genus Haemophilus}

The relationship of the genus Haemophilus to other genera which have been included in the family Brucellaceae, or its predecessor Parvobacteriaceae, has not been considered in this study. These problems were recently studied by Johnson \& Sneath (I973) and Sneath \& Johnson (1973), who demonstrated a close phenetic relationship between the genera Haemophilus, Pasteurella and Actinobacillus, which on the other hand are well separated from the genera Brucella, Bordetella and Moraxella. These studies did not include strains of A. actinomycetemcomitans. The taxonomic position of this species is highly questionable. In Bergey's Manual of Determinative Bacteriology (1974) it is excluded from the genus 
Actinobacillus and listed as species incertae sedis. As demonstrated previously, the species has a close phenetic similarity to $H$. aphrophilus and the question of its taxonomic position is connected with the taxonomic position of this species, and possibly $H$. paraphrophilus as well. These problems have considerable importance to the definition of the genus Haemophilus. The preservation of $H$. aphrophilus as a species and the inclusion of $A$. actinomycetemcomitans as a species in the genus Haemophilus would require a revision of the definition put forward by the Subcommittee on the Taxonomy of Haemophilus (Zinnemann, 1967). Such a revision would imply the possible affiliation with the genus Haemophilus of a number of bacteria hitherto excluded. Further studies are required before any such far-reaching decisions are taken.

I am grateful to Mrs Käthe Wedel Christensen and Mrs Lene Cramer for their skilful technical assistance throughout the course of the work and to Mrs Karen Helbo for preparing the typescript.

Many scientists generously contributed strains from their own collections. Particularly valuable material was received from $\mathrm{Dr}$ H. Lautrop and Dr C. H. Mordhorst (Statens Seruminstitut, Copenhagen, Denmark), Dr P. Bülow (Statens Seruminstitut, Århus, Denmark), Dr W. Frederiksen (Statens Seruminstitut, Ålborg, Denmark), Dr C. R. Dawson (Francis I Proctor Foundation for Ophthalmology, San Francisco, California), Dr Ragnhild Nielsen (Statens Veterinære Serumlaboratorium, Copenhagen), and Dr W. Sims (Royal Dental Hospital, London). The advice and encouragement of Dr Lautrop during all phases of the study is gratefully acknowledged. Dr C. Rindom Schiøtt, Dr H. S. Bleeg and Professor $\mathrm{K}$. Zinnemann have given me much valuable advice and moral support, and Dr A. Leth Bak and Dr C. Christiansen (University of Århus) have kindly placed at my disposal the apparatus used for determining DNA base compositions. Dr A. Thylstrup (Royal Dental College, Århus) is thanked for statistical help; Dr V. Aagaard-Hansen (Jydsk Teknologisk Institut) kindly performed the gas chromatographic analysis.

\section{REFERENCES}

Ajello, G. W., Deacon, W. E., Paul, L. \& Walls, K. W. (1956). Nutritional studies of a virulent strain of Haemophilus ducreyi. Journal of Bacteriology 72, 802-808.

Alexander, H. E. (1958). The Hemophilus group. In Bacterial and Mycotic Infections of Man, 3rd edn, p. 474. Edited by R. J. Dubos. Philadelphia and Montreal: Lippincott.

Alexander, H. E. \& Leidy, G. (1950). Transformation type specificity of $H$. influenzae. Proceedings of the Society for Experimental Biology and Medicine 73, 485-487.

Alexander, H. E. \& Leidy, G. (195I $a$ ). Determination of inherited traits of $H$. influenzae by deoxyribonucleic acid fractions isolated from type-specific cells. Journal of Experimental Medicine 93, 345-359.

Alexander, H. E. \& Leidy, G. (195I $b)$. Induction of heritable new type in type-specific strains of $H$. influenzae. Proceedings of the Society for Experimental Biology and Medicine 78, 625-626.

DE Assis, A. (1926). Sur la biologie du bacille de Ducrey. Comptes Rendus des séances de la Société de biologie 95, $1008-1009$.

BAILIE, W. E. (1969). Characterization of Haemophilus somnus (new species), a microorganism isolated from infectious thromboembolic meningoencephalomyelitis of cattle. Ph.D. thesis, Kansas State University.

Bailie, W. E., Coles, E. H. \& Weide, K. D. (I973). Deoxyribonucleic acid characterization of a microorganism isolated from infectious thromboembolic meningoencephalomyelitis of cattle. International Journal of Systematic Bacteriology 23, 23 1-237.

Bakos, K. (1955). Studien über Haemophilus suis mit besonderer Berïcksichtigung der serologischen Differenzierung seiner Stämme. Thesis, Uppsala University.

Bakos, K., Nilsson, A. \& Thal, E. (1952). Untersuchungen über Haemophilus suis. Nordisk veterinarmedicin 4, $24 \mathrm{I}-255$.

Beattie, K. L. \& Setlow, J. K. (1970). Transformation between Haemophilus influenzae and Haemophilus parainfluenzae. Journal of Bacteriology 104, 390-400.

Befson, P. B. (1946). Studies on chancroid. IV. The Ducrey bacillus: growth requirements and inhibition by antibiotic agents. Proceedings of the Society for Experimental Biology and Medicine 6r, 8I-85. 
Bergey, D. H., Harrison, F. C., Breed, R. S., Hammer, B. W. \& Huntoon, F. M. (I923). In Bergey's Manual of Determinative Bacteriology, Ist edn, p. 271. Baltimore: The Williams \& Wilkins Co.

Bergey's Manual of Determinative Bacteriology, 7 th edn (1957). Edited by R. S. Breed, E. G. D. Murray and N. R. Smith. London: Ballière, Tindall and Cox.

Bergey's Manual of Determinative Bacteriology, 8th edn (1974). Edited by R. E. Buchanan and N. E. Gibbons. Baltimore: The Williams and Wilkins Co.

Bergquist, L. M. \& Seracy, R. L. (I963). A micromethod for detection of utilization of phenylalanine by microorganisms. American Journal of Clinical Pathology 39, 544-545.

Biberstein, E. L. \& Cameron, H. S. (i96I). The family Brucellaceae in veterinary research. Annual Review of Microbiology $\mathbf{1 5}, 93-118$.

Biberstein, E. L. \& Gills, M. G. (1961). Catalase activity of Haemophilus species grown with graded amounts of hemin. Journal of Bacteriology 81, 380-384.

Biberstein, E. L., Mini, P. D. \& Gills, M. G. (1963). Action of Haemophilus cultures on $\delta$-aminolevulinic acid. Journal of Bacteriology 86, 8I 4-8I9.

Biberstein, E. L. \& Spencer, P. D. (I962). Oxidative metabolism of Haemophilus species grown at different levels of hemin supplementation. Journal of Bacteriology 84, 916-920.

Biberstein, E. L. \& White, D. C. (1969). A proposal for the establishment of two new Haemophilus species. Journal of Medical Microbiology 2, 75-78.

Biberstein, E. L. \& ZinnemanN, K. (I97I). Report (1966-1970) of the Subcommittee on the Taxonomy of Haemophilus to the International Committee of Nomenclature of Bacteria. International Journal of Systematic Bacteriology 21, 133-1 34.

BILlen, D. (195I). The inhibition by nitrate of enzyme formation during growth of Escherichia coli. Journal of Bacteriology 62, 793-797.

Blackwood, A. C., Neish, A. C. \& Ledingham, G. A. (1956). Dissimilation of glucose at controlled pH values by pigmented and non-pigmented strains of Escherichia coli. Journal of Bacteriology 72, 497499.

DE BLIECK, L. (I932). A haemoglobinophilic bacterium as the cause of contagious catarrh of the fowl (Coryza infectiosa gallinarum). Veterinary Journal 88, 9-I 3.

Boling, M. E. (1972). Homology between the deoxyribonucleic acids of Haemophilus influenzae and Haemophilus parainfluenzae. Journal of Bacteriology $112,745-750$.

Bouvier, G. (I960). Isolement de souches de Brucella d'arrière-faix positifs et négatifs à l'examen microscopique. Schweizer Archiv für Tierheilkunde 120, 2 I I-2 16.

Boyce, J. M. H., Frazer, J. \& ZinnemanN, K. (1968). The growth requirements of Haemophilus aphrophilus. Journal of Medical Microbiology 2, 55-62.

Braend, M. \& Flatla, J. L. (1954a). Rhinitis infectiosa atroficans hos gris. Nordisk veterinarmedicin 6, $8 \mathrm{I}-\mathrm{I} 22$.

Braend, M. \& Flatla, J. L. (1954b). Noen undersøkelser over Haemophilus suis. Nordisk veterinarmedicin 6, 269-280.

Brown, L. N., Dierks, R. E. \& Dillman, R. C. (I970). Problems in differential diagnosis of Haemophilus somnus infections ('thrombo') of feedlot cattle. The Bovine Practitioner 5, 36-37.

BrumfitT, W. (1959). Some growth requirements of Hamophilus influenzae and Hamophilus pertussis. Journal of Pathology and Bacteriology 77, 95-100.

Butler, L. O. (1962). A haematin-independent mutant of Haemophilus influenzae. Journal of General Microbiology 29, $189-197$.

Clarke, P. H. \& Cowan, S. T. (1952). Biochemical methods for bacteriology. Journal of General Microbiology 6, I $87-197$.

Cowan, S. T. \& STEEL, K. J. (1965). Manual for the Identification of Medical Bacteria, p. 148. Cambridge: Cambridge University Press.

Criswell, B. S., Marston, J. H., Stenback, W. A., Black, S. H. \& Gardner, L. (i971). Haemophilus vaginalis 594, a Gram-negative organism? Canadian Journal of Microbiology 17, 865-869.

Davis, J. D. (I9I7). Food accessory factors (vitamins) in bacterial culture with especial reference to hemophilic bacilli. Journal of Infectious Diseases 21, 392-403.

Davis, D. J., Pittman, M. \& Griffitts, J. J. (I950). Hemagglutination by the Koch-Weeks bacillus (Hemophilus aegyptius). Journal of Bacteriology 59, 427-431.

Dawson, B. \& Zinnemann, K. (1952). Incidence and type distribution of capsulated $H$. influenzae strains. British Medical Journal i, 740-742.

Deacon, W. E., Albritron, D. C., Edmundson, W. F. \& Olansky, S. (i954). Study of Ducrey's Bacillus and recognition of a Gram-positive smooth phase. Proceedings of the Society for Experimental Biology and Medicine 86, 26I-264.

Deacon, W. E., Albritton, D. C., Olansky, S. \& Kaplan, W. (1956). V.D.R.L. chancroid studies. I. A simple procedure for the isolation and identification of Hemophilus ducreyi. Journal of Investigative Dermatology 26, 399-406.

Delaplane, J. P., Erwin, L. E. \& Stuart, H. O. (1934). A hemophilic bacillus as the cause of an infectious rhinitis. Agricultural Experimental Station. Rhode Island State College Bulletin No. 244, pp. 1-I 2. 
Delaplane, J. P., Erwin, L. E. \& Stuart, H. O. (1938). The effect of the X factor, of sodium chloride, and of the composition of the nutrient media upon the growth of the fowl coryza bacillus, Hemophilus gallinarum. Journal of Agricultural Research 56, 919-926.

Diernhofer, K. (1949). Haemophile Bakterien im Geschlechtstrakt des Rindes. Wiener tierärtzliche Monatsschrift 36, 582-588.

DorfF, B. \& Kilian, M. (1974). Haemophilus aphrophilus endocarditis. Scandinavian Journal of Infectious Diseases 6, 29I-294.

DuCREY, A. (1889). Experimentelle Untersuchungen über den Ansteckungsstoff des weichen Schankers und über die Bubonen. Monatshefte für praktische Dermatologie 9, 387-405.

Duguid, J. P., Smith, I. W., Dempster, G. \& Edmunds, P. N. (1955). Non-flagellar filamentous appendages ('fimbriae') and haemagglutinating activity in Bacterium coli. Journal of Pathology and Bacteriology 70, 335-348.

Eliot, C. P. \& Lewis, M. R. (1934). A hemophilic bacterium as a cause of infectious coryza in the fowl. Journal of the American Veterinary Medical Association 84, 878-888.

ENGBAK, H. C. (1949). Undersøgelser Over Pfeiffers Bacil. Thesis. Copenhagen: Nyt Nordisk ForlagArnold Busck.

Fildes, P. (1921). The nature of the effect of blood pigment upon the growth of $B$. influenzae. British Journal of Experimental Pathology 2, 16-25.

Fleming, A. \& MACleAN, I. H. (1930). On the occurrence of influenza bacilli in the mouths of normal people. British Journal of Experimental Pathology r1, I 27-1 34.

Frazer, J. \& Rogers, K. B. (1972). The isolation of an X-dependent strain of Haemophilus from otitis media identified as $H$. haemoglobinophilus (canis). Journal of Clinical Pathology 25, I79-I 80.

FrIEDBERGER, E. (1903). Ueber ein neues zur Gruppe des Influenzabacillus gehöriges hämoglobinophiles Bakterium ('Bacillus haemoglobinophilus canis'). Zentralblatt für Bakteriologie, Parasitenkunde, Infektionskrankheiten und Hygiene. (Abteilung I) 33, 40I-407.

Gardner, H. L. \& Dukes, C. D. (1955). Haemophilus vaginalis vaginitis. A newly defined specific infection previously classified 'nonspecific' vaginitis. American Journal of Obstetrics and Gynecology 69, 962-976.

Gilder, H. \& Granick, S. (1947). Studies on the Hemophilus group of organisms. Quantitative aspects of growth on various porphin compounds. Journal of General Physiology 31, 103-1 I 7 .

GiNGRICH, W. \& SCHLENK, F. (I944). Codehydrogenase I and other pyridinum compounds as V-factor for Haemophilus influenzae and $H$. parainfluenzae. Journal of Bacteriology 47, 535-550.

GrassBerger, R. (1897). Beiträge zur Bakteriologie der Influenza. Zeitschrift für Hygiene und Infektionskrankheiten 25, 453-476.

GreGORY, D. W. (1944). Nutrient requirements of Haemophilus gallinarum. American Journal of Veterinary Research 5, 72-78.

Griffin, P. J. (I95I). Cocarboxylase and adenosine triphosphate as growth factors for Hemophilus piscium. Archives of Biochemistry 30, 100-102.

GrIfFIN, P. J. (1952). Further studies on the nutrition of Hemophilus piscium. Yale Journal of Biology and Medicine 24, 4I I-4I 8.

Hababou-Sala, J. (1925). Nouvelles recherches sur la streptobacille de Ducrey. Bulletin de la Société française de Dermatologie et de Syphilographie No. 32, pp. 96-106. Strasbourg: Réunion Dermatologique.

Hable, K. A., Logan, G. B. \& Washington, J. A. (1971). Three Hemophilus species. Pathogenic activity. American Journal of Diseases in Children 121, 35-37.

Harding, A. L., Anderson, P., Howie, V. M., Ploussard, J. H. \& Smith, D. H. (1973). Hemophilus influenzae isolated from children with otitis media. In Hemophilus influenzae, pp. $21-28$. Edited by S. H. W. Sell and D. J. Karzon. Nashville, Tennessee: Vanderbilt University Press.

Harr, J. R., Tinsley, I. J. \& Weswig, P. H. (I969). Haemophilus isolated from a rat respiratory epizootic. Journal of the American Veterinary Medical Association 155, I $126-1$ I 30.

HARRIS, D. L., Ross, R. F. \& SwITZER, W. P. (1969). Incidence of certain microorganisms in nasal cavities of swine in lowa. American Journal of Veterinary Research 30, I62 I-I 624.

Hauduroy, P., Ehringer, G., Urbain, A., Guillot, G. \& Magrou, J. (1937). Dictionnaire des Bactéries Pathogènes, p. 258. Paris: Masson.

Hinz, K.-H. (1973). Beitrag zur Differenzierung von Haemophilus-Stämmen aus Hühnern. I. Mitteilung: Kulturelle und biochemische Untersuchungen. Avian Pathology 2, 2 I I-229.

HJärRe, A., Dinter, Z. \& BaKos, K. ( 1952). Vergleichende Untersuchungen über eine influenzaähnliche Schweinekrankheit in Schweden und Shopes Schweineinfluenza. Nordisk veterinarmedicin 4, $1025-1045$.

HJärre, A. \& Wramby, G. (1943). Ueber die fibrinöse Serosa-Gelenkentzündung (Glässer) beim Schwein. Infektionskrankheiten der Haustiere 6o, 37-64.

Hucker, G. J. \& ConN, H. J. (1923). Methods of Gram staining. New York State Agricultural Experimental Station Technical Bulletin No. 93, p. I 29.

Hute, M. (1956). Sur la présence de Haemophilus influenzae dans les conjunctivites saisonnières en Tunisie. Annales de l'Institut Pasteur 9o, 106-109.

Hutr, M. (1959). L'ureáse et la lysine-décarboxylase de Haemophilus influenzae et des espèces apparentées. Archives de l'Institut Pasteur de Tunis 36, 29-35. 
Index Bergeyana (1966). Edited by R. E. Buchanan, J. G. Holt and E. F. Lessel. London: E. \& S. Livingstone.

Ingham, H. R. \& TuRk, D. C. (I969). Haemophili from eyes. Journal of Clinical Pathology 22, $258-262$.

Ivler, D., Preston, H. M. \& Portnoy, B. (1963). Direct hemagglutination by Haemophilus influenzae. Proceedings of the Society for Experimental Biology and Medicine 114, 232-234.

Johnson, R. (1972). Aspects of the taxonomy of Bordetella and related organisms. Thesis, University of Leicester.

JohnSON, R. \& SNEATH, P. H. A. (1973). Taxonomy of Bordetella and related organisms of the families Achromobacteriaceae, Brucellaceae and Neisseriaceae. International Journal of Systematic Bacteriology 23, $38 \mathrm{I}-404$.

Jones, D. \& Weitzman, P. D. J. (I971). Taxonomic significance of citrate synthase. Journal of General Microbiology 69, xi.

JoRDAN, E. O. (1919). The production of indole by certain strains of the Pfeiffer bacillus. Journal of the American Medical Association 72, 1542-1543.

KAIRIES, A. (1935). Influenzaerkrankungen bei Frettchen und Beschreibung eines Bacterum influenzae putoriorum multiforme. Zeitschrift für Hygiene und Infektionskrankheiten 117, $12-17$.

KaIries, A. \& Schwartzer, K. (1936). Studien zu einer bakteriellen Influenza der Mäuse und Beschreibung eines 'Bacterium influenzae murium'. Zentralblatt für Bakteriologie, Parasitenkunds, Infektionskrankheiten und Hygiene (Abteilung I) 137, 35I-359.

Kennedy, P. C., Frazier, L. M., Theilen, G. H. \& Biberstein, E. L. (1958). A septicemic disease of lambs caused by Hemophilus agni (new species). American Journal of Veterinary Research 19, 645-654.

KeOGH, E. V. \& NoRTH, E. A. (1948). The haemagglutinin of Haemophilus pertussis. I. Haemagglutinin as a protective antigen in experimental murine pertussis. Australian Journal of Experimental Biology and Medical Science 26, 315-322.

Kersters, K. \& DE LeY, J. (197I). Enzymic test with resting cells and cell-free extracts. In Methods in Microbiology, vol. 6A, p. 44. Edited by J. R. Norris and D. W. Ribbons. London and New York: Academic Press.

KhaIRAT, O. ( 1940 ). Endocarditis due to a new species of Haemophilus. Journal of Pathology and Bacteriology 50, 497-505.

Kilian, M. (1974). A rapid method for the differentiation of Haemophilus strains. The porphyrin test. Acta pathologica et microbiologica scandinavica B 82, 835-842.

Kilian, M. \& Bülow, P. (1976). Rapid diagnosis of Enterobacteriaceae. Detection of bacterial glycosidases. Acta pathologica et microbiologica scandinavica (in the Press).

Kilian, M., Heine-Jensen, J. \& Bülow, P. (1972). Haemophilus in the upper respiratory tract of children. A bacteriological, serological and clinical investigation. Acta pathologica et microbiologica scandinavica B 8o, $571-578$.

Kilian, M., Mordhorst, C. H., Dawson, C. R. \& Lautrop, H. (1976). The taxonomy of haemophili isolated from conjunctivae. Acta pathologica et microbiologica scandinavica (in the Press).

KILIAN, M. \& SCHIøTT, C. R. (1975). Haemophili and related bacteria in the human oral cavity. Archives of Oral Biology (in the Press).

Kilian, M. \& Theilade, J. (1975). Cell wall ultrastructure of strains of Haemophilus ducreyi and Haemophilus piscium. International Journal of Systematic Bacteriology 25, 351-356.

King, E. O. \& TAтum, H. W. (1962). Actinobacillus actinomycetemcomitans and Hemophilus aphrophilus. Journal of Infectious Diseases $1 \mathbf{1}$, 85-94.

Köве, K. (I933). Die Aetiologie der Ferkelgrippe (enzootische Pneumonie des Ferkels). Zentralblatt für Bakteriologie, Parasitenkunde, Infektionskrankheiten und Hygiene (Abteilung I) 129, I6I-1 76.

Koch, R. \& Carson, M. J. (1955). Management of Hemophilus influenzae, type b, meningitis. Analysis of I 28 cases. Journal of Pediatrics 46, I 8-29.

Kovács, N. (1956). Identification of Pseudomonas pyocyanea by the oxidase reaction. Nature, London 178 , 703.

Kraut, M. S., Attebery, H. R., Finegold, S. M. \& Sutter, V. L. (1972). Detection of Haemophilus aphrophilus in the human oral flora with a selective medium. Journal of Infectious Diseases 126, 189-192.

KRISTENSEN, M. (I922). Investigations into the occurrence and classification of the haemoglobinophilic bacteria. Thesis. Copenhagen: Levin \& Munksgaard.

Lapage, S. P. (196I). Haemophilus vaginalis and its role in vaginitis. Acta pathologica et microbiologica scandinavica 52, 34-54.

LAUTrop, H. (1960). Laboratory diagnosis of whooping-cough or Bordetella infections. Bulletin of the World Health Organization 23, I 5-3I.

Lehmann, K. B. \& Neumann, R. (I 896). Atlas und Grundriss der Bakteriologie und Lehrbuch der Speciellen Bakteriologischen Diagnostik, vol. 2, ist edn, p. I 87. München: Lehmann.

Lehmann, K. B. \& Neumann, R. (1907). Atlas und Grundriss der Bakteriologie und Lehrbuch der Speciellen Bakteriologischen Diagnostik, vol. 2, 4th edn, p. 270. München: Lehmann.

Leidy, G., Hahn, E. \& Alexander, H. E. (I956). On the specificity of the desoxyribonucleic acid which induces streptomycin resistance in Hemophilus. Journal of Experimental Medicine 104, 305-320. 
Leidy, G., Hahn, E. \& Alexander, H. E. (1959). Interspecific transformation in Hemophilus: a possible index of relationship between $H$. influenzae and $H$. aegyptius. Proceedings of the Society for Experimental Biology and Medicine 102, 86-88.

Leidy, G., JAFFEe, I. \& Alexander, H. E. (1965). Further evidence of a high degree of genetic homology between $H$. influenzae and $H$. aegyptius. Proceedings of the Society for Experimental Biology and Medicine II8, 67I-679.

Lewis, P. A. \& Shope, R. E. (193I). Swine influenza. II. A hemophilic bacillus from the respiratory tract of infected swine. Journal of Experimental Medicine 54, 36I-37I.

Little, T. W. A. \& Harding, J. D. J. (1971). The comparative pathogenicity of two porcine Haemophilus species. Veterinary Record 88, 540-545.

Lwoff, A. \& Lwoff, M. (1936a). Sur la nature du facteur V. Comptes rendus hebdomadaires des séances de l'Académie des sciences 203, 520-522.

Lworf, A. \& Lwoff, M. (1936 b). Sur le rôle physiologique des codéhydrogénases pour Hemophilus parainfluenzae. Comptes rendus hebdomadaire des séances de l'Académie des sciences 203, 896-899.

Lworf, A. \& Lwoff, M. (1937a). Studies on codehydrogenases. I. Nature of growth factor 'V'. Proceedings of the Royal Society B $\mathbf{1 2 2}, 352-359$.

Lwoff, A. \& Lwoff, M. (I937b). Studies on codehydrogenases. II. Physiological function of growth factor ' $\mathrm{V}$ '. Proceedings of the Royal Society $\mathrm{B} \mathbf{1 2 2}, 360-373$.

Lwoff, A. \& Lwoff, M. (1937c). Role physiologique de l'hémine pour Hamophilus influenza Pfeiffer. Annales de l'Institut Pasteur 59, I 29-I 36.

Lwoff, A. \& PJrosky, I. (1937). Détermination du facteur de croissance pour Hamophilus ducreyi. Comptes rendus des séances de la Société de biologie 124, I $169-1$ I 7 I.

MARMUR, J. (1961). A procedure for the isolation of deoxyribonucleic acid from microorganisms. Journal of Molecular Biology 3, 208-218.

Matthews, P. R. J. \& Pattison, I. H. (196I). The identification of a Haemophilus-like organism associated with pneumonia and pleurisy in the pig. Journal of Comparative Pathology $7 \mathbf{1}, 44-52$.

McGaughey, C. A. (1932). Organisms of the B. influenza group in fowls. Journal of Comparative Pathology $45,58-66$.

Miles, A. A. \& Gray, J. (1938). Hamophilus para-influenze endocarditis. Journal of Pathology and Bacteriology 47, 257-277.

Miles, D. G., Anthony, H. D. \& Dennis, S. M. (1972). Haemophilus somnifer (n.sp) infection in sheep. American Journal of Veterinary Research 33, 431-435.

Mitchell, C. A. (I 925). Haemophilus ovis (nov. spec.) as the cause of a specific disease of sheep. Journal of the American Veterinary Medical Association 68, 8-1 8.

Murray, R. G. E. (1939). Parvobacteriaceae. In Bergey's Manual of Determinative Bacteriology, 5th edn, p. 309. Baltimore: The Williams \& Wilkins Co.

Møllek, V. (1955). Simplified tests for some amino acid decarboxylases and for the arginine dihydrolase system. Acta pathologica et microbiologica scandinavica 36, 158-1 72 .

Nelson, J. B. (I933). Studies on an uncomplicated coryza of the domestic fowl. I. Isolation of a bacillus which produces a nasal discharge. Journal of Experimental Medicine 58, 289-295.

Neveu-Lemaire, M. (1921). Précis de la parasitologie humaine, 5th end. Paris: J. Lemaire.

Nicolau, S. \& Banciu, A. (1926). Recherches biologiques sur le streptobacille de Ducrey. Comptes rendus des séances de la Société de biologie 95, 409-4I I.

NiCOLET, J. (1968). Sur l'hémophilose du porc. I. Identification d'un agent fréquent: Haemophilus parahaemolyticus. Pathologia et microbiologia 31, 2 I 5-225.

NicOLET, J. (1970). Aspects microbiologiques de la pleuropneumonie contagieuse de porc. Thesis, Université de Berne.

Okuda, K. \& Takazoe, I. (I974). Haemagglutinating activity of Bacteroides melaninogenicus. Archives of Oral Biology 19, 4I5-4I6.

OlANDER, H. J. (1963). A septicaemic disease of swine and its causative agent Haemophilus parahaemolyticus. Ph.D. thesis, University of California.

PAGE, L. A. ( 1962). Haemophilus infections in chicken. I. Characteristics of 12 Haemophilus isolates recovered from diseased chickens. American Journal of Veterinary Research 23, 85-95.

Pedersen, K. B., Frøholm, L. O. \& Bøvre, K. (1972). Fimbriation and colony type of Moraxella bovis in relation to conjunctival colonization and development of keratoconjunctivitis in cattle. Acta pathologica et microbiologica scandinavica B 8o, 9I I-9I 8.

PfEIFFER, R. (1892). Vorläufige Mittheilungen über die Erreger der Influenza. Deutsche medizinische Wochenschrift $\mathbf{1 8}, 28$.

PINSKY, M. J. \& STOKES, J. L. (1952). Requirements for formic hydrogenlyase adaptation in nonproliferating suspensions of Escherichia coli. Journal of Bacteriology 64, I $5 \mathrm{I}-\mathrm{I} 6 \mathrm{I}$.

Pirtman, M. (1931). Variation and type specificity in the bacterial species Haemophilus influenzae. Journal of Experimental Medicine 53, 471-492.

Pittman, M. (1935). The interrelation of the amount of V-factor and the amount of air necessary for growth of Hemophilus influenzae type b in certain media. Journal of Bacteriology 30, 149-16I. 
Pittman, M. (1953). A classification of the hemolytic bacteria of the genus Haemophilus: Haemophilus: haemolyticus Bergey et al. and Haemophilus parahaemolyticus nov. spec. Journal of Bacteriology 65, 750-75I.

Pittman, M. \& Davis, D. J. (1950). Identification of the Koch-Weeks bacillus (Hemophilus aegyptius). Journal of Bacteriology 59, 4I 3-426.

Pritchett, I. W. \& Stillman, E. G. (19I9). The occurrence of Bacillus influenzae in throats and saliva. Journal of Experimental Medicine 29, 259-266.

Radostits, O. M., Ruhnke, H. L. \& Losos, G. J. (1963). An outbreak of meningitis in swine caused by Haemophilus species of bacterium. Canadian Veterinary Journal 4, 265-270.

RADTKE, G. (1938). Untersuchungen über die Ursache und das Wesen der Schnüffelkrankheit des Schweines. Archiv für wissenschaftliche und praktische Tierheilkunde 72, 371-423.

Reymann, F. (1947). A study of the growth conditions of Haemophilus ducreyi. Acta pathologica et microbiologica scandinavica 24, 208-212.

Reymann, F. (1949a). Sensitivity of Haemophilus ducreyi to penicillin, streptomycin and sulfathiazole. Acta pathologica et microbiologica scandinavica 26, 309-318.

REYMANN, F. (1949b). An investigation of the biochemical reactions of Hemophilus ducreyi. Acta pathologica et microbiologica scandinavica $26,345-353$.

Reymann, F. (1950). Type differentiation of Haemophilus ducreyi. Acta pathologica et microbiologica scandinavica $27,364-377$.

REYMANN, F. (195I). Studies on the bacteriology' of Haemophilus ducreyi with special reference to the diagnosis of chancroid. Thesis. Copenhagen: Danish Science Press.

Reyn, A., Birch-Andersen, A. \& LAPAge, S. P. (1966). An electron microscope study of thin sections of Haemophilus vaginalis (Gardner and Dukes) and some possibly related species. Canadian Journal of Microbiology 12, 1 $125^{-1} 136$.

Rhein, M. (I919). Sur la production d'indol par le bacille de Pfeiffer. Comptes rendus des séances de la Société de biologie 82, $138-139$.

Rivers, T. M. (1920). The biological classification of influenzae bacilli. Johns Hopkins Hospital Bulletin 3r, 50-53.

RIVERS, T. M. (I922a). Influenza-like bacilli. Growth of influenza-like bacilli on media containing only an autoclave-labile substance as an accessory food factor. Johns Hopkins Hospital Bulletin 33, 149I 5 I.

RIVERS, T. M. (1922b). Bacillus hemoglobinophilus canis (Friedberger) (Hemophilus canis emend.). Journal of Bacteriology 7, 579-8I.

Rivers, T. M. \& BAYNE-JonEs, S. (1923). Influenza-like bacilli isolated from cats. Journal of Experimental Medicine 37, $13 \mathrm{I}-138$.

RIVERS, T. M. \& KoHN, L. A. (I921). The biological and serological reactions of influenza bacilli producing meningitis. Journal of Experimental Medicine 34, 477-494.

Roberts, D. H., Hanson, B. S. \& Timms, L. (I964). Observations on the incidence and significance of Haemophilus gallinarum in outbreaks of respiratory disease among poultry in Great Britain. Veterinary Record 76, I 5I2-15I6.

Rogers, K. B., Zinnemann, K. \& Foster, W. P. (1960). The isolation and identification of Haemophilus spp. from unusual lesions in children. Journal of Clinical Pathology 13, 519-524.

Rosher, A. B. (1931). The effect of the X and V growth-factors on the pathogenicity of indole-producing strains of influenza bacilli. British Journal of Experimental Pathology 12, I 33-1 36.

RYAN, W. J. (1968). An X-factor requiring Haemophilus species. Journal of General Microbiology 52, $275^{-286 .}$

SANDERSON, E.S. (1940). Laboratory aspects of chancroid, granuloma inguinale and lymphogranuloma venereum. American Journal of Public Health 30, 683-686.

Schalm, O. W. \& BeAch, J. R. (1934). The etiology of a respiratory disease of chicken. Science, New York 79, $416-417$.

SchaLm, O. W. \& BeACH, J. R. (1936). Cultural requirements of the fowl-coryza bacillus. Journal of Bacteriology 3I, I6I-I 69 .

Schiefer, B., Moffatt, R. E., Greenfield, J., Agar, J. L. \& Majka, J. A. (1974). Porcine Hemophilus parahemolyticus pneumonia in Saskatchewan. I. Natural occurrence and findings. Canadian Journal of Comparative Medicine 38, 99-104.

Schneerson, R. \& Robbins, J. B. (1973). Studies on Hemophilus influenzae isolated from otitis media. In Hemophilus influenzae, pp. 13-20. Edited by S. H. W. Sell and D. T. Karzon. Nashville, Tennessee: Vanderbilt University Press.

Shifrine, M. \& Biberstein, E. L. (I960). A growth factor for Haemophilus species secreted by a pseudomonad. Nature, London $\mathbf{1 8 7}, 623$.

Shope, R. E. (1964). Porcine contagious pleuropneumonia. I. Experimental transmission, etiology and pathology. Journal of Experimental Medicine 119, 357-368.

Sims, W. (1970). Oral haemophili. Journal of Medical Microbiology 3, 6I 5-625.

SмIтн, M. M. (1931). Observations on Bacillus (Haemophilus) influenzae with special reference to morphology and colonial characters. Journal of Hygiene 31, 32 I-335. 
Smith, W., Hale, J. H. \& O’Callaghan, C. H. (1953). Haem utilisation and nitrate reduction by Haemophilus influenzae. Journal of Pathology and Bacteriology 65, 229-238.

SNeAth, P. H. A. \& Johnson, R. (1973). Numerical taxonomy of Haemophilus and related bacteria. International Journal of Systematic Bacteriology 23, 405-418.

Sneath, P. H. A. \& Skerman, V. B. D. (I966). A list of type and reference strains of bacteria. International Journal of Systematic Bacteriology I6, I-I 33 .

Snieszko, S. F., Griffin, P. J. \& Friddle, S. B. (I950). A new bacterium (Hemophilus piscium N.SP.) from ulcer disease of trout. Journal of Bacteriology 59, 699-7 IO.

Stenderup, A. \& Bak, A. L. (1968). Deoxyribonucleic acid base composition of some species within the genus Candida. Journal of General Microbiology 52, 23 I-236.

Sokal, R. R. \& Rohlf, F. J. (1969). Biometry. The Principles and Practice of Statistics in Biological Research, p. 237. San Francisco: W. H. Freeman.

Stillman, E. G. \& Bourn, J. M. (1920). Biological study of the hemophilic bacilli. Journal of Experimental Medicine 32, 665-682.

Sutter, V. L. \& Finegold, S. M. (1970). Haemophilus aphrophilus infections: clinical and bacteriological studies. Annals of the New York Academy of Sciences r74, 468-487.

Tamura, J. T. \& Fleming, D. E. (1949). Critical growth factors of Bacterium tularense. Society of American Bacteriologists. Abstracts of Papers 47, 37.

ThJøTtA, T. \& AvERY, O. T. (I92I). Studies on bacterial nutrition. II. Growth accessory substances in the cultivation of hemophilic bacilli. Journal of Experimental Medicine 34, 97-I I4.

ToshaCH, S. \& BaIN, G. O. (1958). Acquired aortic sinus aneurysm caused by Hemophilus aphrophilus. American Journal of Clinical Pathology 30, 328-335.

Tunevall, G. (195I). Studies on Haemophilus influenzae. Biochemical activities. Acta pathologica et microbiologica scandinavica $29,387-396$.

Tunevall, G. (1952). Studies on Haemophilus influenzae. Transfer of capsule formation ability and type specificity to non-capsulated respiratory strains. Acta pathologica et microbiologica scandinavica $3^{\mathbf{I}}$, 233-245.

Turk, D. C. \& MAY, J. R. (1967). Haemophilus influenzae. Its Clinical Importance, pp. II, 95-I02, 115. London: English Universities Press.

Tweedy, J. M. \& PARK, R. W. A. (I968). Evidence for the presence of fimbriae (pili) on Vibrio species. Journal of General Microbiology 5I, 235-244.

UnNa, P. G. (I 892). Der Streptobacillus des weichen Schankers. Monatshefte für praktische Dermatologie r4, 485-490.

VAlENTINE, F. C. O. \& Rivers, T. M. (1927). Further observations concerning growth requirements of hemophilic bacilli. Journal of Experimental Medicine 45, 993-1002.

White, D.C. (1962). Cytochrome and catalase patterns during growth of Haemophilus parainfluenzae. Journal of Bacteriology $\mathbf{8 3}, 85 \mathrm{I}-859$.

White, D. C. (1963). Respiratory systems in the hemin-requiring Haemophilus species. Journal of Bacteriology 85, 84-96.

White, D. C. \& Granick, S. (1963). Hemin biosynthesis in Haemophilus. Journal of Bacteriology 85, 842850.

White, D. C., Leidy, G., Jamieson, J. D. \& Shope, R. E. (I964). Porcine contagious pleuropneumonia. III. Interrelationship of Hemophilus pleuropneumoniae to other species of Hemophilus: nutritional, metabolic, transformation and electron microscopy studies. Journal of Experimental Medicine 120, I-I 2.

White, D. C. \& Sмiтh, L. (I962). Hematin enzymes of Hemophilus parainfluenzae. Journal of Biological Chemistry 237, I 332-1 336.

Wilson, G. S. \& Miles, A. A. (1964). Topley and Wilson's Principles of Bacteriology and Immunology, 5th edn, pp. 969, 970-972. London: Edward Arnold.

Winslow, C. E. A., Broadhurst, J., Buchanan, R. E., Krumwiede, C., Jr., Rogers, L. A. \& Smith, G. H. (1917). The families and genera of the bacteria. Preliminary report of the Committee of the Society of American Bacteriologists on characterization and classification of bacterial types. Journal of Bacteriology 2, 505-566.

Winslow, C. E. A., Broadhurst, J., Buchanan, R. E., Krumwiede, C., JR., Rogers, L. A. \& Smith, G. H. (1920). The families and genera of the bacteria. Final report of the Society of American Bacteriologists on characterization and classification of bacterial types. Journal of Bacıeriology 5, 19I-229.

WolfF, A. (1903). Ueber einen beim Tier gefundenen influenzaähnlichen Bacillus. Zentralblatt für Bakteriologie, Parasitenkunds, Infektionskrankheiten und Hygiene (Abteitung 1) 33, 407-4I I.

Woods, G. T., Jensen, A. H., Gossling, J., Rhoades, H. E. \& Nickelson, W. F. (1972). The effect of medicated feed on the nasal microflora and weight gain of pigs. Canadian Journal of Comparative Medicine 36, 49-54.

YABE, S. (1921). Grouping of influenza bacilli. British Journal of Experimental Pathology 2, 197-204.

ZinnemanN, K. (1960). Haemophilus influenzae and its pathogenicity. Ergebnisse der Mikrobiologie, Immunitätsforschung und experimentellen Therapie 33, 307-368. 
ZinnemanN, K. (1967). Report of the Subcommittee on the Taxonomy of Haemophilus (1962-1966). International Journal of Systematic Bacteriology 17, 165-166.

ZinNemanN, K. (197I). International Committee on Nomenclature of Bacteria. Subcommittee on the Taxonomy of Haemophilus. Minutes of Meeting, I I August 1970. International Journal of Systematic Bacteriology 2r, I32-133.

Zinnemann, K., Rogers, K. B., Frazer, J. \& Boyce, J. M. H. (1968). A new V-dependent Haemophilus species preferring increased $\mathrm{CO}_{2}$ tension for growth and named Haemophilus paraphrophilus nov. sp. Journal of Pathology and Bacteriology 96, 41 3-419.

Zinnemann, K., Rogers, K. B., Frazer, J. \& Devaraj, S. K. (I97I). A haemolytic V-dependent $\mathrm{CO}_{2}-$ preferring Haemophilus species Haemophilus paraphrohaemolyticus nov. spec. Journal of Medical Microbiology 4, I 39-143.

Zinnemann, K. \& Turner, G. C. (I963). The taxonomy of 'Haemophilus vaginalis' (Corynebacterium vaginale). Journal of Pathology and Bacteriology 85, 2 I 3-2 I 9. 